\title{
Southern Plains Assessment of Vulnerability and Preliminary Adaptation and Mitigation Strategies for Farmers, Ranchers and Forest Land Owners
}

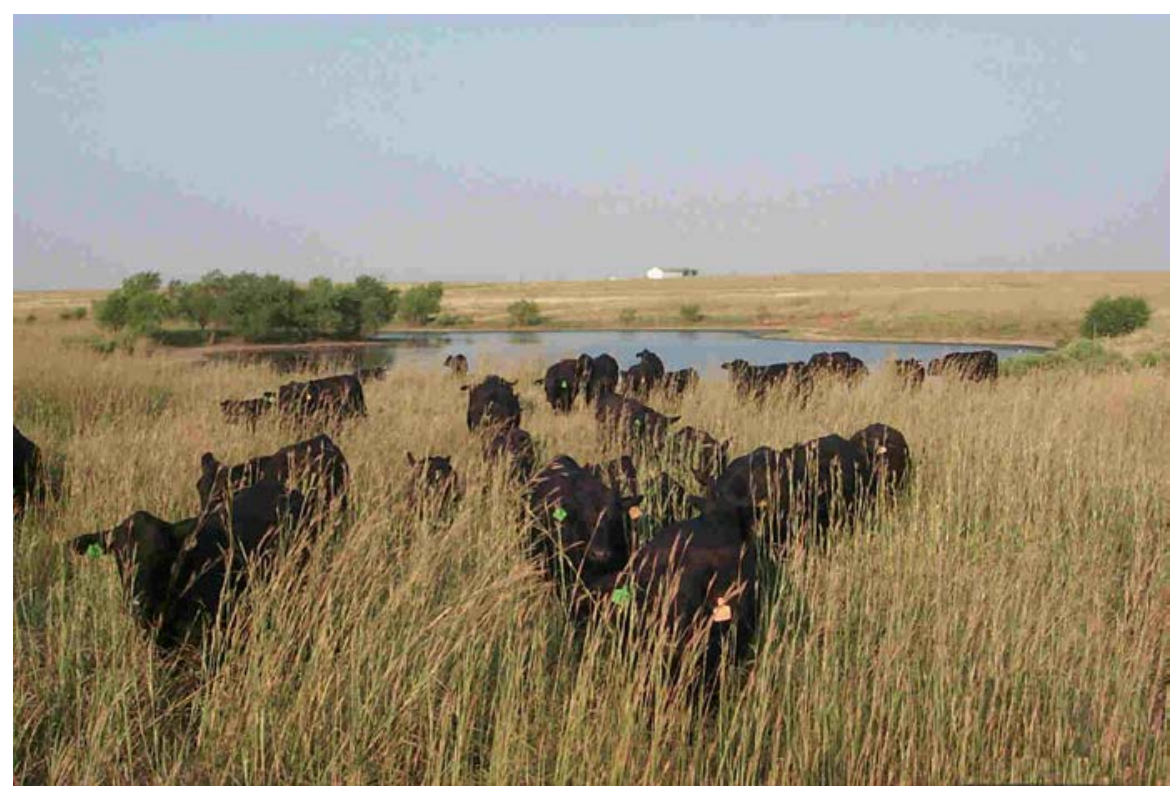

Photo Credit: Michael Brown, USDA, ARS.

Authors: Jean L. Steiner, Laboratory Director and Acting Lead, Southern Plains Climate Hub; Jeanne M. Schneider, Consultant, Weather Sense LLC, formerly Lead, Southern Plains Climate Hub; Clay Pope, Consultant, CSP LLC; Sarah Pope, Consultant, CSP LLC; Paulette Ford, US Forest Service; and Rachel F. Steele, National Climate Hubs Coordinator, Washington D.C.

USDA Southern Plains Climate Hub USDA-ARS Grazinglands Research Laboratory 7207 West Cheyenne Street, El Reno, OK 73036

\section{October 2015}

Contributors: Our thanks to Rafael Guerrero, NRCS; Juliet Bochicchio, RD; Wendy Hall and Marlene Cole, APHIS; Sharon Hestvik, RMA; Adrian Polansky, FSA; Michele Schoeneberger and Gary Bentrup, National Agroforestry Center (Forest Service); David Meriwether, Steve McNulty, and Priya Shahani, Forest Service. We acknowledge ICF International for their contributions to the Greenhouse Gas Profile.

Edited By: Terry Anderson, ARS

Suggested Citation: Steiner, J.L., J.M. Schneider, C. Pope, S. Pope, P. Ford, R.F. Steele 2015. Southern Plains Assessment of Vulnerability and Preliminary Adaptation and Mitigation Strategies for Farmers, Ranchers, and Forest Land Owners, T. Anderson, Ed., United States Department of Agriculture, 61 pp. 


\section{Contents}

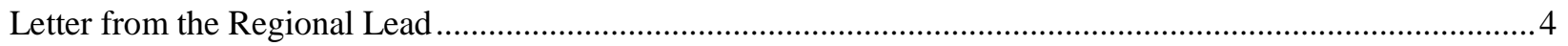

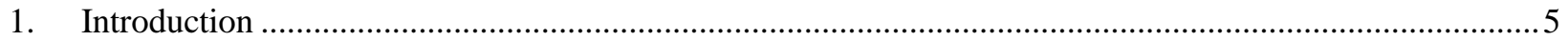

$1.1 \quad$ Description of the Region and Key Resources..............................................................................

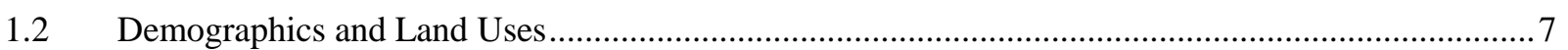

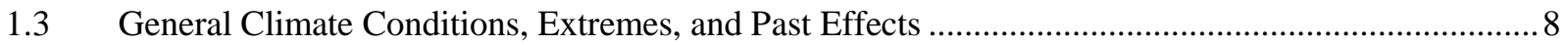

1.4 Summary of NCA Regional Climate Scenarios .............................................................................

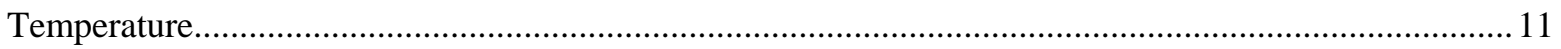

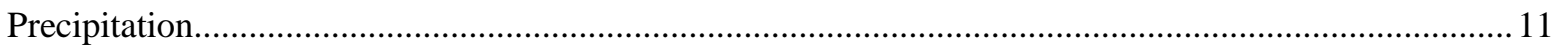

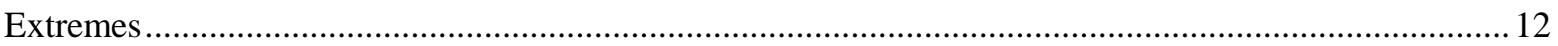

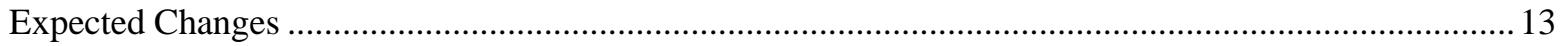

2 Regional Agriculture Sensitivities to Climate Change and Adaptation Strategies.....................................14

2.1 Cropping Systems Overview of Risks, Vulnerabilities and General Adaptation Strategies ...............14

Cropping Systems Overview ......................................................................................................... 14

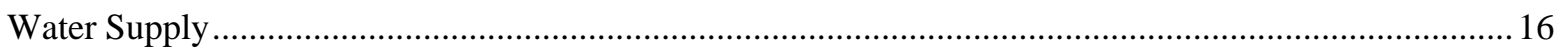

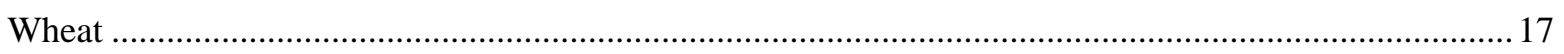

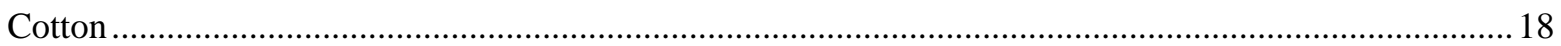

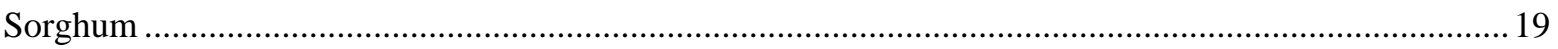

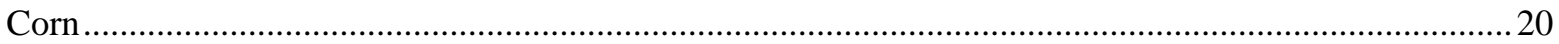

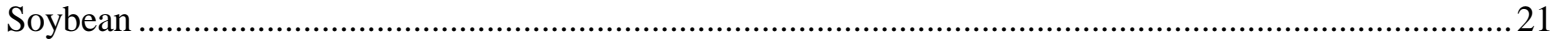

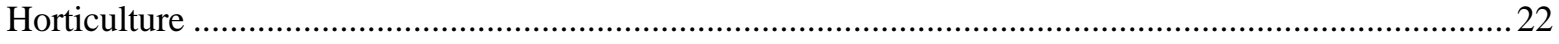

2.2 Livestock Systems Overview of Risks, Vulnerabilities and General Adaptation Strategies..............23

Beef Cattle Production and Associated Grazing Systems ......................................................................... 23

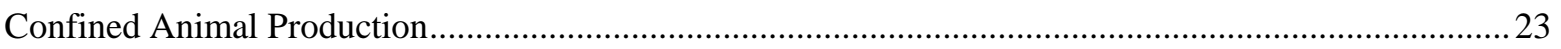

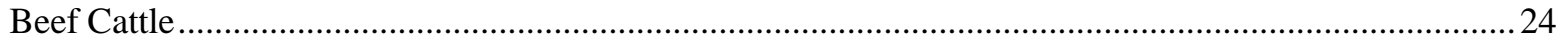

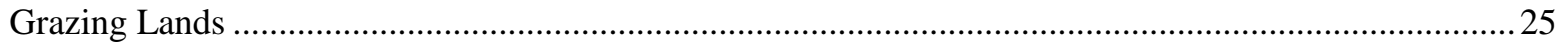

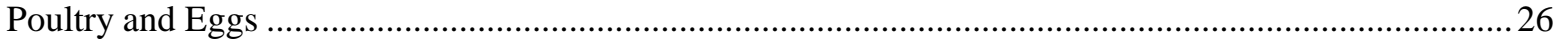

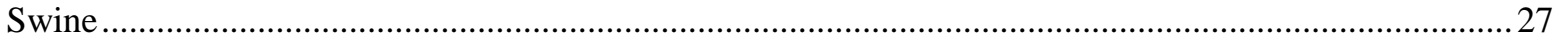

Dairy

3 Regional Forestry Sensitivities to Climate Change and Adaptation Strategies .........................................29

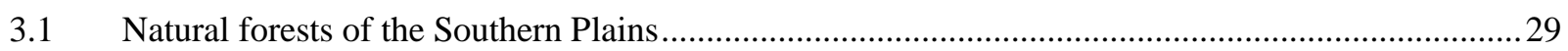

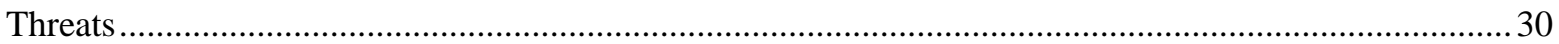

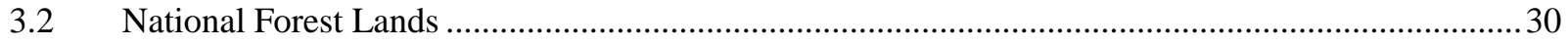

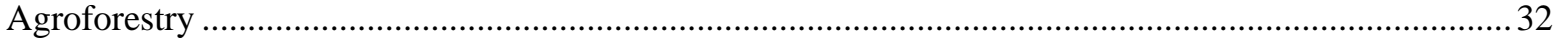

4 Greenhouse Gas (GHG) Emissions Profile from Agriculture and Forests within the Region and Mitigation

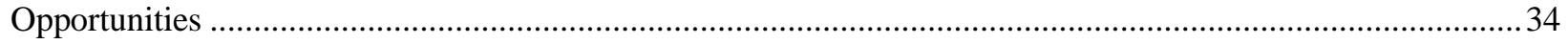

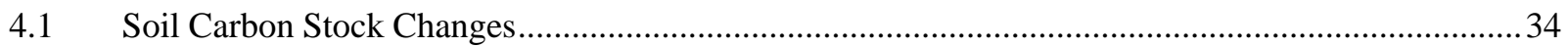




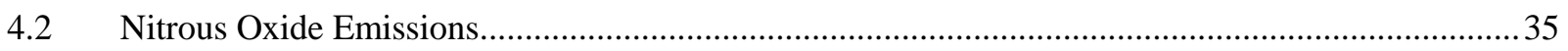

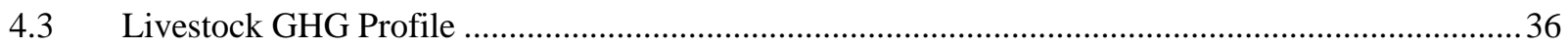

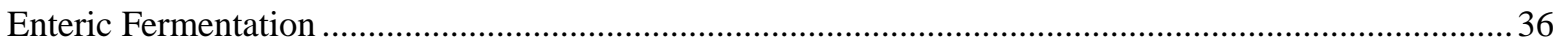

Emissions from Manure Management Systems ……................................................................................. 37

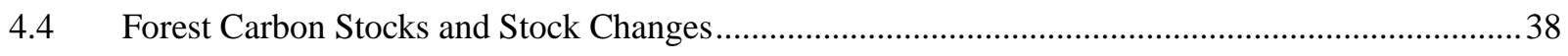

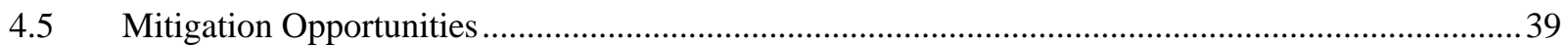

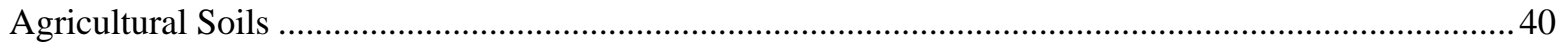

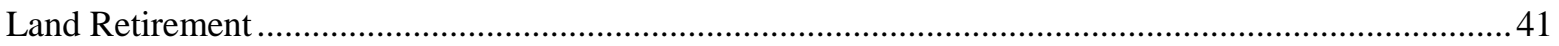

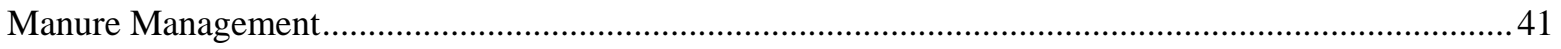

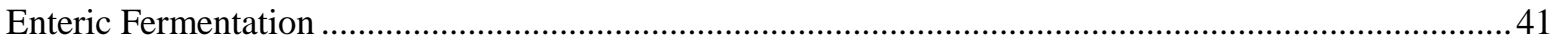

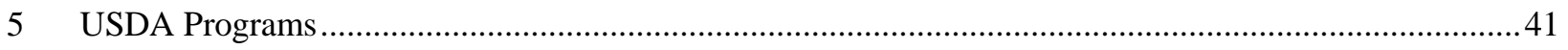

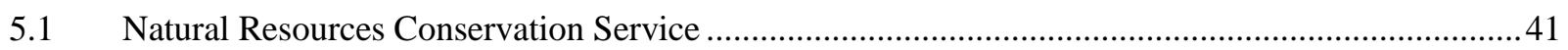

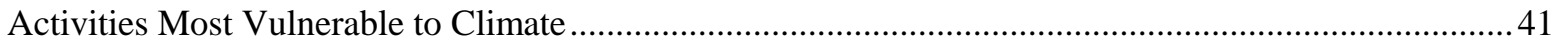

Programs to Address Risks and Vulnerabilities ......................................................................................... 42

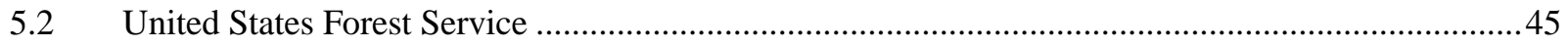

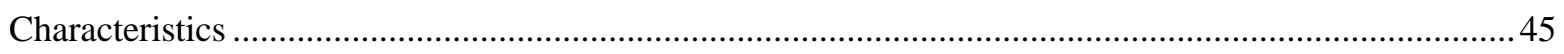

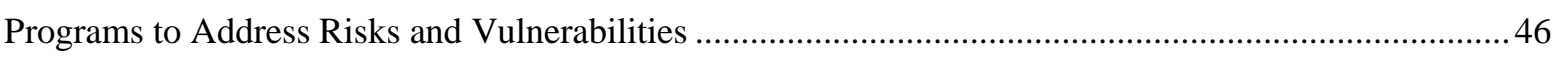

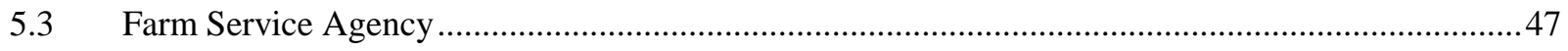

Activities Most Vulnerable to Climate Change........................................................................................... 48

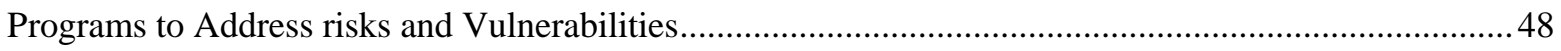

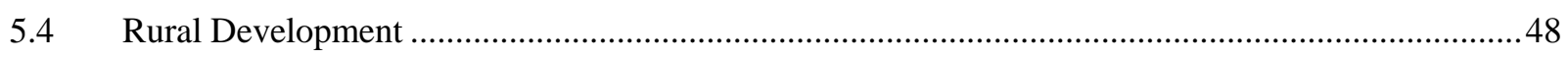

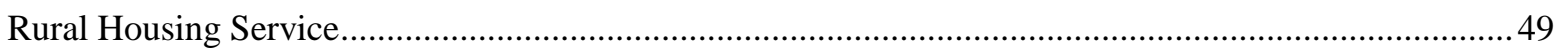

Rural Business-Cooperative Service ..................................................................................................... 49

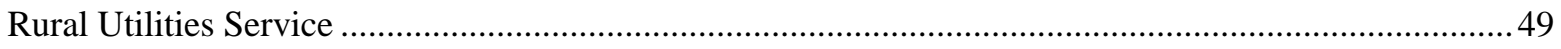

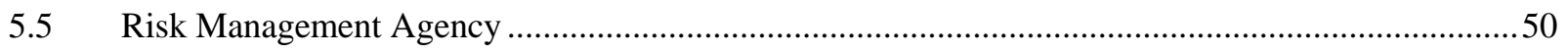

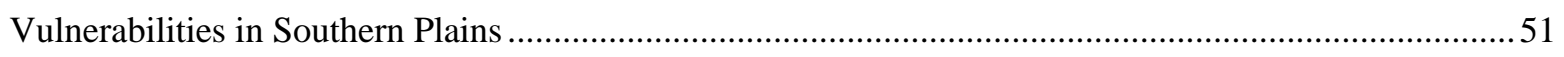

5.6 Animal and Plant Health Inspection Service............................................................................ 52

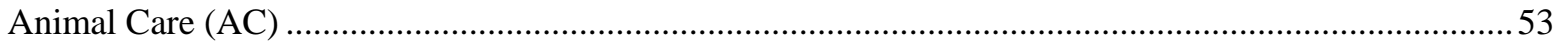

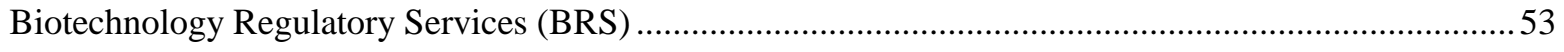

Plant Protection and Quarantine (PPQ) .............................................................................................. 53

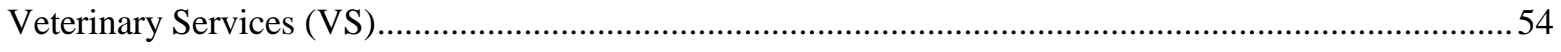

Policy and Program Development (PPD) ..................................................................................... 56

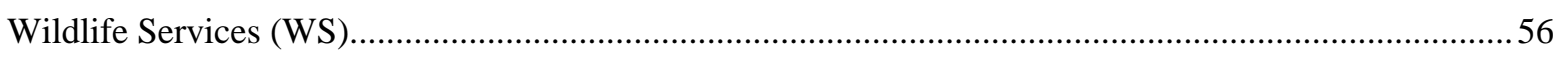

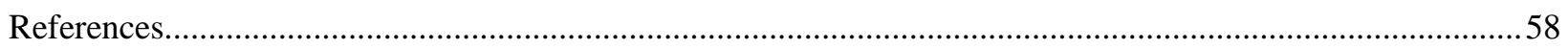




\section{Letter from the Regional Lead}

Among all the points of debate and discussion around climate change and the associated effects on agriculture in the Southern Plains region, one critical aspect is frequently missed: the increasing variability in day-to-day weather. Highly variable weather has been a benchmark of life and agriculture in the Southern Great Plains since long before the states of Kansas, Oklahoma, and Texas were formed. Coping successfully with the droughts and wild weather has been a point of pride for agricultural producers in this region.

Change is here, however, and it is not friendly to agriculture. Over the last 15 years, the region has experienced an increasing frequency of some of the more extreme events central to agriculture, a direct result of more dynamic atmospheric behavior. It has suffered through extensive, crippling periods of drought that ended with record-breaking downpours and flooding. Additionally, agricultural systems are challenged by "unseasonable" late-spring hard freezes, "unseasonable” cold snaps cycling with "unseasonable" warm spells through summer and winter, as well as heavier than historic rainfalls when the rains do fall. Weather predictability is at a new low compared with that of the last 30 years of the 20th century. These weather events contribute to shifts in average temperature and average precipitation that are associated with a changing climate, but it is the day-to-day weather that determines the success of every agricultural enterprise. It is often observed that it's not the averages that are crippling agriculture here ... it's the variability. The region faces in a situation without dependable seasonal patterns for rainfall or temperature, the basis for existing agronomic guidance. Our agricultural systems are being repeatedly stressed, with increased risk to all of our enterprises. And based on everything we know about the physics and fluid dynamics of our earth-ocean-atmosphere system, this variability is expected to continue and probably worsen.

Given this understanding, it is critical that the Southern Plains Climate Hub facilitate and support the development of agricultural management options that will be resilient and productive under increasingly variable weather. Developing these new options is a tall order, but not impossible. We are delighted that this is the International Year of Soils, because better soil health management is one of the primary opportunities for agricultural adaptation to the more variable weather and changing climate in the Southern Great Plains. Experimentation with alternatives is already occurring, as are efforts to better understand our opportunities to mitigate further climate change through agronomic management. We hope to accelerate the process, coordinate, or co-inform the efforts, and provide the useful results to producers in this three-state region as they are developed.

Jean L. Steiner

Director, Southern Plains Climate Hub 


\section{Introduction}

The Southern Plains region contributes significantly to the Nation's wheat and beef production. Winter wheat is the principal annual crop, with much of it serving dual-use as a cool-season annual forage in addition to grain production. Cattle are raised on extensive pasture and rangelands across the region.

Agricultural production and farm income in the Southern Plains are sensitive to weather variability. For example, the severe 2010/2011 drought resulted in the loss of billions of dollars in the agriculture sector. Agricultural losses were estimated to exceed \$1.7 billion in Oklahoma and $\$ 5.2$ billion in Texas, with more than half the Texas losses attributed to livestock and hay enterprises. Examples of climate and weatherrelated events in this region include:

- Drought: In 2011 alone, drought resulted in \$12 billion in direct agricultural losses in the region (Kunkel et al., 2013). While 2012 and 2013 rains brought welcome relief in many areas, drought persisted into 2015 in places such as southwestern Oklahoma, when drought was ended with record breaking rainfall. The search is on for ways to adapt, survive, and succeed despite the weather.

- Temperature changes: Another region-wide change is in overnight low temperatures, especially

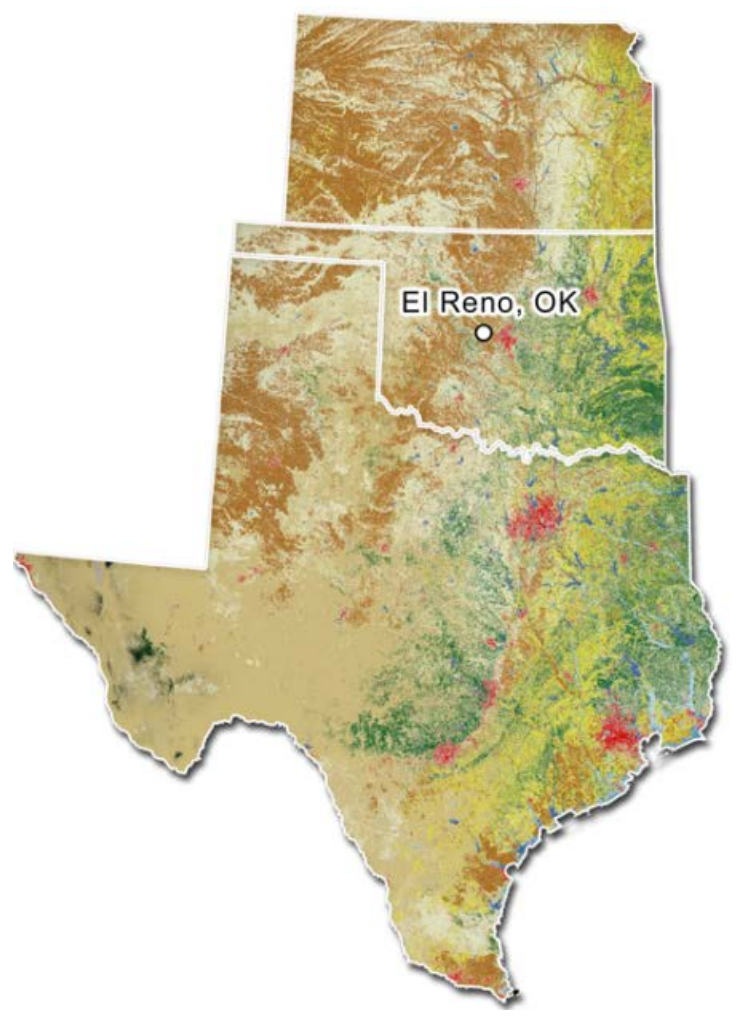

Figure 1: Southern Plains Hub. Brown, cultivated land; tan, grassland; green, forest; red, developed; blue, water in the winter during a series of consecutive warm days. The average winter lows are significantly warmer than those that occurred in the 1960-1990 period, or even 1970-2000. This is another aspect of climate change that is expected to continue and worsen. Effects on winter crops include insufficient vernalization for some winter wheat varieties, and greater vulnerability of winter crops to late-spring hard freezes. Generally, winter crop productivity has become less dependable, especially when exacerbated by drought.

- Pests and diseases: Warmer temperatures have resulted in insects, weeds, and crop diseases moving north and to higher elevations, or surviving winters that used to keep them in check. Although some pest and pathogen species or strains will increase with climate change and others will decline, overall, pest, weed, and disease pressures on crops are expected to continue and intensify.

\subsection{Description of the Region and Key Resources}

The USDA Southern Plains Climate Hub (Figure 1) includes significant coverage of grassland, cropland, and forest land (U.S. Geological Survey, 2011). The value of agricultural production in the Southern Plains regions exceeded \$59 billion in the 2012 Agricultural Census (Table 1), with livestock accounting for about 58 percent of total agricultural sales. Crop and livestock commodities that exceeded \$1 billion across the three-State region include wheat, corn, horticultural crops, cotton, hay and forages, sorghum, soybean, beef cattle, poultry and eggs, dairy, and swine (Table 1). The Southern Plains region contributes significantly to the Nation's wheat and beef production. Winter wheat is the principal rain-fed annual crop, with much of it serving dual-use as a cool-season annual forage in addition to grain production. 
Cattle are raised on pasture and rangelands across the region. Corn is the primary irrigated crop in the Ogallala Aquifer region of the Kansas, Oklahoma, and Texas High Plains.

Horticultural crops and cotton are

increasingly important in the southern portion of the region, and corn and soybean are more important in the northern part of the region. Soils of the southern Great Plains prairie regions include Mollisols, which formed as a result of long-term accumulations of plant material and are high in organic matter content. They are characterized by a thick, dark surface horizon and a high ( $>50 \%)$ base saturation. Mollisols characteristically support grassland or prairie vegetation in climates that have moderate to pronounced seasonal moisture deficits under a wide range of temperature regimes. The typical topography associated with Mollisols is flat or gently rolling to undulating (Ojima et al., 2015).

In the more humid portions of the Southern Plains, soils are dominated by Alfisols, which develop in higher rainfall environments. They have undergone moderate leaching and have subsurface accumulation of clay and greater than 35 percent base saturation. These soils are generally occupied by forests, savannas, and open prairies. At the time of European settlement of the southern Great Plains, woody plants were largely restricted to riparian or deeply dissected areas that seldom experienced fire. However, beginning in the early 20th century, woody plant encroachment into traditional Agricultural Statistics Service, 2014).
Table 1: Value of production of major crop and livestock commodities in the Southern Plains. Source: (National Agricultural Statistics Service, 2014).

\begin{tabular}{|lrrrr|} 
Commodity & Kansas & Oklahoma & Texas & \multicolumn{2}{l}{$\begin{array}{l}\text { Southern } \\
\text { Plains }\end{array}$} \\
\hline \multicolumn{3}{c}{ Billion\$ } \\
\hline Crops & 6.984 & 1.876 & 7.367 & 16.227 \\
\hline Wheat & 2.474 & 0.946 & 0.618 & 4.038 \\
\hline Corn & 2.297 & 0.203 & 1.454 & 3.954 \\
\hline Horticultural ${ }^{1}$ & 0.093 & 0.268 & 1.738 & 2.101 \\
\hline Cotton & & 0.052 & 1.619 & 1.671 \\
\hline Hay & 0.359 & 0.271 & 0.958 & 1.588 \\
\hline Sorghum & 0.579 & 0.034 & 0.743 & 1.356 \\
\hline Soybean & 1.102 & 0.048 & 0.037 & 1.187 \\
\hline Livestock & 11.477 & 5.254 & 18.009 & 34.740 \\
\hline Beef cattle & 10.153 & 3.403 & 13.013 & 3.374 \\
\hline Poultry, eggs & 0.088 & 0.961 & 2.325 & 2.344 \\
\hline Dairy & 0.482 & 0.164 & 1.698 & 1.592 \\
\hline Swine & 0.697 & 0.656 & 0.239 & 59.966 \\
\hline Total Agriculture & 18.461 & 7.130 & 25.376 & \\
\hline & & & & \\
\hline
\end{tabular}

Table 2: Farms and farm operators in the Southern Plains. Source: (National

\begin{tabular}{|lrrrr|}
\multicolumn{1}{l}{ Kansas } & Oklahoma & Texas & \multicolumn{1}{l|}{$\begin{array}{l}\text { Southern } \\
\text { Plains }\end{array}$} \\
\hline Farms, $n$ & 61,773 & 80,245 & 248,809 & \multicolumn{1}{c|}{390,827} \\
\hline Tenure & & & & \\
\hline Full owner, $n$ & 35,465 & 51,605 & 179,783 & 266,853 \\
\hline Part owner, $n$ & 21,564 & 23,702 & 54,297 & 99,563 \\
\hline Tenant, $n$ & 4,744 & 4,938 & 14,729 & 24,411 \\
\hline Irrigation, acres & $2,881,292$ & 479,750 & $4,489,169$ & $7,850,211$ \\
\hline Operators, $n$ & 92,892 & 121,603 & 375,888 & 590,383 \\
\hline $\begin{array}{l}\text { Primary occupation } \\
\text { farming, } \%\end{array}$ & 32 & 28 & 28 & 29 \\
\hline Women, $n$ & 26,096 & 39,216 & 122,478 & 187,790 \\
\hline Hispanic, $n$ & 990 & 1,749 & 32,264 & 35,003 \\
\hline Black, $n$ & 228 & 1,784 & 11,719 & 13,310 \\
\hline Native, $n$ & 594 & 11,536 & 3,820 & 15,950 \\
\hline Asian, $n$ & 120 & 483 & 1,226 & 1,829 \\
\hline${ }^{1}$ Tenure of primary operator & & & \\
\hline
\end{tabular}

grassland areas became a substantial land management issue that continues to occur at a rapid rate. The eastern portions of the region were forested, ranging from mixed hardwoods in eastern Kansas to mixed hardwoods and pines through eastern Oklahoma and Texas. 


\subsection{Demographics and Land Uses}

The 2012 Census of Agriculture indicates the Southern Plains region has 390,827 farms, with 590,383 operators (Table 2). Since the 2007 Agricultural Census, farm numbers, and numbers of operators decreased in Kansas and Oklahoma, whereas they increased slightly in Texas, primarily in eastern Texas. Most farms in the region are operated by full or part owners of the land, but only about 29 percent of

operators consider farming their primary occupation. About 32 percent of all operators are women and more than 11 percent identify as a minority. The largest minority producers are farmers of Hispanic and Latino origin, predominantly in Texas. The majority of Native American operators in the region are in Oklahoma.

Figure 2 illustrates the distribution of farms across the United States, with the largest concentration of farms located in the central part of the country (i.e., the Northern Plains, Southern Plains, and Midwest). Forestland is the dominant land use in the eastern half of the United States, and the Pacific Northwest.

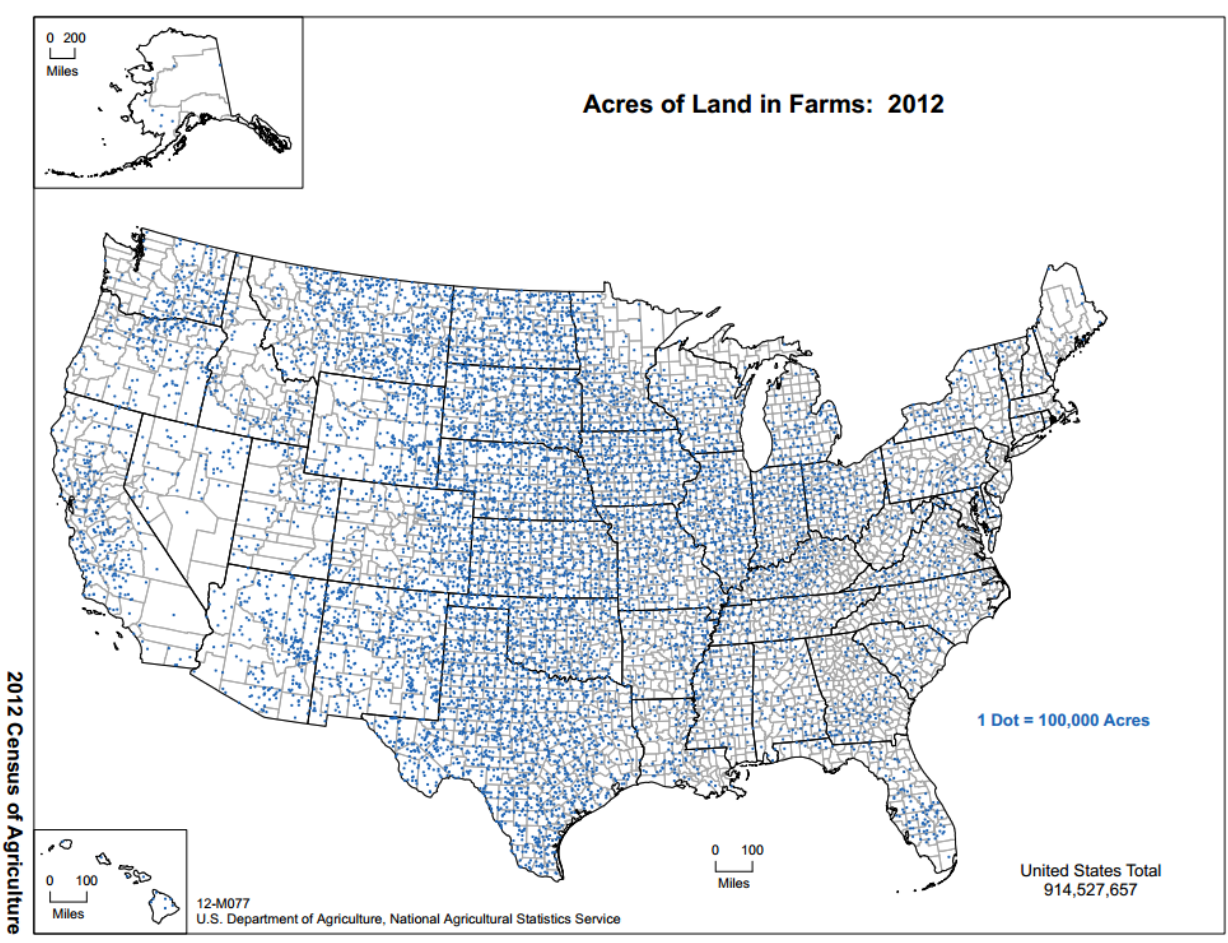

Figure 2: Acres of Land in Farms ${ }^{1}$ in 2012 (National Agricultural Statistics Service, 2014)

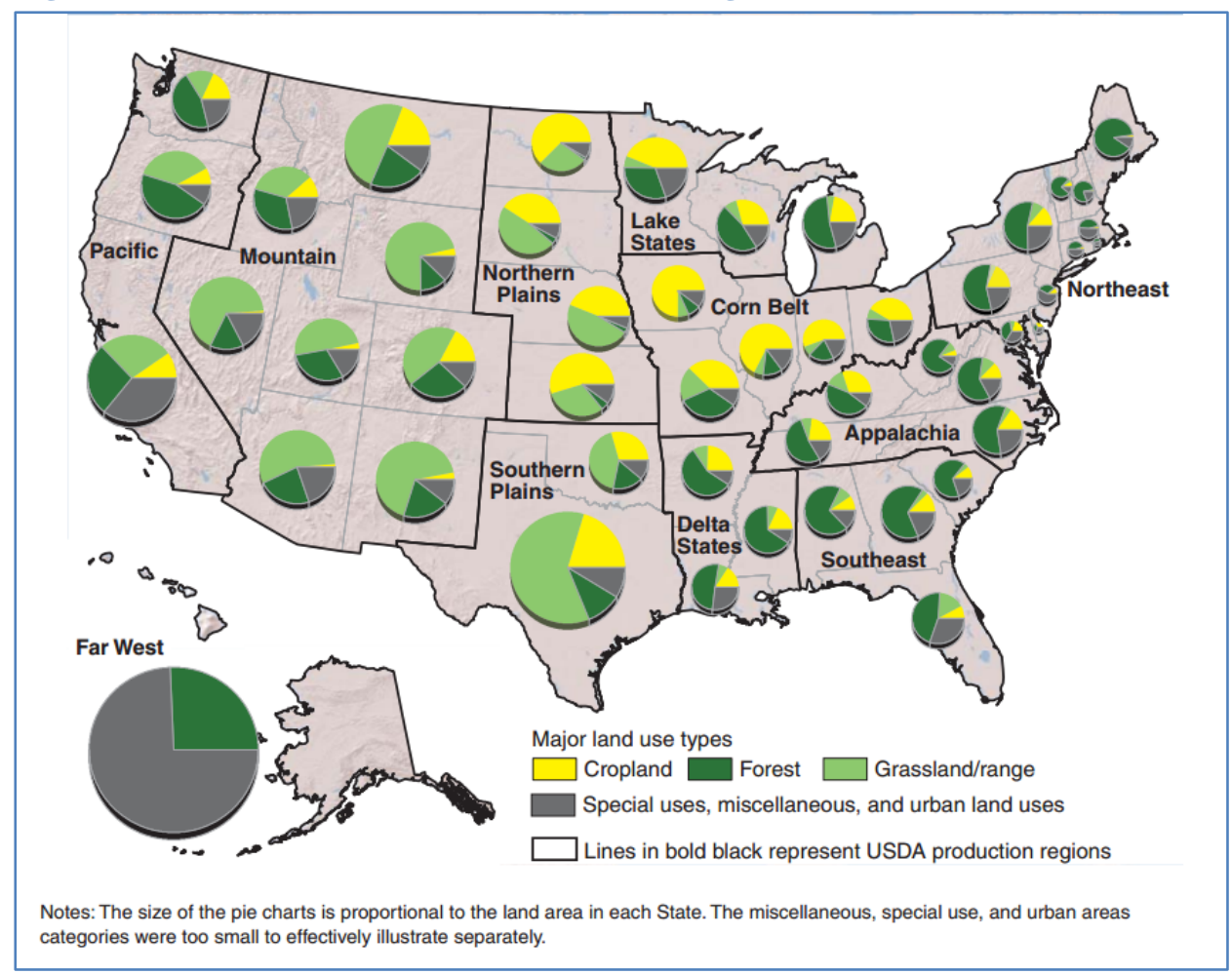

Figure 3: Shares of land in major uses, by State, 2007 (Nickerson et al., 2011) 
Grassland and cropland are the majority land uses in the West, Northern Plains and Southern Plains, and Midwest (Figure 3).

Many rural counties in the Great Plains, including the Southern Plains, have experienced a long downward trajectory of decreasing population (Figure 4). Many of these counties are losing infrastructure required to sustain healthy agriculture and healthy rural communities. Lack of community resources only increases the vulnerability of many of these rural residents to climate stressors. The counties that show population increase are largely urban or areas of rapid increase in the energy sectors. This leads to booming populations, large numbers of persons immigrating into the area with limited social connections, and limited

housing, transportation, and other infrastructure to support the increasing populations. Several counties in Oklahoma and Texas have exhibited persistent poverty over recent decades (Figure 5),

constituting some of the most vulnerable counties to natural disasters, including climaterelated stresses.

\subsection{General Climate Conditions, Extremes, and Past Effects}

The agricultural sector is already experiencing the effects of a changing climate. Growing seasons are longer, drought is more prevalent, and

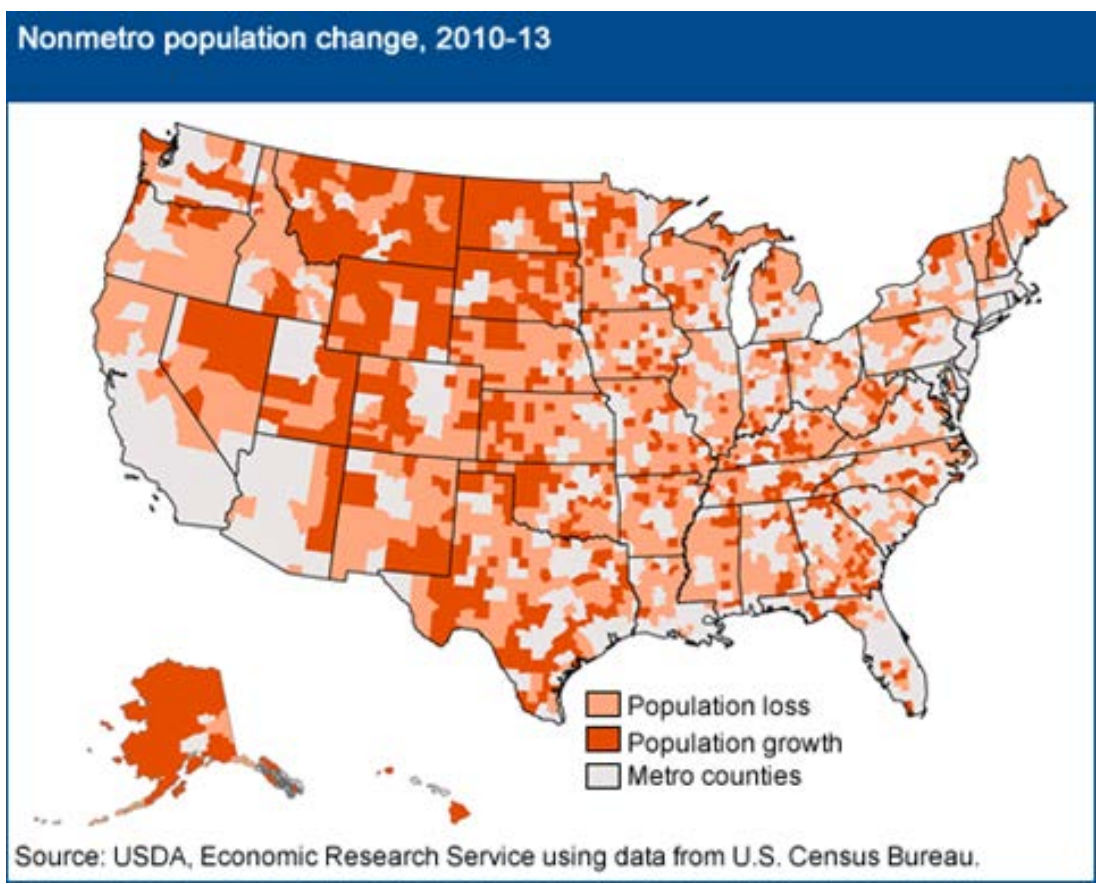

Figure 4: Population change by county.(Economic Research Service, 2011b).

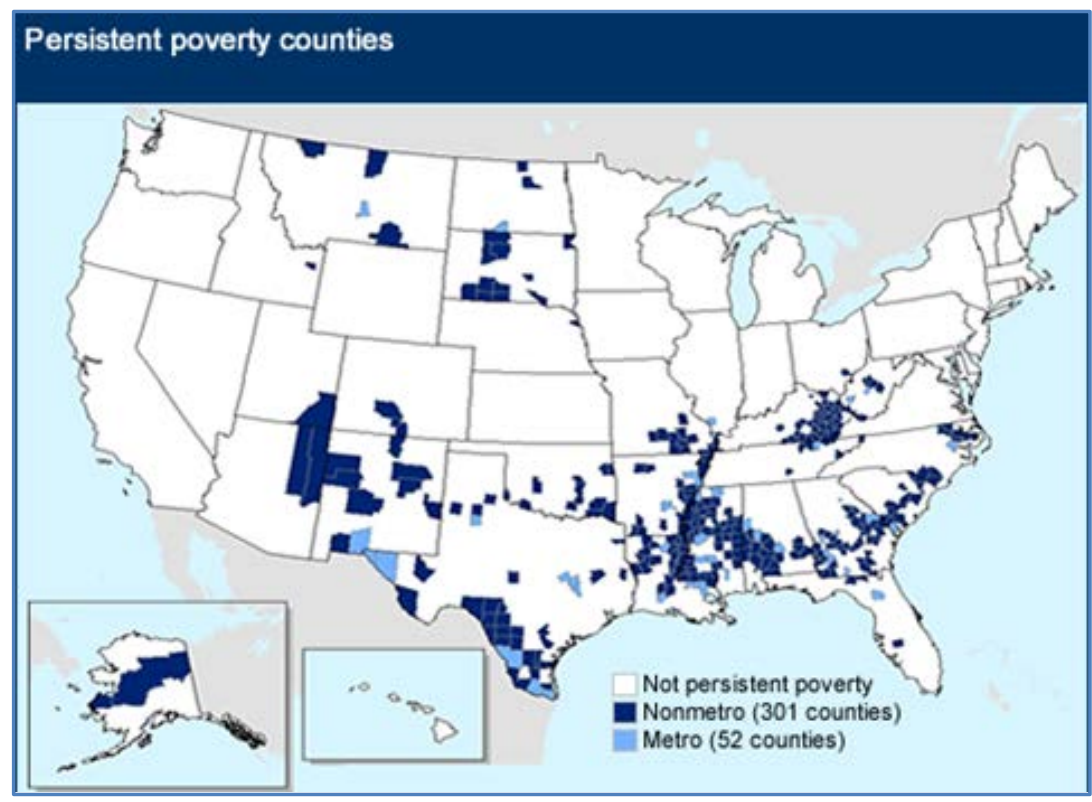

Figure 5: Counties with persistent poverty. Source: (Economic Research Service, 2011b). extreme weather events are affecting agricultural operations. Because crops and environments differ significantly across regions of this country, the vulnerabilities are described by region. Climate change is already affecting the American people in far-reaching ways. Certain types of extreme weather events with links to climate change have become more frequent and intense, including prolonged periods of heat, heavy downpours, and, in some regions, floods, and droughts. Climate change poses a major challenge to 
U.S. agriculture because of the critical dependence of agricultural systems on climate. Temperature increases has a multitude of effects on agricultural crops and all biological organisms as summarized by Hatfield and Prueger (2015). Climate change has the potential to both positively and negatively affect the location, timing, and productivity of crop, livestock, and fishery systems at local, national, and global scales.

The United

States produces nearly $\$ 330$ billion per year in agricultural commodities.

The U.S. agricultural commodity productivity is vulnerable to direct effects on crops and livestock from changing climate conditions, extreme weather events, and

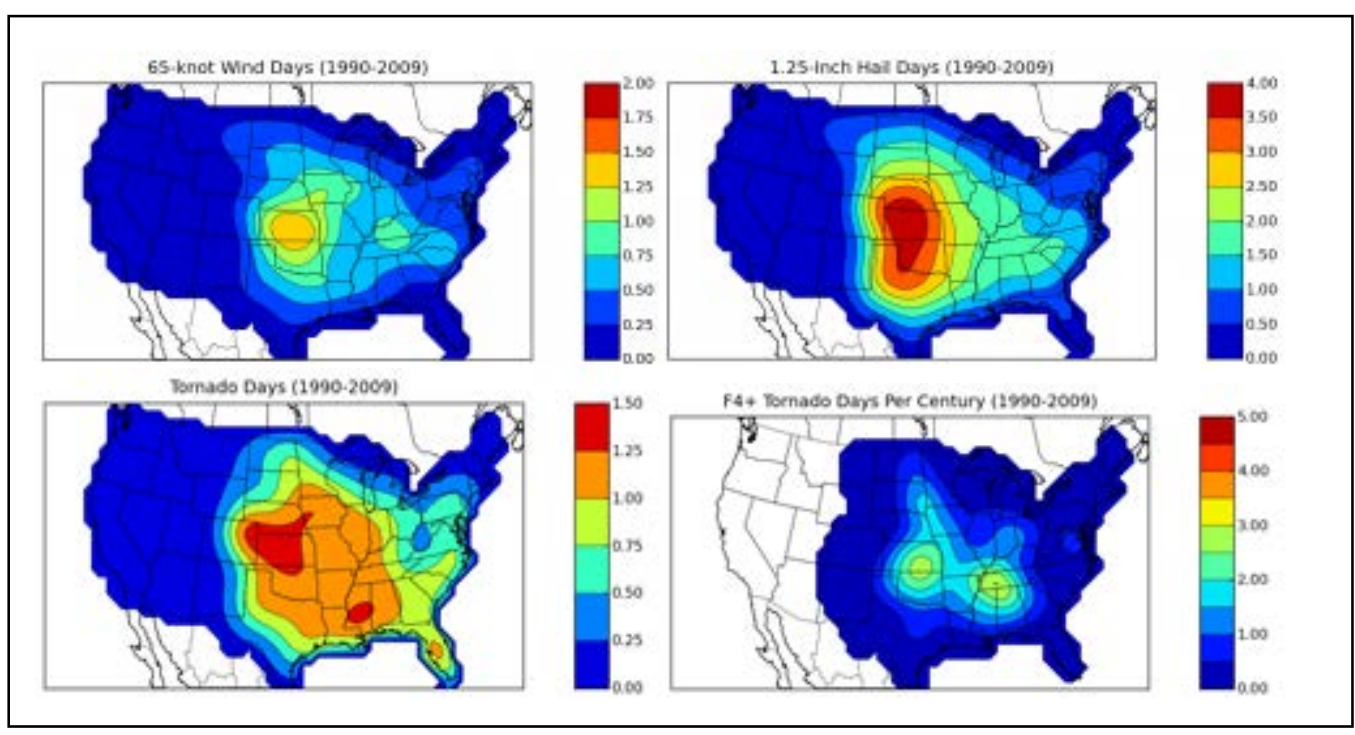

Figure 6: Extreme Climate Events. Source: Oklahoma Mesonet. Source: (Oklahoma Climatological Survey, 2015a)

indirect effects through increasing pressures from pests and pathogens. Climate change will also alter the stability of food supplies and create new food security challenges for the United States as the world seeks to feed nine billion people by 2050. Although the agriculture sector has proven to be adaptable to a range of stresses, as evidenced by continued growth in production and efficiency across the United States, climate change poses a new set of challenges. The Southern Plains States experience high levels of extreme events (Figure 6) including high wind speeds, hail, and tornados.

\subsection{Summary of NCA Regional Climate Scenarios}

Scenarios are defined as "quantitative and narrative descriptions of plausible future conditions that provide assumptions for analyses of potential effects and responses to climate change” (Kunkel et al., 2013). The regional scenarios presented below are meant to help understand what future conditions could be; they were developed using a wide range of assumptions about population growth, economic development, the evolution of technology, and decisions about environmental protection (Melillo et al., 2014).

The Southern Plains climate is characterized by gradients (Figure 7) and by variability at multiple scales. As illustrated by the graphic on the cover of this report, throughout the period of record, there has been large interannual variability overlain on multiyear cycles of wetter and drier periods. This pattern, illustrated for Oklahoma, is characteristic of the Southern Plains. Additionally, average annual temperature (Figure 8) shows similar high interannual variability and multiyear warmer and cooler periods that generally correspond to wet:cool and dry:warm periods. Unlike precipitation, which shows no upward or downward trajectory in recent decades, the average annual temperature has trended toward warmer across wet and dry years. 

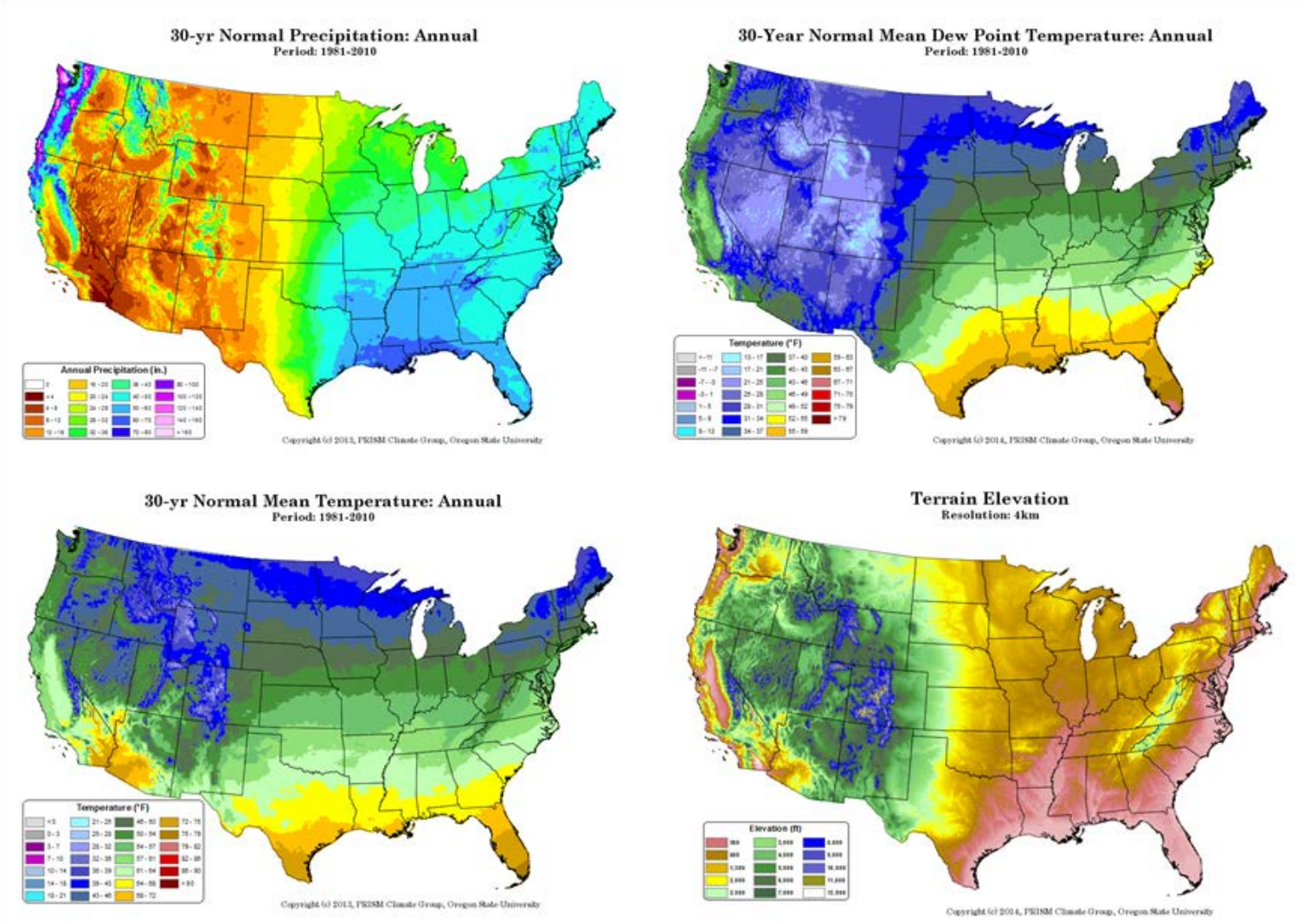

Figure 7: Gradients across the Southern Plains as illustrated by maps of average annual precipitation, temperature, dew point temperatures (low temperatures indicate lower humidity), and digital elevation. Source: PRISM.

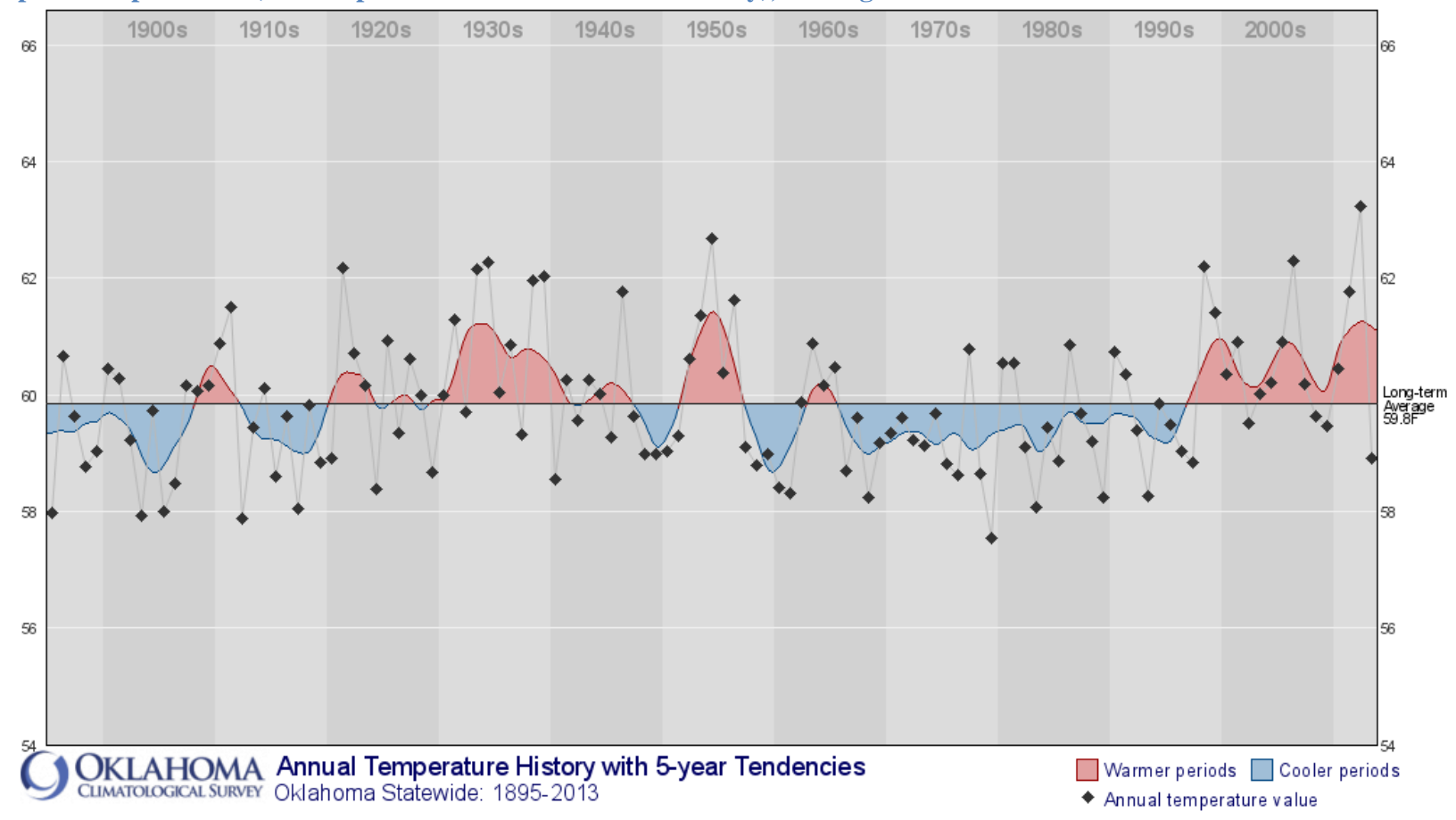

Figure 8: Annual and 5-year moving average of mean temperature in Oklahoma, 1995-2014. Source: (Oklahoma Climatological Survey, 2015b). 


\section{Temperature}

Annual temperatures in the Great Plains for the past 20 years have been higher than the 1901-1960 average for all seasons. The Southern Plains are typically warm and humid during summer due to a semipermanent high pressure system in the subtropical Atlantic bringing in warm, humid ocean air (Kunkel et al., 2013).

Since the early 20th century, the freeze-free season has been increasing in duration (see Figure 9) with the last occurrence of $32^{\circ} \mathrm{F}$ in the spring occurring earlier and the first occurrence in the fall occurring later in the year (Kunkel et al., 2013). Table 3 provides the trends in temperature increase/anomaly ${ }^{1}$ in the Southern Plains for the time period 1895-2011. The most significant anomaly is in the winter season, with a

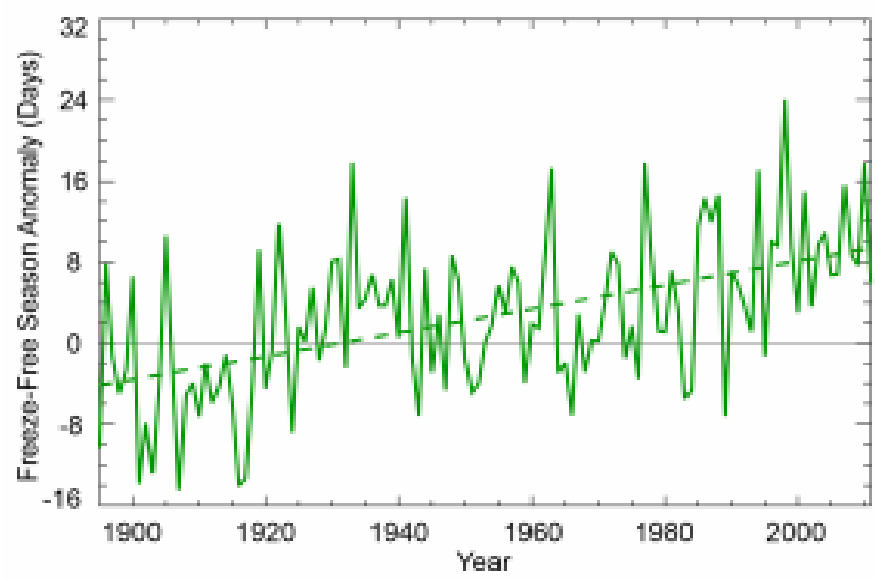

Figure 9: Difference in mean annual freeze-free season length for the U.S. Great Plains (deviations from the 1901-1960 average). Source: (Kunkel et al., 2013). $0.14^{\circ} \mathrm{F} /$ decade increase (Kunkel et al., 2013).

\section{Precipitation}

Annual precipitation for the Great Plains during the 1990s was greater than the 1901-1960 average, less than the average during the early 2000s, and (with the exception of 2012) greater than average in recent years. The driest decades in the Great Plains were the 1950s and 1930s, with 1956 recorded as the driest year on record (Kunkel et al., 2013). ${ }^{2}$ The variability in precipitation is greater in the southern Great Plains compared with that of the north.

According to the Palmer Drought Severity Index, which is an indicator of soil moisture, the 2011 drought in the Southern Plains was the most intense drought event in the area on record since 1895 (see Figure 10). In Texas and Oklahoma, the summer of 2011 was the warmest on record. In Texas the summer of 2011 was also the driest, and in Oklahoma it was the second driest. Losses from this drought were estimated at \$12 billion with 95 fatalities (Kunkel et al., 2013). Using tree rings as a proxy for drought, the Texas drought in 2011 was the worst drought, and the drought of the 1950s was the longest drought in the past 429 years (Kunkel et al., 2013).

\footnotetext{
${ }^{1}$ A temperature anomaly is a departure from a reference value over a long-term average. Positive anomalies demonstrate that the observed temperature was warmer than the reference value, and negative anomalies indicate the observed temperatures were cooler than the reference value (National Oceanic and Atmospheric Administration, 2015b).

${ }^{2}$ For State-level comparative seasonal or annual climate trend analysis data from the National Climate Data Center monthly and annual temperature and precipitation datasets see http://charts.srcc.lsu.edu/trends/.
} 


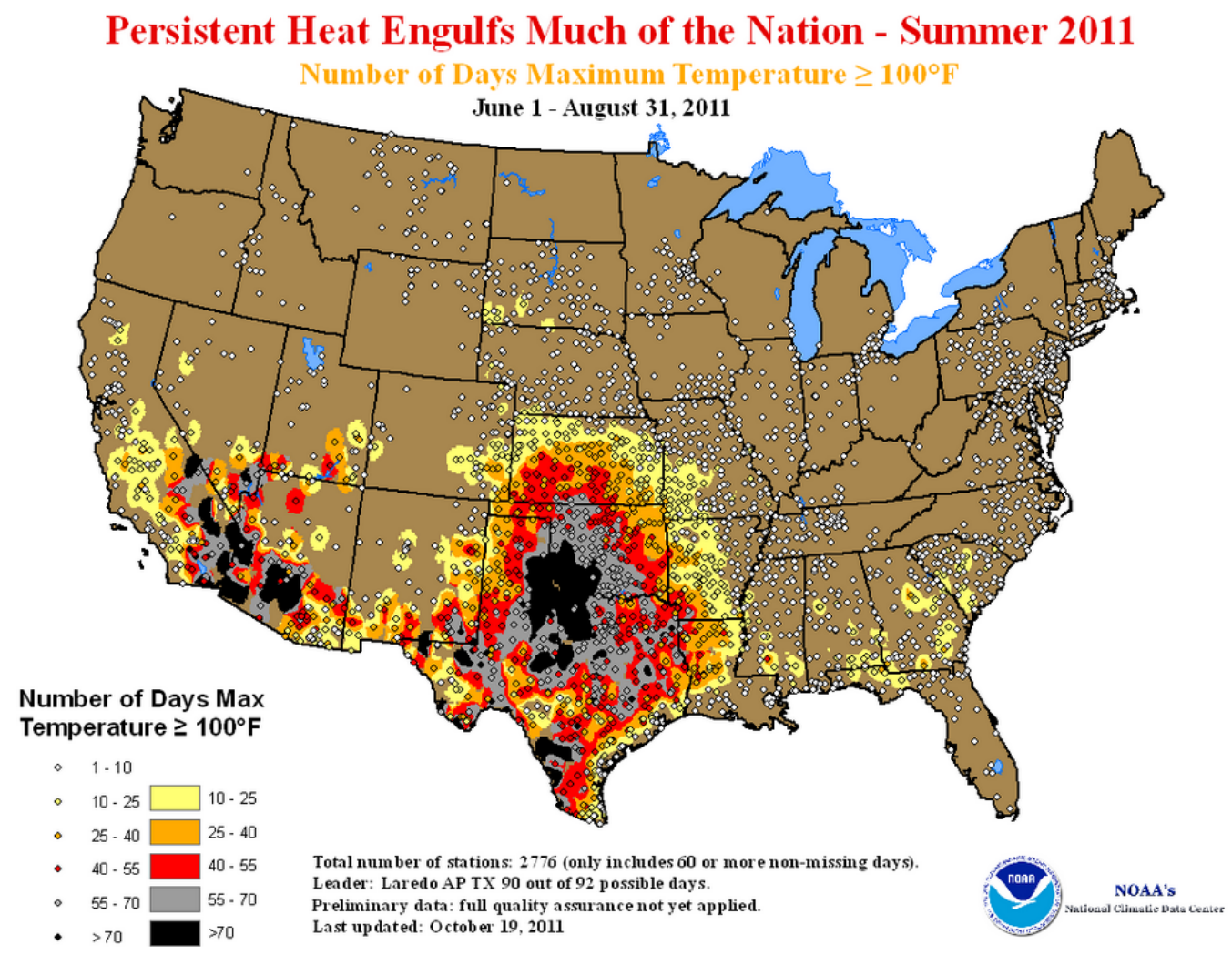

Figure 10: Number of days with maximum temperature $\geq 100^{\circ} \mathrm{F}$. Source: (National Oceanic and Atmospheric Administration, 2015a).

\section{Extremes}

Extremes of hot and cold have historically typified the Great Plains. However, the overall trend has been toward hotter extreme hot periods and warmer cold periods over the past century (Figure 10). Since 1990, more extreme precipitation events were observed with the greatest single-day downpours occurring in 2007 (Kunkel et al., 2013) (Figure 11). Historic rains in Texas and Oklahoma in May 2015 (Crouch, 2015) ended persistent drought that started in 2010 (Texas) and 2011 (Oklahoma), but the storms that broke Oklahoma's drought spawned more than

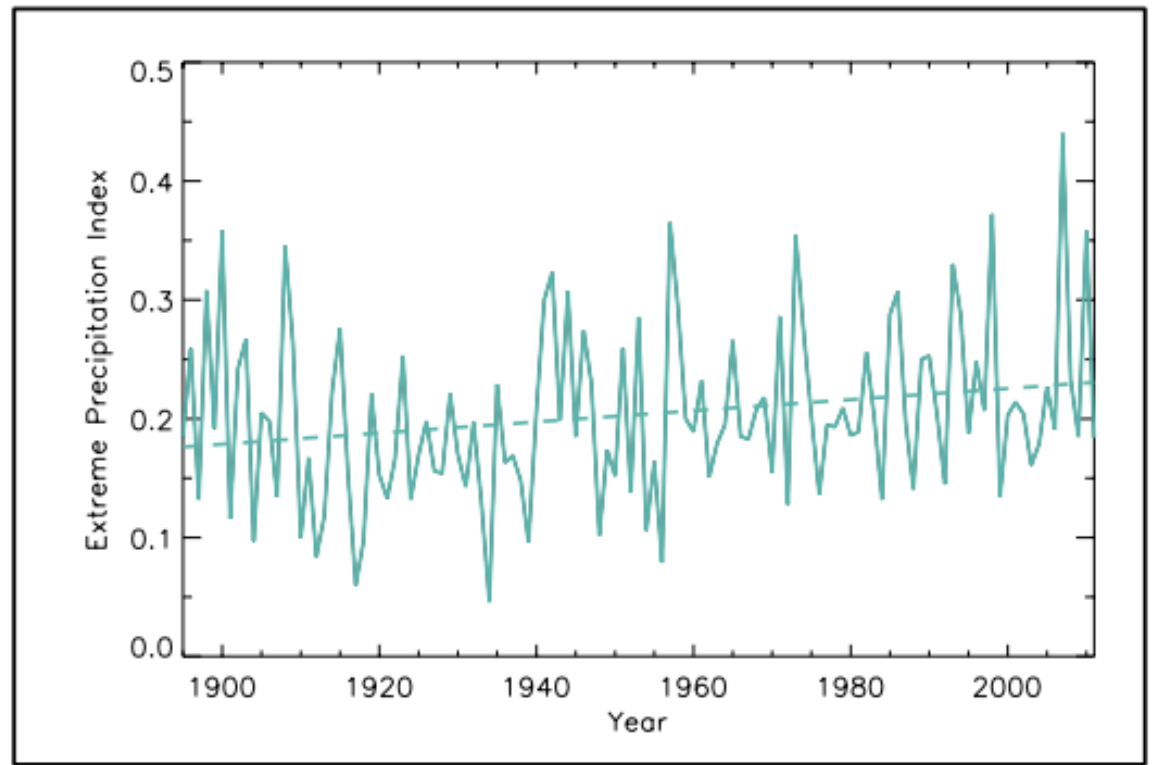

Figure 11: Time series of extreme precipitation index for the occurrence of 1-day, 1in-5-year extreme precipitation, for the Great Plains region. The dashed line is a linear fit. Based on daily COOP data from long-term stations in the National Climatic Data Center's Global Historical Climate Network data set. Source: (Kunkel et al., 2013). 
60 tornados, catastrophic floods, and 11 fatalities (Oklahoma Mesonet, 2015). Oklahoma City received 19.48 inches of rainfall in May 2015, the most precipitation ever recorded in a single month for that station. The highest number of heat waves since the 1930s occurred in 1954 and 2012. Trends in snowfall amounts have been decreasing, particularly in the eastern Southern Plains (Kunkel et al., 2013).

The Southern Plains is often referred to as "tornado alley" due to the frequency of tornadoes in the area (i.e., more than 100 per year on average in Texas and more than 50 per year in Kansas and Oklahoma). Over the 1895-2011 period in the Great Plains, extreme precipitation events demonstrate substantial interannual and decadal-scale variability, with an overall upward trend (Figure 11). The number of years since 1990 with a high number of extreme events is greater compared with the previous 20 years of data (Kunkel et al., 2013).

\section{Expected Changes}

There has been a loss of seasonal precipitation patterns in the region so that every year the rainfall pattern is different. When it does rain in the region, it tends to come in heavy storms that produce erosion and flash flooding, rather than light rains that usefully recharge soil moisture for crops. In the Southern Plains, high temperatures are projected to occur much more frequently, with days higher than $100^{\circ} \mathrm{F}$ projected to quadruple by mid-century. Similar increases in the Southern Plains are expected in the number of nights with minimum temperatures higher than $80^{\circ} \mathrm{F}$. These increases in extreme heat will have many negative consequences, including increases in surface water evaporation and heat stress; they will more than offset the benefits associated with warmer winters, such as longer growing seasons. More overwintering insect populations are also expected, although there is a lack of data to predict specific responses for specific pathogens and pest species. Large parts of Oklahoma and Texas are projected to see longer dry spells (up to 5 more days on average by mid-century). A summary of the regional vulnerabilities and expected changes across the Southern Plains is provided below (Kunkel et al., 2013):

- Increased Flooding/Intense Precipitation: Hurricanes and coastal flooding. Flash flooding associated with intense storms.

- Increased Frequency and Intensity of Droughts: Drought resulted in \$5.2 billion in direct agricultural losses in August 2011 in Texas (National Oceanic and Atmospheric Administration, 2015a).

- Temperature Shifts: The average winter lows are significantly warmer than those that occurred in the 1960-1990 or even 1970-2000 periods.

- Intensified Pest, Weed, and Disease Outbreaks: With warmer temperatures, insects, weeds, and crop diseases have moved north and to higher elevations, or are surviving winters.

- More frequent fires: Drought is associated with a high risk of grass and brush fires, exacerbated by encroachment of woody brush into grasslands and fragmentation of the landscape associated with increased periurban population. ${ }^{3}$

- Increased Extreme Weather Events: This region is prone to tornadoes, thunderstorms, hail, ice, heat waves, gale-force winds, and other damaging weather events.

- Additional Expected Vulnerabilities: Sea-level rise effects along the Texas Gulf Coast. Combinations of high temperature, low humidity, and high wind speed results in very high evaporative demand.

\footnotetext{
${ }^{3}$ Peri-urbanization relates to the process of dispersive urban growth that creates hybrid landscapes of fragmented urban and rural characteristics (Food and Agriculture Organization of the United Nations, 2002).
} 


\section{Regional Agriculture Sensitivities to Climate Change and Adaptation Strategies}

Agricultural systems across the Southern Plains vary east to west, driven largely by precipitation gradients ranging from about 4.9 feet of annual precipitation in the east to less than 0.66 feet annual precipitation in the west. Significant irrigated regions are important in supporting highly productive and diverse agriculture. Agriculture in the Southern Plains of the United States will face continuing pressure due to the effects of climate change. Of immediate concern are the challenges the industry faces related to increased frequency, duration and severity of droughts as well as the negative effects related to increased flash flooding resulting from intense rain events.

The ability of production agricultural systems to persist despite increasing variability in weather events resulting from changing climate, both to maintain crop production and to provide adequate forage and water for livestock, is critical to the future in this region. Increased grazing pressure in response to a desire to maximize profits during droughts also exacerbates these issues. The Southern Plains has always been challenged by variable rates and timing of precipitation to maintain agriculture production. Climate change increases the exposure of the Southern Plains to these challenges. Reduced crop production; inadequate water for livestock, both for consumption and forage production; and the potential for increased wind and water erosion of soil are all expected to increase as a result of climate change. Intermittent stream flow in our rivers, creeks, and streams will also be affected by reduced rainfall and the lack of sub-soil moisture and its effects on the hydrological cycle, affecting both agriculture as well as municipal water supplies.

Violent rain events have always taken place on the Southern Plains. The changes in climate we have been experiencing have resulted in increased potential for even more extreme rain events than those normally experienced in the past. Increased gully, sheet, and rill erosion of soil due to heavy precipitation on exposed ground is of major concern. In addition, the risk of flash flooding and its effects on property, infrastructure, and human life are increased due to the ongoing climate. Heavy rain events will also pose additional challenges related to increased runoff from agriculture land and the potential for increased levels of turbidity, nutrients, and bacteria in the form of non-point source pollution in surface water.

Additional pressure will be felt by production agriculture from issues such as late season freezes on winter wheat, increased exposure to invasive species and pests, later freeze kill on summer crops such as grain sorghum, and changes in rainfall patterns reducing the dependability of precipitation in the spring and summer months.

\subsection{Cropping Systems Overview of Risks, Vulnerabilities and General Adaptation Strategies}

\section{Cropping Systems Overview}

\section{Rainfed Cropping}

Wheat, cotton, and sorghum are important rainfed crops through much of the Southern Plains. In the more humid east, corn and soybean are important. Other crops include sunflower, canola, peanut, and a wide variety of hay crops. All rainfed cropping is highly subject to drought. Cropland soils are generally depleted of soil organic matter and crops are subject to both wind and water erosion. Late season frosts have caused extensive losses to wheat in recent years in Kansas and Oklahoma and extreme heat waves stress summer crops throughout the region. 


\section{Irrigated Cropping}

The Ogallala Aquifer supports a vital irrigated agriculture in western Kansas, and the panhandles of Oklahoma and Texas. Corn and other feed grains have been important irrigated crops and irrigation cropping has fostered extensive confined animal agriculture in this region. Additionally, the region has a bioenergy industry and the cropping-energy-feedlot sectors are tightly interlinked. In the southern High Plains near Lubbock, cotton is the dominant crop. However, the Southern Plains portion of the aquifer is depleting and in some cases irrigation has already been lost. Other areas are experiencing declining water levels with associated increased pumping costs and decreased well output. There is increasing competition for water in this region from oil and gas exploration. Water policy and law differs across the three States and across Tribal governments, and in Kansas and Texas also differs across groundwater management districts.

Another important irrigated area is the Rio Grande Valley, which supports one of the Nation's major vegetable and citrus production areas and is subject to tropical storms, heat stress, drought, and a variety of insect and disease pressures. Irrigated areas in subhumid parts of the region, such as the Rush Springs aquifer area of Oklahoma, have greater potential for recharge than the Ogallala, but the hydrogeology and sustainability of that aquifer is not well quantified. Irrigation from surface water supplies, such as cotton production near Lake Altus in southwestern Oklahoma is highly subject to drought, with no water available for irrigation from 2011 through 2014. Additionally, specialty crops, nut tree crops, and direct market produce crops are largely irrigated and are faced with a number of pest challenges that are highly sensitive to climate challenges. When considering fresh surface and groundwater sources separately, surface water supplies 68 percent of Great Plains water needs and groundwater provides 32 percent. For irrigated agriculture, surface water provides 57 percent and groundwater 43 percent of total withdrawals. However, at a State level, the distribution is more skewed. In Colorado, Montana, and Wyoming, surface water provides more than 80 percent of irrigation needs. At a broader scale, in Kansas, Nebraska, and Texas, groundwater provides more than 75 percent of irrigation needs (Ojima et al., 2015). 


\section{Water Supply}

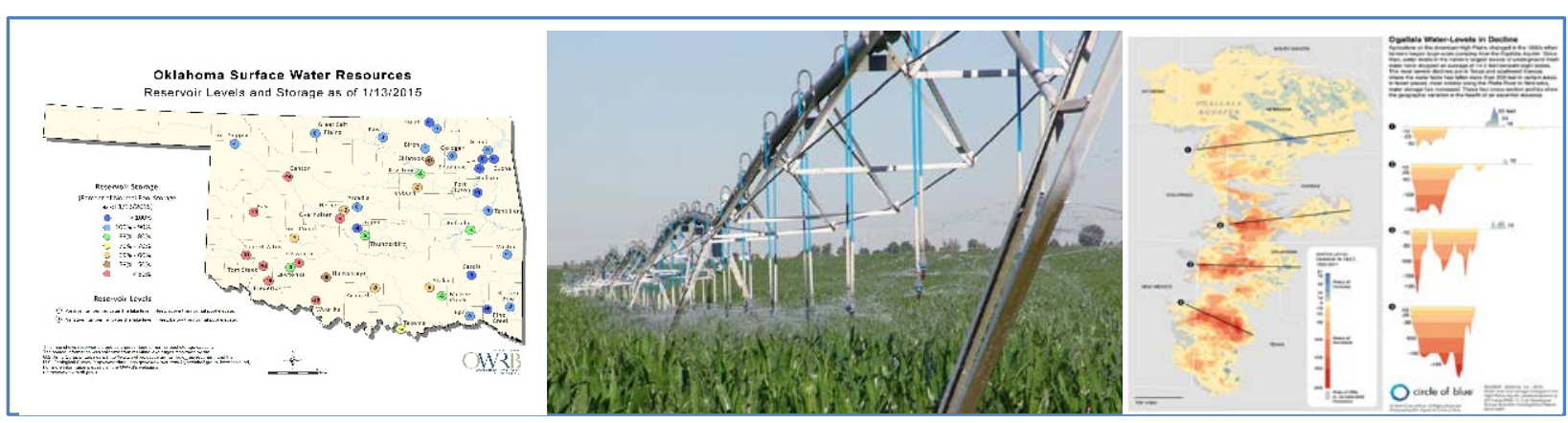

\section{Characteristics 4}

The Southern Plains States of Kansas, Oklahoma, and Texas rely on surface and groundwater supply to mitigate agricultural losses during drought. Parts of the three States rest above the Ogallala aquifer, a finite source of water used extensively for irrigation. The region also is home to numerous impoundments created through programs operated by NRCS, the U.S. Army Corps of Engineers, and the Bureau of Reclamation.

Risks

- Multiyear drought and pluvial periods.

- More extreme weather events (e.g., downpours and droughts).

- High potential evapotranspiration related to high temperature, low humidity, and high wind speed.

- Diminishing supply of ground water.

\section{Vulnerabilities}

- Decline in surface level in reservoirs during drought reduces water available for irrigation and rural community public water supply.

- Increased pumping for irrigation or cooling of livestock in confined systems accelerates the decline in groundwater levels, increases energy costs for pumping, and decreases the useful life of the aquifer.

- Reduced livestock water in streams, ponds, and wells with extended droughts.

- Higher water temperature combined by reduced dilution of contaminants during low flow periods may result algal blooms, including toxic blooms.

- Runoff during intense storms on low-vegetative cover lands transport more sediment and contaminants to water bodies.

- Flooding of low-lying cropland and pastures during extreme rainfall.

\section{Adaptation Strategies}

- Maintain vegetative cover on the land surface and encourage the adoption of conservation tillage to reduce evaporation, reduce soil temperature, erosion, and increase infiltration.

- Restore grass on highly erodible land, implement improved pasture management, adopt no-till cropping, utilize cover crops, restore riparian areas, and establish filter wetlands to address nutrient and bacteria runoff from agricultural land and reduce sedimentation.

- Adopt high-efficiency irrigation systems and implement irrigation scheduling.

- Implement water conservation programs and drought preparedness in rural communities.

- Implement floodplain management plans.

- Repair and maintain existing water impoundments.

- Construct new impoundments to provide additional water supply for agriculture and communities.

References: McGuire (2014).

\footnotetext{
${ }^{4}$ https://www.owrb.ok.gov/supply/drought/reservoirstorage.php
} 


\section{Wheat}

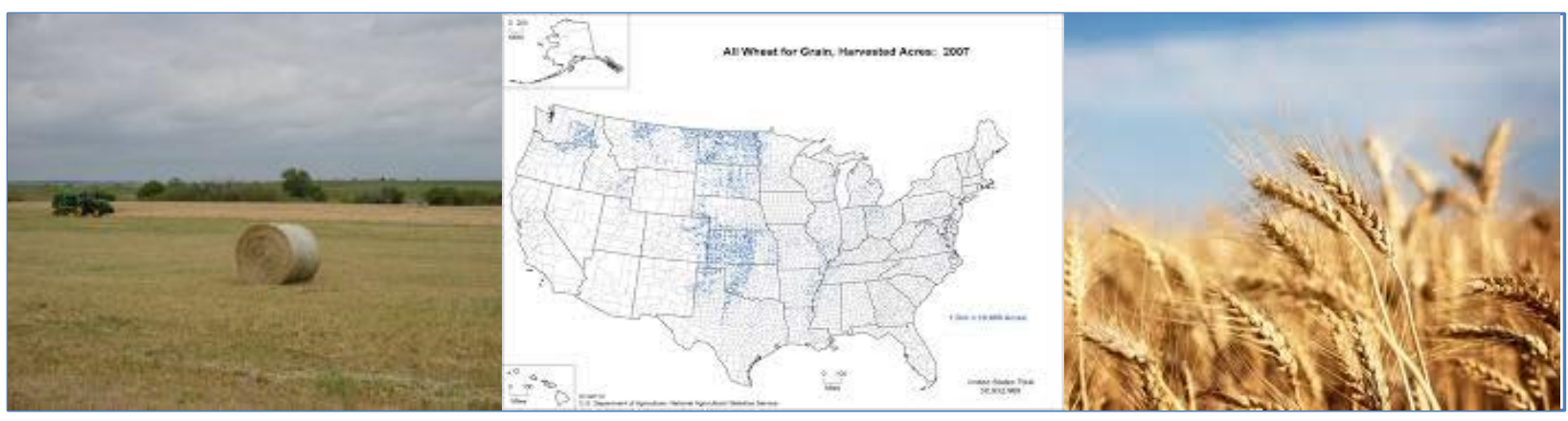

\section{Characteristics}

Wheat is grown on approximately 20.6 million acres in the Southern Plains States of Kansas, Oklahoma, and Texas (National Agricultural Statistics Service, 2014), which represents roughly 37 percent of the wheat acreage and approximately 43 percent of the wheat production in the United States. In addition to grain production, much of the region's wheat acreage is used to supply fall and winter forage to beef cattle in dual purpose graze-grain systems.

Risks

- Longer, hotter growing seasons with earlier arrival of spring.

- Increased extreme weather events (e.g., downpours and droughts).

- Altered distribution of seasonal precipitation.

- Late spring frosts.

- Heat waves.

- Increased overall temperatures during winter wheat growing months.

\section{Vulnerabilities}

- Some wheat varieties may not meet vernalization requirements during unusually warm seasons.

- Unreliable fall planting.

- Reduced winter grazing potential due to changes in rain patterns.

- Warmer and drier springs can lead to shortened seed filling and reduced yield.

- Increased potential of soil erosion from higher frequency of downpours and exposure to high wind on ground exposed through conventional tillage.

- Reduced forage production and livestock gains with higher incidence of drought occurrence.

- Reduced livestock water in streams, ponds, and wells with extended droughts creating challenges on dual purpose wheat acres.

- Higher heat stress on animals grazing on wheat pasture.

- Higher pest pressure on livestock due to longer and warmer growing seasons.

- Increased pests due to changes in weather patterns leading to reduced quality of harvested wheat.

\section{Adaptation Strategies}

- Incorporation of cover crops on fallow acres with an emphasis on increasing plant cover to improve soil health for benefits to soil water holding capacity and nutrient cycling.

- Research on wheat varieties that are less susceptible to late season freezes and drought conditions.

- Conversion of conventional tilled cropping systems to no-till or reduced tillage systems to reduce erosion, reduce fuel usage, increase soil moisture, and improve soil health.

- Integrated pest management.

- Conversion to more efficient irrigation systems on irrigated acres.

- Additional water sources and sources of shade for livestock on dual purpose wheat acres. 


\section{Cotton}

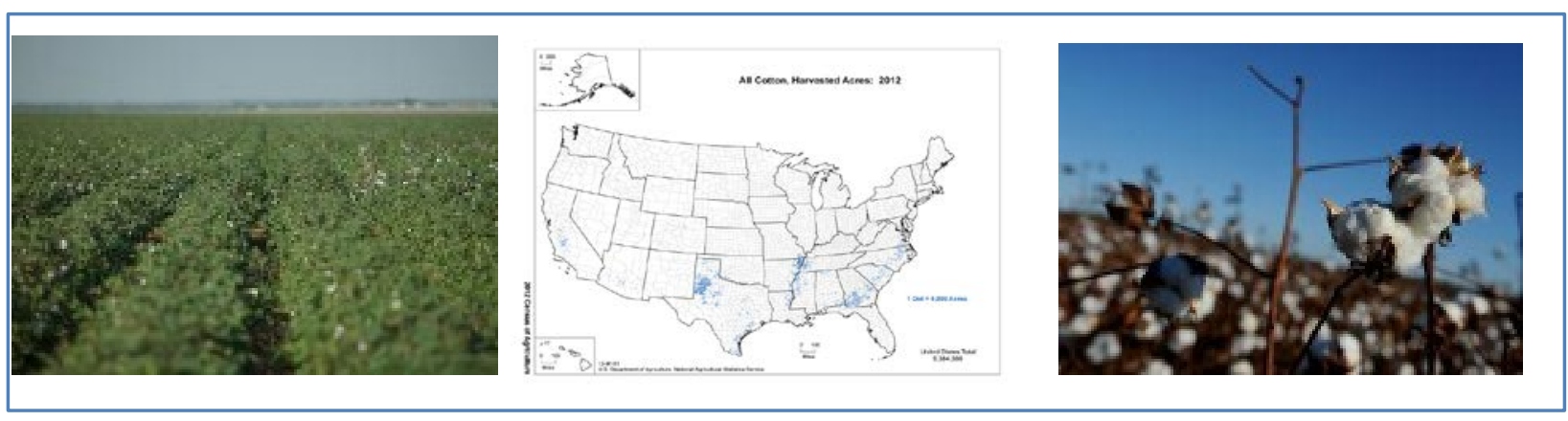

\section{Characteristics}

Cotton is grown on approximately 7.2 million acres in the Southern Plains states of Kansas, Oklahoma, and Texas (National Agricultural Statistics Service, 2014), primarily in the semiarid regions of Texas, which represents roughly 58 percent of the cotton acreage and approximately 42 percent of the cotton production in the United States. Cotton is grown under rain-fed conditions as well as under irrigation from groundwater (Ogallala Aquifer and other) and surface water supplies (e.g. Altus-Lugar Irrigation system in Oklahoma).

Risks

- Increased extreme weather events (e.g., downpours and droughts).

- Altered precipitation distribution (more winter and spring precipitation, less summer precipitation).

- Late spring frosts. Early autumn frost.

- Rapid dynamics in temperature patterns.

- High soil temperature.

- High potential evaporation related to high temperature, low humidity, and high wind speed.

- Severe storms (ice, hail, wind, tornadic activity).

\section{Vulnerabilities}

- Drought and heat stress on plants.

- Reduced surface water supply.

- Accelerated decline of groundwater levels.

- Less reliable spring and fall precipitation.

- Increase pest pressures.

- Increased energy costs associated with declining irrigation water supply.

- Seedling loss to wind erosion or high soil surface temperatures.

- Increased potential of soil erosion from higher frequency of downpours and exposure to high wind on ground exposed through conventional tillage.

- Increased pests due to changes in weather patterns leading to reduced quality of harvested wheat.

\section{Adaptation Strategies}

- Incorporation of cover crops with an emphasis on improved soil health for benefits to soil water holding capacity and nutrient cycling.

- Integrated pest management programs.

- Risk management through marketing and insurance programs.

- Research on varieties that are less susceptible to drought conditions.

- Conversion of conventional tilled cropping systems to no-till or reduced tillage systems to reduce erosion, reduce fuel usage, increase soil moisture, and improve soil health.

- Integrated pest management.

- Conversion to more efficient irrigation systems on irrigated acres. 


\section{Sorghum}

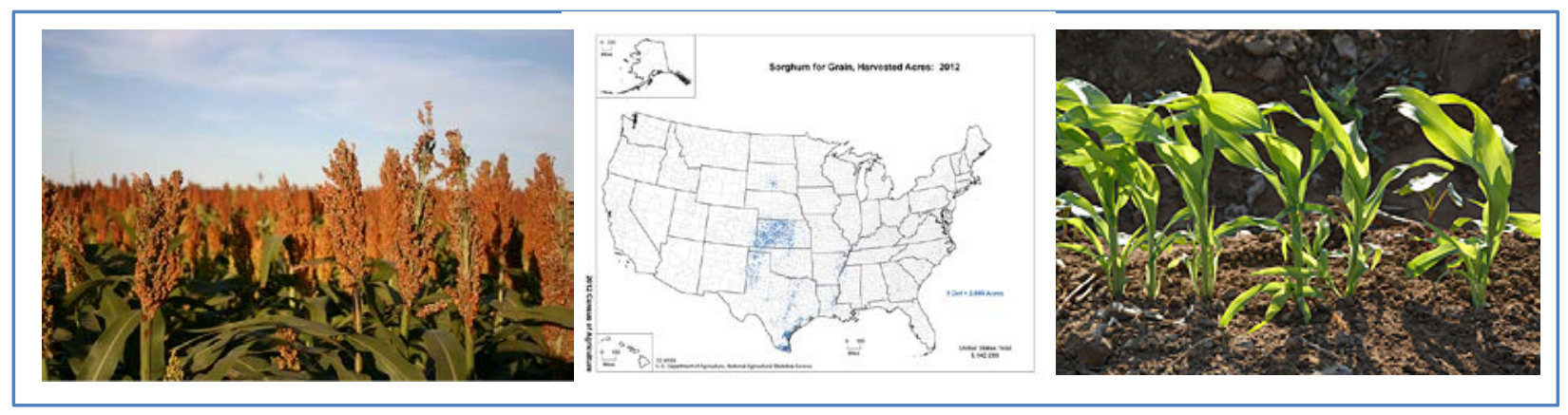

Characteristics

Grain sorghum is grown on approximately 4.2 million acres in the Southern Plains States of Kansas, Oklahoma, and Texas (National Agricultural Statistics Service, 2014). An additional 0.26 million acres of forage sorghum is also grown. There is an emerging market for sorghum as a bioenergy crop.

Risks

- Increased extreme weather events (e.g., downpours and droughts).

- Altered distribution of seasonal precipitation (more winter and spring precipitation, but less summer precipitation).

- Heat waves.

- Early fall frost.

- High potential evaporation related to high temperature, low humidity, and high wind speed.

\section{Vulnerabilities}

- Drought and heat stress on plants.

- Increase pest pressures.

- Poor head emergence and seed set associated with drought.

- Greater soil erosion from higher frequency of downpours on lands with low plant cover.

- More pests due to changes in weather patterns leading to reduced quality of harvested wheat.

\section{Adaptation Strategies}

- Incorporation of cover crops with an emphasis on increasing plant cover to improve soil health for benefits to soil water holding capacity and nutrient cycling.

- Integrated pest management programs.

- Risk management through marketing and insurance programs.

- Emphasis on conversion of conventional tilled cropping systems to no-till or reduced tillage systems to reduce erosion, reduce fuel usage, increase soil moisture, and improve soil health.

- Integrated pest management.

- Heat, drought, and pest tolerant varieties. 


\section{Corn}

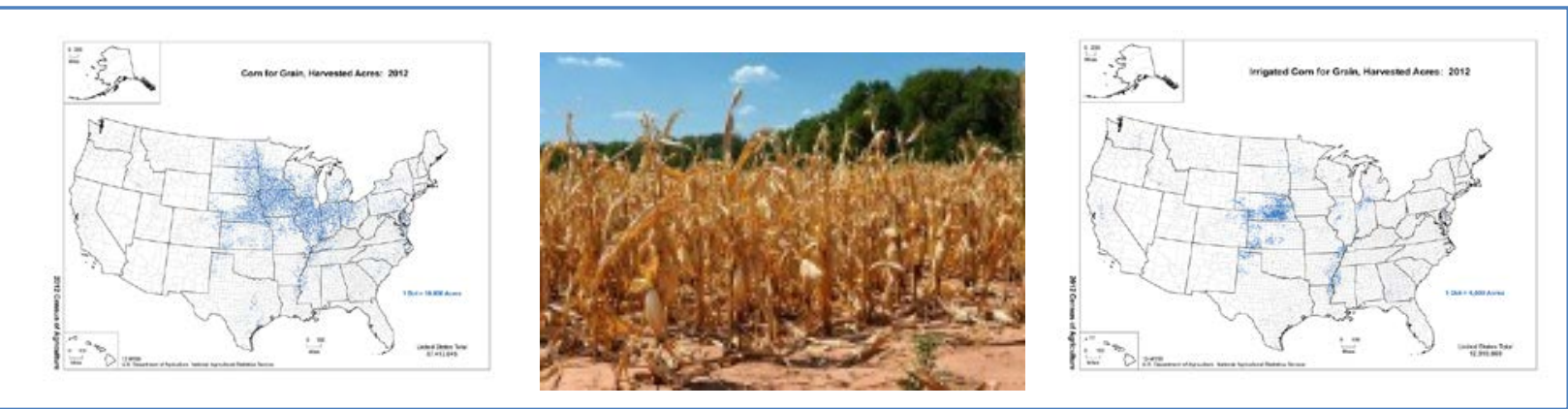

Characteristics

Corn is grown on approximately 5.86 million acres in the three Southern Plains States of Kansas, Oklahoma, and Texas (National Agricultural Statistics Service, 2014). Although rain-fed corn is grown primarily in eastern Kansas and Texas, irrigated corn is grown primarily in the Ogallala area in the Texas and Oklahoma panhandles and western Kansas.

Risks

- Greater extreme weather events (e.g., downpours and droughts).

- Altered distribution of seasonal precipitation (more winter and spring precipitation, but less summer precipitation).

- Heat waves.

- Rapid dynamics in temperature dynamics.

Vulnerabilities

- Drought stress on plants.

- Heat stress, particularly during tasseling and pollination.

- Greater pressures from pests.

- Depletion of irrigation water supplies.

- High energy costs.

- Increased soil erosion from higher frequency of downpours on lands with low plant cover.

Adaptation Strategies

- Heat and drought tolerant varieties.

- Better irrigation efficiency.

- Limited irrigation management systems.

- Emphasis on increasing plant cover to improve soil health for benefits to soil water holding capacity and nutrient cycling.

- Integrated pest management.

- Risk management through marketing and insurance programs. 


\section{Soybean}
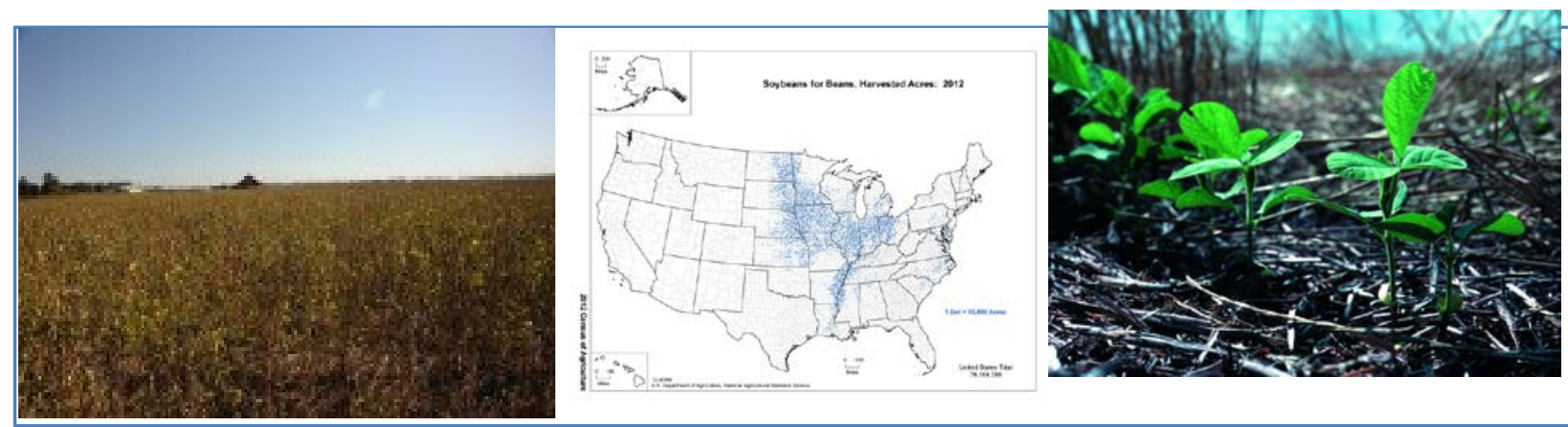

Characteristics

Soybean is grown on approximately 4.17 million acres in the Southern Plains States of Kansas, Oklahoma, and Texas (National Agricultural Statistics Service, 2014), primarily in eastern Kansas.

Risks

- Increased extreme weather events (e.g., downpours and droughts).

- Altered distribution of seasonal precipitation (more winter and spring precipitation, but less summer precipitation).

- Heat waves.

- Rapid dynamics in temperature dynamics.

\section{Vulnerabilities}

- Drought and heat stress on plants.

- Increase pest pressures.

- Increased soil erosion from higher frequency of downpours on lands with low plant cover.

\section{Adaptation Strategies}

- Incorporation of cover crops with an emphasis on increasing plant cover to improve soil health for benefits to soil water holding capacity and nutrient cycling.

- Integrated pest management programs.

- Risk management through marketing and insurance programs.

- Research with an emphasis on varieties that are less susceptible to drought conditions.

- Emphasis on conversion of conventional tilled cropping systems to no-till or reduced tillage systems to reduce erosion, reduce fuel usage, increase soil moisture, and improve soil health.

References:(National Agricultural Statistics Service, 2014) 


\section{Horticulture}

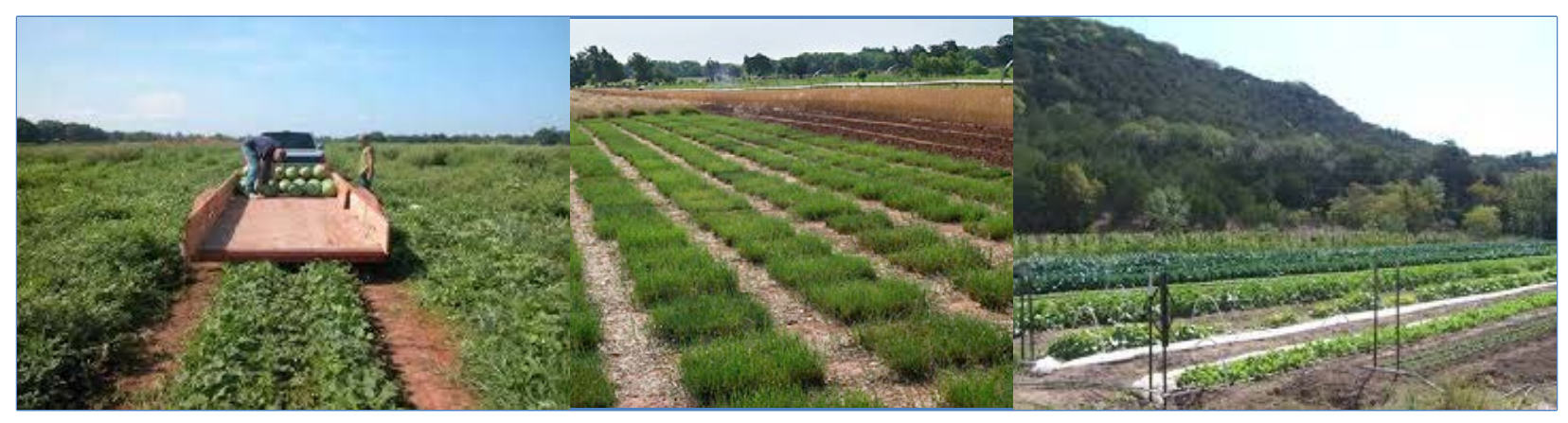

\section{Characteristics}

The Southern Plains States of Kansas, Oklahoma, and Texas support a wide variety of vegetable, fruit, ornamental, turf, and horticultural crops. Capital investment and production costs are extremely high for these crops, resulting in large financial vulnerability to extreme climate. The crops are almost always irrigated, due to the high investment.

\section{Risks}

- Increased extreme weather events (e.g., downpours and droughts).

- Late spring frosts. Early autumn frost.

- Heat waves.

- Rapid dynamics in temperature dynamics.

- High soil temperature.

- High potential evaporation related to high temperature, low humidity, and high wind speed.

- Severe storms (ice, hail, wind, tornadoes).

\section{Vulnerabilities}

- Late freezes may result in crop loss, including potential loss of perennial tree crops.

- Heat waves and rapid dynamics between hot and cold temperature extremes degrade the productivity and particularly the quality of the products.

- Accelerated decline of groundwater level may increase cost of irrigation.

- Greater pest pressures associated with longer growing seasons and more rapid heat unit accumulation.

- Poor seed set associated with drought and/or heat stress during pollination.

- Increased soil erosion from higher frequency of downpours on lands with low plant cover.

- Damage to greenhouses, hoop houses, and production infrastructure may result in crop loss and expensive repair or rebuilding.

\section{Adaptation Strategies}

- Develop efficient irrigation systems and efficient methods to use water for cooling.

- Develop spraying systems to mitigate late frost effects on crops.

- Develop/plant more heat and drought tolerant varieties.

- Emphasis on increasing plant cover to improve soil health for benefits to soil water holding capacity and nutrient cycling.

References: (Melillo et al., 2014). 


\subsection{Livestock Systems Overview of Risks, Vulnerabilities and General Adaptation Strategies}

\section{Beef Cattle Production and Associated Grazing Systems}

Beef cattle production is one of the largest sources of farm-gate income in Southern Plains States. All phases of beef production — cow/calf, stocker grazing, and finishing — are important in this region. The extensive grazing phases are based on a diversified land use base that includes native prairie grasses, a variety of pastures, and annual cropping. Winter wheat is important cool season forage, often in dualpurpose systems that produce both forage and grain. Drought is a primary climate concern for beef cattle, affecting forage availability, forage quality, water supply, and associated heat stress on cattle.

\section{Confined Animal Production}

In addition to beef cattle feedlots, large dairy and swine systems are important, generally in the semiarid western regions. These systems are dependent on water supply, often from the Ogallala aquifer, and are affected by high energy costs and animal health/productivity issues associated with high temperature. Poultry production is very important in the eastern portion of the Southern Plains. Poultry production interfaces with beef cattle production in that poultry litter is commonly applied to pastures as fertilizer. Nutrient enrichment in watersheds has caused extensive cross-State conflict associated with water quality in water supply (Tulsa) and recreation reservoirs as well as in scenic rivers that are important for recreational tourism. 


\section{Beef Cattle}

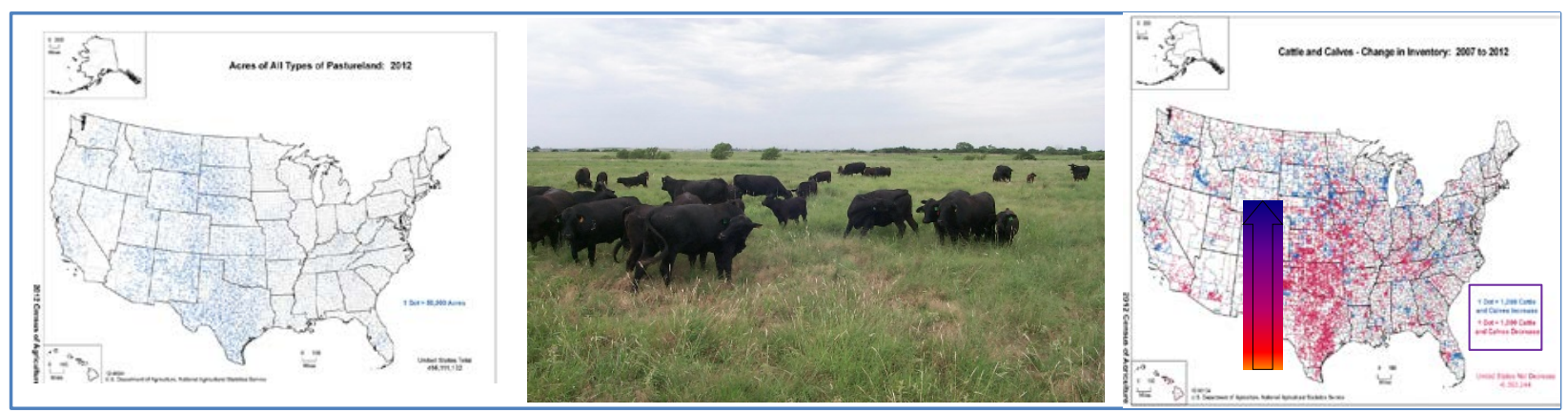

Characteristics

The Southern Plains States of Kansas, Oklahoma, and Texas raise approximately 7.3 million head of beef cattle (National Agricultural Statistics Service, 2014), which account for nearly \$27 billion in total sales. All three States rank in the top ten among States in both cattle sales and total cattle inventory. Texas and Kansas rank in the top five among States in the number of total cattle on feed.

Risks

- Exposure to extreme temperatures, both in regards to heat waves and cold snaps; vulnerability to stress created by rapid and extreme changes in temperature.

- Rapid dynamics in temperature dynamics.

- High potential evaporation and stress to water supply related to high temperature, low humidity, and high wind speed.

- Drought.

- Effect on forage and feed supply due to changes in rainfall patterns and overall temperatures.

\section{Vulnerabilities}

- Loss of productivity and increase in death loss during cold weather extremes and heat waves.

- Greater stress due to rapid changes in extreme temperature.

- Changes in rainfall and temperature patters leading to long-term risk to available forage both in pasture and rangeland and dual purpose winter wheat grazing.

- Higher energy costs.

- Greater stress on water supplies for beef cattle consumption.

- Enhanced woody plant expansion (e.g., eastern red cedar) which reduces productivity and carrying capacity, as well as increases risk of wildfire.

- Vegetation shifts may influence threatened and endangered species, and species of concern.

\section{Adaptation Strategies}

- Adopt or develop breeds that are more tolerant to extremes of heat and cold.

- Construct energy and water efficient facilities.

- Develop additional water supplies and facilities providing shade and cooling for cattle.

- Adopt silvopasture systems to provide shade for cattle and diversify enterprises.

- Convert acres used for producing feed and forage from conventional tilled cropping systems to no-till or reduced-tillage systems with the inclusion of cover crops designed to be utilized as additional sources of grazing and haying for beef cattle herds.

- Adapt grazing management to match forage availability and demand including flexibility in stocking rates, time and season of grazing to provide greater vegetation heterogeneity.

- Practice grassbanking (resting of pastures for $>1$ year) to provide forage during dry periods.

- Adopt proactive management strategies to reduce invasive species to reduce risk of wildfires, and promote resiliency of native plant communities. 


\section{Grazing Lands}

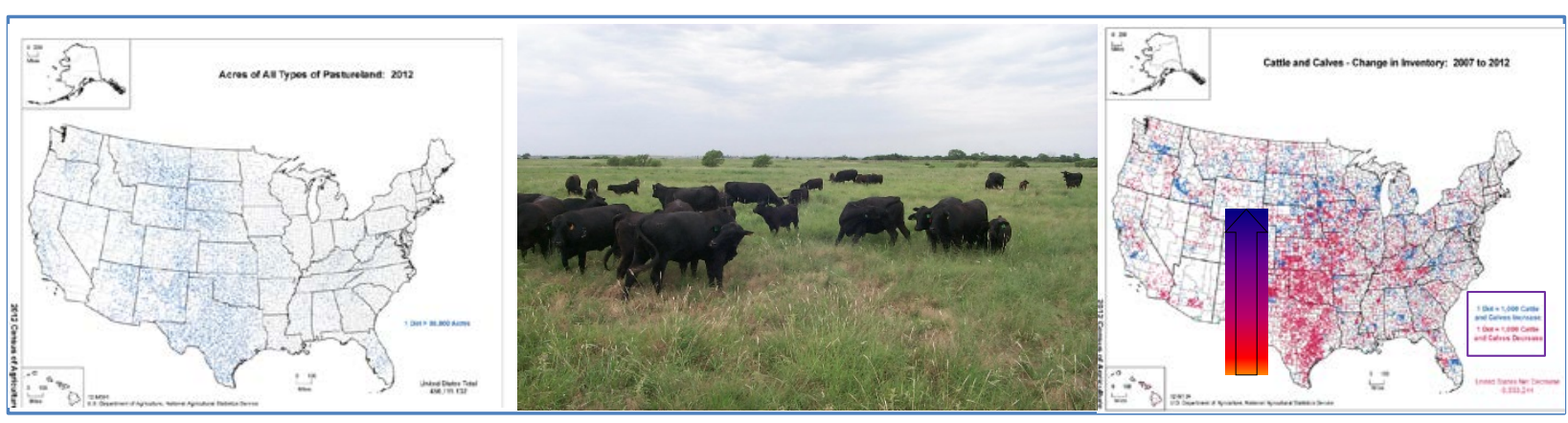

Characteristics

The Southern Plains States of Kansas, Oklahoma, and Texas holds approximately 156.6 million acres of grazing land (i.e., rangeland and pastureland) (National Agricultural Statistics Service, 2014), which represents roughly 30 percent of the privately owned grazing land in the United States. These lands support ruminant livestock production, primarily beef cattle. The region also has a growing goat industry and some sheep that utilize these acres.

\section{Risks}

- Longer, hotter growing seasons with earlier arrival of spring.

- More and greater extreme weather events (e.g., downpours and droughts).

\section{Vulnerabilities}

- Warmer and expected drier summers increase risk of wildfires.

- Greater potential of soil erosion from higher frequency of downpours on grazing lands with low plant cover.

- Lower forage production and livestock gains with higher incidence of drought occurrence.

- Less water for livestock in streams, ponds, and wells with extended droughts.

- Greater heat stress on animals.

- Greater pest pressure on livestock due to longer and warmer growing seasons.

- Enhanced woody plant expansion (e.g., eastern red cedar), which reduces productivity and carrying capacity, and increases risk of wildfire.

- Vegetation shifts may influence threatened and endangered species, and species of concern.

\section{Adaptation Strategies}

- Adapt grazing management to provide flexibility to match forage availability and forage demand.

- Establish flexibility in stocking rates, time, and season of grazing (and rest) across ranches/watersheds/landscapes to provide greater vegetation heterogeneity.

- Practice grassbanking (resting of pastures for $>1$ year) to provide forage during dry periods.

- Undertake proactive management strategies to reduce invasive species to reduce risk of wildfires, and promote resiliency of native plant communities.

- Emphasize expanding plant cover to improve soil health for benefits to soil water holding capacity and nutrient cycling.

- Expand and improve water sources for livestock and the incorporation of strategies to reduce heat and cold stress on animals (i.e. providing shelter).

Reference (National Agricultural Statistics Service, 2014). 


\section{Poultry and Eggs}

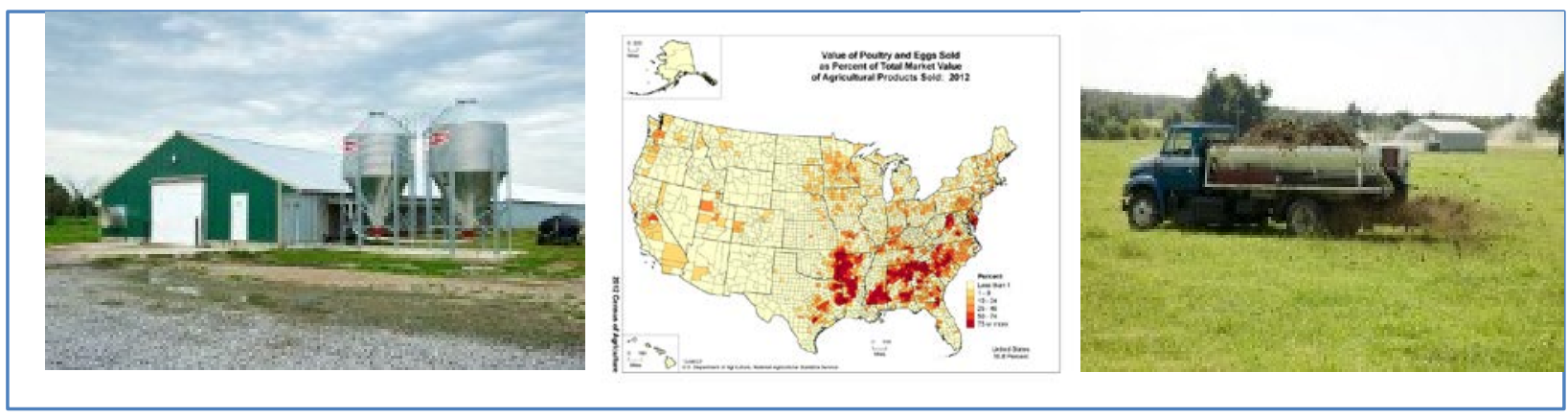

\section{Characteristics}

The Southern Plains states of Kansas, Oklahoma, and Texas produce approximately 802 million broilers generating roughly 4.8 billion pounds of meat (National Agricultural Statistics Service, 2014). The region also producers roughly 5.8 billion eggs annually. Most of the production for this region is in the eastern portions of Oklahoma and Texas. Poultry production is primarily conducted on family farms under contract with large integrated corporate producers that determine acceptable facility design and production practices. Poultry litter is often used as a fertilizer source on pastures and other crops, and areas with concentrated poultry production often have surplus $\mathrm{N}$ and $\mathrm{P}$ within the watersheds where the poultry litter is land applied.

\section{Risks}

- Increased extreme weather events (e.g., downpours and droughts).

- Heat waves.

- Rapid dynamics in temperature dynamics.

- Severe storms (ice, hail, wind, tornadic activity)

\section{Vulnerabilities}

- Health problems and productivity losses during rapidly dynamic temperature swings and heat waves.

- Increased energy costs for cooling during heat waves.

- Increased risk of nutrient runoff from poultry litter fertilized pastures and fields during higher frequency of downpours.

\section{Adaptation Strategies}

- Breeding to increase heat tolerance of flocks.

- Engineering facilities to minimize temperature changes.

- Introduction of energy efficiencies in poultry production.

- Water efficiency strategies.

- Research to develop alternative waste management strategies that are not subject to runoff.

- Emphasis on increasing plant cover to improve soil health for benefits to soil water holding capacity and nutrient cycling in order to reduce nutrient runoff.

Reference: (National Agricultural Statistics Service, 2014) 
Swine

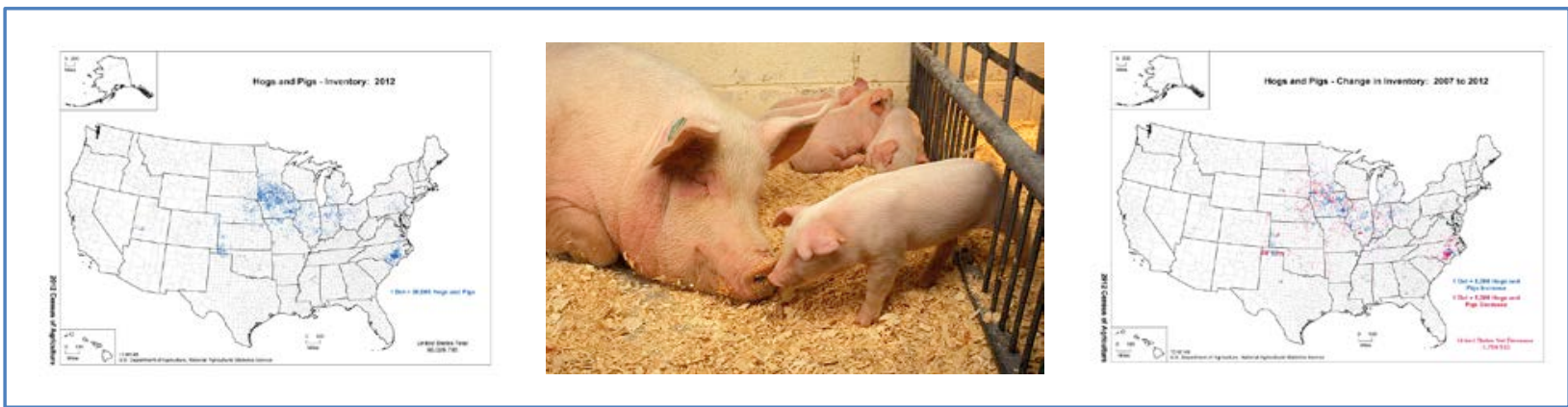

Characteristics

The Southern Plains states (Kansas, Oklahoma, and Texas) produced almost \$1.6 billion of swine in 2012 (National Agricultural Statistics Service, 2014). Most are produced in the western, drier portions of the region, primarily in the Ogallala aquifer area.

Risks

- Heat waves.

- Rapid dynamics in temperature dynamics.

- High potential evaporation related to high temperature, low humidity, and high wind speed.

- Drought.

\section{Vulnerabilities}

- Health problems and productivity losses during rapidly dynamic temperature swings and heat waves.

- Higher energy costs for cooling during heat waves.

- Greater risk of nutrient runoff from animal waste systems.

- Accelerated decline of groundwater level leading to long term risk of feed supplies.

Adaptation Strategies

- Adopt develop breeds that are more heat tolerant.

- Construct energy and water efficient facilities.

- Engineer facilities to minimize temperature changes.

- Increase energy use efficiency.

- Improve water efficiency and recycling strategies.

- Carry out research to develop alternative waste management strategies that are not subject to runoff.

Reference: (National Agricultural Statistics Service, 2014). 


\section{Dairy}

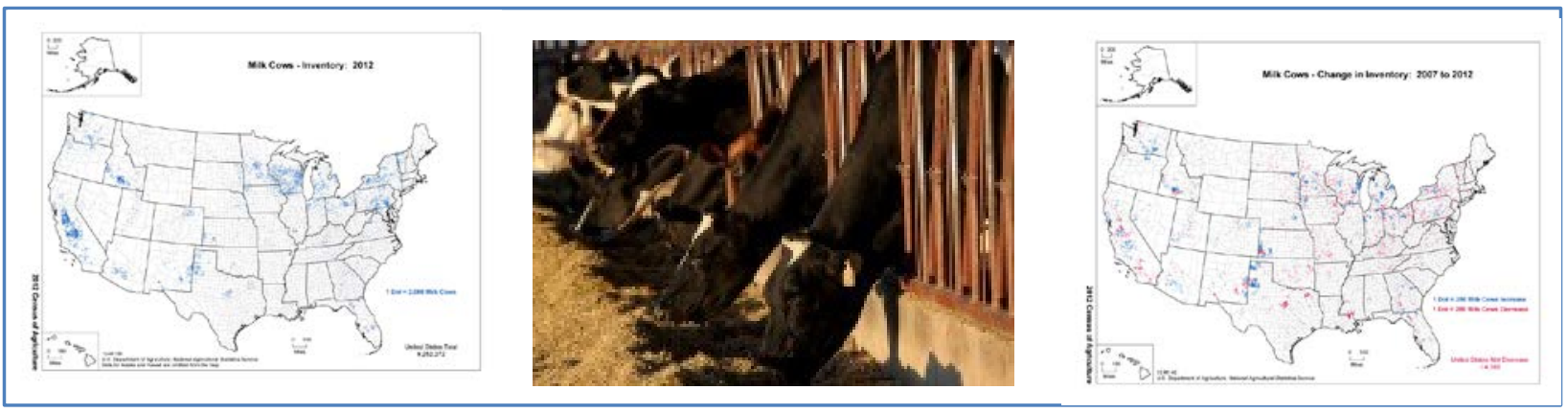

Characteristics

The Southern Plains states (Kansas, Oklahoma, and Texas) produce over $\$ 2.3$ billion of dairy products primarily in Texas (National Agricultural Statistics Service, 2014). Since 2007, there has been a rapid expansion of herds in the High Plains regions, overlaying the Ogallala aquifer. During that time, dairies in the more humid portions of the region have declined.

Risks

- Heat waves.

- Rapid dynamics in temperature dynamics.

- High potential evaporation related to high temperature, low humidity, and high wind speed.

- Drought.

\section{Vulnerabilities}

- Health problems and productivity losses during rapidly dynamic temperature swings and heat waves.

- Increased energy costs for cooling during heat waves.

- Increased risk of nutrient runoff from animal waste systems.

- Accelerated decline of groundwater level leading to long term risk of feed supplies.

\section{Adaptation Strategies}

- Adoption or development of breeds that are more heat tolerant.

- Energy and water efficient facilities.

- Engineering facilities to minimize temperature changes.

- Increasing energy use efficiency.

- Water efficiency and recycling strategies.

- Research to develop alternative waste management strategies that are not subject to runoff.

- For forage lands supporting dairy, emphasis on maintaining plant cover to improve soil health for benefits to soil water holding capacity and nutrient cycling.

Reference: (National Agricultural Statistics Service, 2014). 


\section{Regional Forestry Sensitivities to Climate Change and Adaptation Strategies}

Encompassing natural and commercially managed forests, as well as naturally occurring and planted tree areas not meeting the definition of forest based on size; forest resources comprise a small but important land area in the Southern Plains Region (Figure 3). These forest resources of the Southern Plains generate many benefits important to agriculture and the surrounding communities by providing watershed regulating services needed for providing clean water resources, climate regulating services from carbon sequestration to air quality, biological diversity regulating services, and cultural services. Collectively, these were estimated to be worth approximately $\$ 92.9$ billion annually in Texas alone (Simpson et al., 2013). Although providing adaptive capacity to the lands, these forest resources are themselves potentially vulnerable to expected stressors from shifting climate and extreme weather and therefore made adaptive.

\subsection{Natural forests of the Southern Plains}

Moving eastward from the short-grass prairies of Texas and Oklahoma, annual precipitation increases, reaching 16 inches $(400 \mathrm{~mm})$ in the Texas and Oklahoma panhandles and western Kansas. This is an important milestone because approximately 16 inches of annual precipitation are needed to support deciduous temperate trees. As annual precipitation first reaches and then exceeds the $400 \mathrm{~mm}$ minimum limit, scattered individual trees transition into savanna (a mixture of trees and grassland). With additional precipitation farther east, trees dominate the landscape, and an open forest develops. Finally, southeastern Kansas and eastern Texas and Oklahoma have sufficient precipitation to support the beginning of the densely spaced, closed canopy of the eastern temperate forest.

The eastern Southern Plains has six major forest types. Two pine-forest types are most common. The loblolly-shortleaf and longleaf-slash forest types are dominated by the four species of southern yellow pine. In these forests, various pine trees make up at least 50 percent of the trees. Historically, longleaf pine (Pinus palustris) occupied a much larger proportion of the region, but was cut and replanted with loblolly pine (Pinus taeda) due to a faster growth rate. Drought tolerant oaks (Quercus sp.), hickories (Carya sp.), and cottonwoods (Populus sp.) comprise most of deciduous species within central and eastern parts of the region, whereas pines (Pinus sp.) are the dominant conifer species.

Most forests in the Southern Plains States are found on private land, generally owned by large timber companies and smaller landowners who practice various forest-based enterprises. In eastern Oklahoma, the forests and large reservoir systems support an important tourism sector.

Throughout Texas, the forestry sector consists of 12 million acres of commercial forests located in primarily 43 counties in East Texas and has remained one of the top 10 manufacturing sectors in the State (Simpson et al., 2013). The forest sector is one of the top two largest manufacturing employers in 25 of the 43 East Texas counties and has a total economic effect of $\$ 27$ billion in industry output, $\$ 9.9$ billion in value-added; $\$ 5.9$ billion in labor income; and, 117,000 jobs for Texans. Likewise, Oklahoma has approximately 10 million acres of forest predominantly located in the central and eastern portion of the State. Oklahoma forests sustain approximately 8,000 jobs and create $\$ 2.8$ billion in annual sales (Johnson et al., 2010). Kansas has approximately 5.2 million acres of forests, woodlands, and trees that occupy approximately 10 percent of the State, with inventory data over the years indicating that forests are continuing to expand. Agroforestry plantings comprise a significant portion of Kansas' forest resources (Atchison et al., 2010). 


\section{Threats}

\section{Drought}

Species located at the margin of their habitat are often highly sensitive to environmental change and variability. Given that at least 16 inches of precipitation are needed annually to maintain tree survival, episodic events such as drought that reduce annual rates below this amount can quickly and severely affect forest health. Such an event occurred in 2011-12 when a growing-season drought effected Southern Plains region and killed more than 1 million trees across Texas and Oklahoma. Future climate model predictions of precipitation within the Southern Plains are highly variable, but there is strong model agreement on increasing air temperature (Texas A\&M Forest Service, 2012). Evapotranspiration increases with increasing air temperature. Therefore, forest water demand will also increase (Sun et al., 2008). Increases in tree water use will reduce stream flow and could negatively affect aquatic habitats and biodiversity even if annual precipitation remains unchanged.

\section{Wildfire}

Droughts are associated with dry weather, but they also often occur with hot conditions. The combination of hot and dry weather poses major risk factors for wildfire. The risk is further enhanced if preceding or currently occurring drought have increased fuel loads through drought-caused mortality. Thinning and reducing forest stocking density are adaptive management practices that will both reduce tree mortality risk due to drought by decreasing the demand on soil moisture, and will also reduce wildfire risk by reducing potential fuel loads. As climate variability increases, the amplitude and frequency of drought cycling forest thinning may need to become more frequent and aggressive.

\section{Insects}

The southern pine beetle (SPB) has long been an episodic problem is eastern Texas with outbreaks occurring across of range of environmental conditions in pine forests (McNulty et al., 1998). Ayres et al. (2000) predicted that SPB outbreaks would become more numerous with climate change due to extended breeding season length and potential for more generations each year. The primary control measure is to quickly locate SPB outbreaks areas and then remove and burn all infested trees.

\subsection{National Forest Lands}

In addition to the commercial forests, Texas also has approximately 653,000 acres of National Forests and 173,000 acres of State and local forests. Key natural resources within the Southern Plains region include several National Forests, including the Ouachita National Forest of Oklahoma; and Davy Crockett, Sabine, and Sam Houston National Forests in Texas. In addition, the Southern Plains region includes 810,993 acres of National Grasslands, including the Kiowa and Rita Blanca in New Mexico, Oklahoma, and Texas, administered by the Cibola National Forest (Albuquerque, NM); the Cimarron and Comanche National Grasslands in Kansas and Colorado, administered by the Pike and San Isabel National Forests (Pueblo, CO); and the Lyndon B. Johnson and Caddo National Grasslands, administered by the National Forests and Grasslands of Texas (Lufkin, TX). The U.S. Forest Service Rocky Mountain Research Station (USFS RMRS) conducted a review and needs assessment that synthesizes knowledge about climate change effects on the native fauna and flora of many of these grasslands, shrublands, and deserts of the interior American West, including parts of the Southern Plains region (Finch, 2012). The assessment is complemented by a web-based tool for managers to assess vulnerability of species to climate change (Bagne et al., 2011). In addition, understanding plant-climate relationships is crucial to addressing the effect of global warming and to developing vegetation management programs that address emerging issues (Clifford et al., 2013; Saenz-Romero et al., 2010). For instance, the timing of both disturbance and precipitation can have a major effect on the effectiveness of restoration treatments (Ford, 2011; Ford \& Johnson, 2006), which is key for practitioners making investments decisions and implementing management actions. In the eastern portion of the Southern Plains and the pine-hardwood forests of 
Arkansas and Texas, studies focus on the effects of climate change, forest management, and insect pests on wildlife and wildlife habitat to provide managers with better tools to restore and manage wildlife populations.

The effects of climate change on ecosystems, resource issues, invasive species, and water quality and quantity will create numerous risks and vulnerabilities. Concerns in the Southern Plains include greater stress on forests due to storms, drought, pests, fire, and sea level rise; wildfires fueled by extended droughts and poor tree health; lack of clean water available to sustain healthy forests; economic pressures due to increased changes in the productivity of high value timber and forest products; and increasing populations and urban areas infringing on existing forestlands.

The Southern Plains States have been part of mitigation and adaptation planning at both State and Federal levels. States emphasized that land management can mitigate climate change and its effects on forests and human communities. Trees and forests have the ability to sequester carbon dioxide, thereby reducing the concentration of that greenhouse gas in the atmosphere and potentially reducing the severity of climate change. Not only planting trees, but also increasing the use of long-lasting forest products can help offset carbon emissions. Planting trees in towns and cities can also help conserve energy, thereby reducing emissions outright. Finally, land management may be tailored to help people and forests adapt to climate change. Conserving and restoring forest lands will help to maintain vital ecosystem services, as will managing for resilience. 
Agroforestry

\begin{tabular}{|c|c|c|c|c|}
\hline$y^{2}+x^{2}-20$ & State & $\begin{array}{l}\text { Windbreaks } \\
\text { (in feet) }\end{array}$ & $\begin{array}{c}\text { Riparian } \\
\text { Forest } \\
\text { Buffers } \\
\text { (in acres) }\end{array}$ & 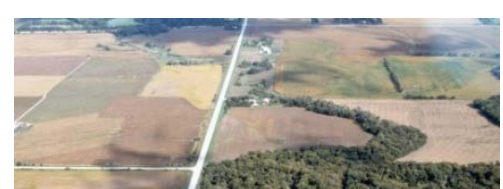 \\
\hline 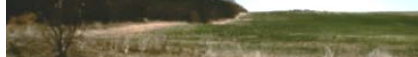 & & \multicolumn{2}{|c|}{ (under contract 2010) } & \\
\hline 25rest: & Kansas & 147,090 & 16 & 3 \\
\hline \multirow{3}{*}{$\begin{array}{l}\text { Kansas wheat field protected by } \\
\text { windbreaks }\end{array}$} & Oklahoma & 8,836 & 1546 & \multirow{3}{*}{ Riparian forest buffer } \\
\hline & Texas & 12,437 & 2065 & \\
\hline & \multicolumn{3}{|c|}{ For more information: http://nac.unl.edu } & \\
\hline
\end{tabular}

Characteristics

Agriculture has used a variety of practices to capitalize on the interactive benefits of combining trees and shrubs with crops and/or livestock to create integrated and sustainable land-use systems in the Southern Plains. These tree-based practices provide effective adaptation strategies for addressing climate change and extreme weather events ranging from drought to overland flow effects. Of agroforestry's five main practices, windbreaks and riparian forest buffers have the greatest relevance to the Southern Plains. Other agroforestry opportunities include silvopasture, which combines trees with forest and livestock production and alley cropping (e.g., nut trees and hay), which can help diversify production and provide other services, thereby reducing risk under uncertain weather. These practices are themselves vulnerable to climate change and must be designed and managed accordingly. See references below for more information on how to use agroforestry for building climate smart operations and lands.

Risks

1. Longer, hotter growing seasons with earlier arrival of spring; declining snowpack.

2. More extreme weather events (e.g., downpours and droughts).

3. Greater wildfire risk from warmer and expected drier summers.

4. More outbreaks of trees pathogens and pests.

\section{Vulnerabilities}

1. Greater susceptibility to diseases and pests as plant stress increases.

2. Potential for the establishment of invasive species within stressed agroforestry plantings.

3. Stress-related mortality of woody plants increasing time before practices become fully functional.

4. Unpredictable shifts in timing for optimal nursery operations (i.e., lifting, storing, and shipping).

\section{Adaptation Strategies}

1. Plant diverse species to hedge bets under the variety of conditions created by shifting weather patterns and climate change.

2. Use seed from locations currently under conditions that are similar to those expected locally under climate change.

3. Plant cultivars developed and selected for better resistance/resilience to stressors.

4. Select woody species with potential to be better adapted to future climate recognizing that these plants may be expected to live 60 years or more.

5. Use establishment (e.g., mulches) and renovation management (e.g., pruning, thinning, and replanting) practices to maintain and improve tree health and function.

References: Schoeneberger (2012) Patel-Weynand, T. et al. (In Review) 


\section{Agroforestry - Working Tree Solutions for the Southern Plains}

Agroforestry is a suite of practices that integrate trees into crop and livestock production to create more diversified, multipurpose and resilient operations and landscapes. Practices include windbreaks for crops, livestock, farmsteads, and communities; alley cropping; silvopasture; riparian forest buffers and forest farming. Small in total area, windbreaks and riparian forest buffers none-the-less have long played important roles in combating the negative effects of climate and weather extremes in the Southern Plains. As part of the Prairie States Forestry Program (1935-1942), windbreaks were planted throughout the Great Plains to protect soils from the ravages of the droughts that created the Dust Bowl. Likewise, windbreaks can increase irrigation/water use efficiency and therefore crop production in this windy and high evapotranspiration demand region (Dickey, 1988). Woody riparian vegetation helps stabilize streambanks, as documented for Kansas during the 1993 floods (Geyer et al., 2000), and provide water quality protection. By providing both climate change mitigation and adaptation services along with other benefits, agroforestry afford farmers, ranchers, Tribes and communities with opportunities to increase the resiliency of the land and general well-being under shifting weather and climate. For example, windbreaks in Kansas have been estimated to provide crop protective services on a yearly basis worth \$31 million and energy savings to farmsteads of around \$26 million, while also generating valued soil conservation and carbon sequestration services (Atchison et al., 2010).

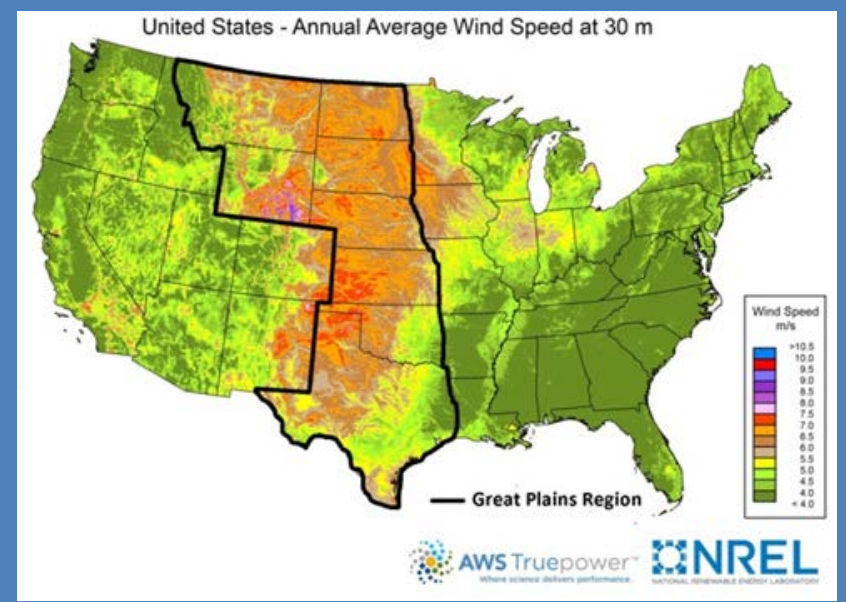

Figure 12: Winds and highly erodible lands are a dominant feature in many parts of the Southern Plains. Windbreaks can serve to provide crop, livestock and farmstead protection, while providing vital soil conservation services.
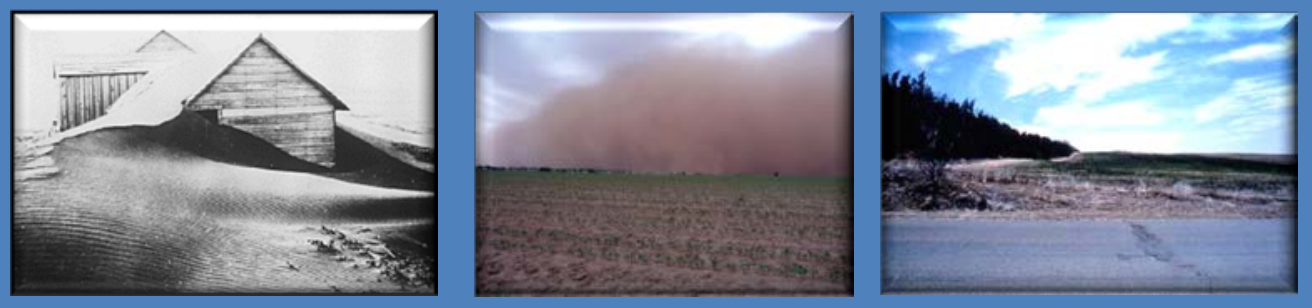

At the USDA National Agroforestry Center (NAC) (http://nac.unl.edu), the U.S. Forest Service and the Natural Resources Conservation Service, along with a national network of partners, develop relevant agroforestry information and assistance to natural resource professional nation-wide. Ongoing efforts include 1) carbon accounting methods for agroforestry and incorporation into the USDA NRCS carbon accounting tool - COMET-Farm (http://cometfarm.nrel.colostate.edu); 2) use of agroforestry to mitigate heat stress in livestock; 3) tools such as AgBufferBuilder (Dosskey, 2015) that can guide more efficient design and placement of practices; and 4) a Great Plains-wide windbreak/crop yields study to assess windbreak effect on crops under current conditions. Agricultural Research Service scientists are examining the potential of windbreaks in the Great Plains to enhance soil carbon, address greenhouse gases, and serve as a biofeedstock source. Future climate variability will be a key factor in the determination regarding how well these plantings can themselves be adapted to future conditions. (See Agroforestry vulnerabilities on previous page.) 


\section{Greenhouse Gas (GHG) Emissions Profile from Agriculture and Forests within the Region and Mitigation Opportunities}

Agriculture in the Southern Plains region (including crop, animal and forestry production) has net greenhouse gas (GHG) emissions of approximately 43 teragrams ${ }^{5}$ carbon dioxide equivalent ( $\mathrm{Tg} \mathrm{CO}_{2}$ eq.). In the region, crop-related nitrous oxide $\left(\mathrm{N}_{2} \mathrm{O}\right)$ emissions are the largest contributor to GHGs at $33 \mathrm{Tg} \mathrm{CO}_{2}$ eq., followed by methane $\left(\mathrm{CH}_{4}\right)$ from enteric fermentation (32 $\mathrm{Tg} \mathrm{CO}_{2}$ eq.), and $\mathrm{CH}_{4}$ and $\mathrm{N}_{2} \mathrm{O}$ from manure management (8 Tg $\mathrm{CO}_{2}$ eq.). Forestry is the largest contributor to net carbon storage at $-26 \mathrm{Tg} \mathrm{CO}_{2}$ eq. followed by soil carbon stock changes at $-5 \mathrm{Tg} \mathrm{\textrm {CO } _ { 2 }}$ eq. ${ }^{6}$

\subsection{Soil Carbon Stock Changes}

Carbon stock changes of major land use and management type for both soil types resulted in a net sequestration of $-4.5 \mathrm{Tg} \mathrm{CO}_{2}$ eq. in 2008 (Table 4). Specifically, cropland production changes on mineral soils sequestered $-1.6 \mathrm{Tg}$ $\mathrm{CO}_{2}$ eq., changes in hay production sequestered $-0.9 \mathrm{Tg} \mathrm{CO}_{2}$ eq., and land removed from agriculture and enrolled in the Conservation Reserve Program sequestered $-2.0 \mathrm{Tg} \mathrm{CO}_{2}$ eq.

Tillage practices contribute to soil carbon stock changes. Table 5 provides the tillage practices by type of crop for the Southern Plains Hub. Management practices that utilize reduced till or no till can contribute to increased carbon storage over time depending on site specific conditions.

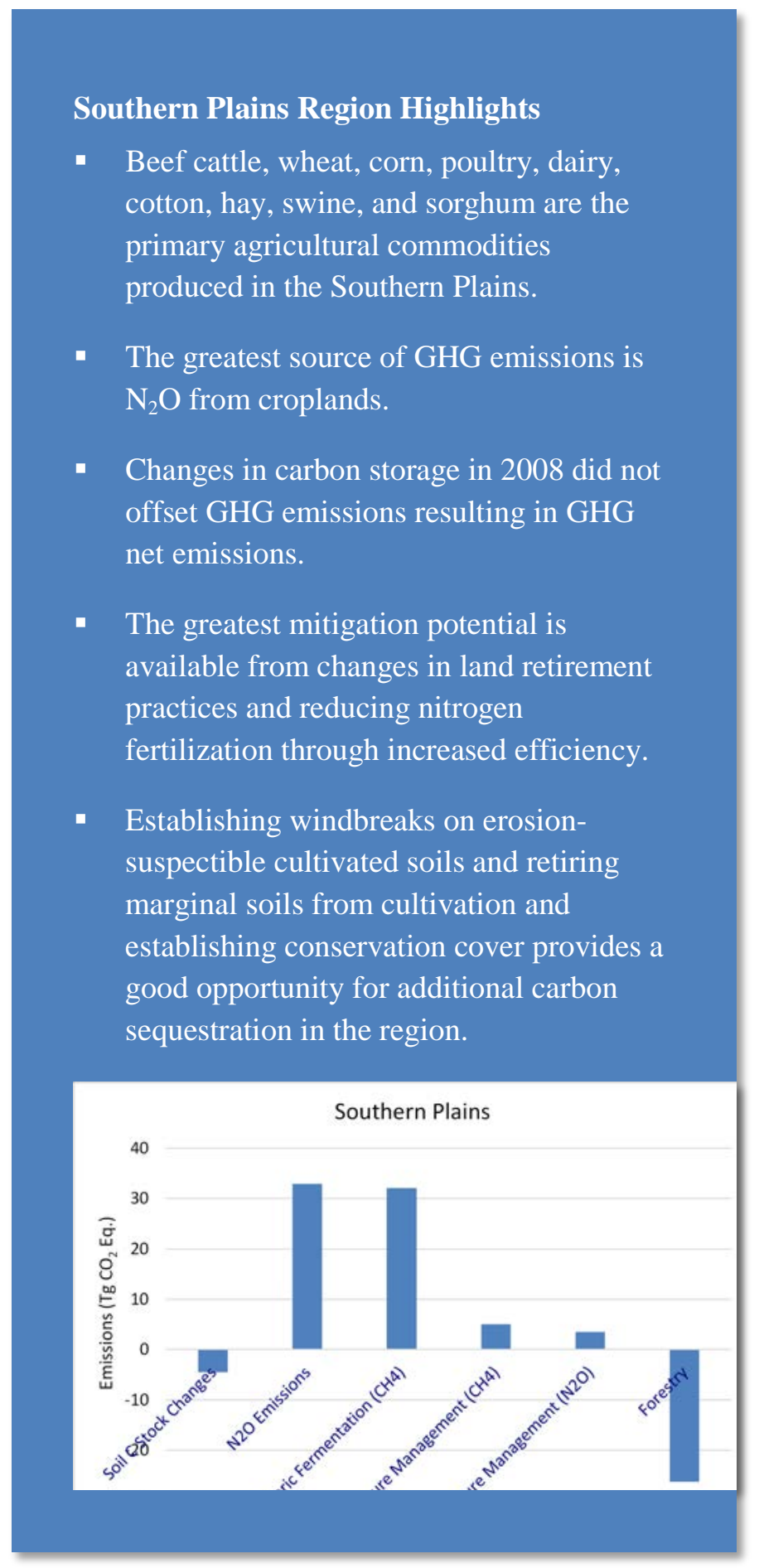

\footnotetext{
${ }^{5} \mathrm{~A}$ teragram (Tg) is $10^{12}$ grams, which is equivalent to $10^{9}$ kilograms and 1 million metric tons.

${ }^{6}$ Net carbon storage is the balance between the release and uptake of carbon by an ecosystem. A negative sign indicates that more carbon was sequestered than greenhouse gases emitted.
}

Greenhouse Gas (GHG) Emissions Profile from Agriculture and Forests within the Region and Mitigation Opportunities 
Table 4: Southern Plains estimates of annual soil carbon stock changes by major land use and management type, 2008

\begin{tabular}{|c|c|}
\hline Land Use & $\begin{array}{c}\text { Emissions } \\
\left(\mathrm{Tg} \mathrm{CO}_{2}\right. \\
\text { eq.) }\end{array}$ \\
\hline Net change, cropland ${ }^{\mathrm{a}}$ & -1.63 \\
\hline Net change, hay & -0.94 \\
\hline $\mathrm{CRP}^{\mathrm{b}}$ & -1.97 \\
\hline $\begin{array}{l}\text { Ag. land on organic } \\
\text { soils }\end{array}$ & 0.00 \\
\hline Total $^{\mathrm{C}}$ & -4.54 \\
\hline
\end{tabular}

Source: USDA (2011)

a Annual cropping systems on mineral soils (e.g., corn, soybean, and wheat).

${ }^{\mathrm{b}}$ Conservation Reserve Program.

${ }^{c}$ Total does not include change in soil organic carbon storage on federal lands, including those that were previously under private ownership, and does not include carbon storage due to sewage sludge applications.
Table 5: Tillage practices in the Southern Plains region by crop type (percent of acres utilizing tillage practice)

\begin{tabular}{|c|c|c|c|c|c|}
\hline $\begin{array}{l}\text { Crop } \\
\text { Type }\end{array}$ & Acres $^{\mathrm{a}}$ & No Tillb & $\begin{array}{l}\text { Reduced } \\
\text { Till }^{\mathbf{b}}\end{array}$ & $\begin{array}{c}\text { Conventiona } \\
1 \text { Till }^{\mathbf{b}}\end{array}$ & $\begin{array}{c}\text { Other } \\
\text { Conservation } \\
\text { Tillage }^{b}\end{array}$ \\
\hline Corn & $4,350,573$ & $37 \%$ & $12 \%$ & $36 \%$ & $15 \%$ \\
\hline Cotton & $4,761,792$ & $8 \%$ & $13 \%$ & $79 \%$ & $0 \%$ \\
\hline Hay & $1,296,655$ & NA & NA & NA & NA \\
\hline Sorghum & $4,729,767$ & $22 \%$ & $13 \%$ & $45 \%$ & $21 \%$ \\
\hline Soybean & $2,914,860$ & $58 \%$ & $8 \%$ & $11 \%$ & $23 \%$ \\
\hline Wheat & $18,506,048$ & $6 \%$ & $34 \%$ & $50 \%$ & $10 \%$ \\
\hline Total & $22,717,562$ & & & & \\
\hline
\end{tabular}

\subsection{Nitrous Oxide Emissions}

In 2008, $\mathrm{N}_{2} \mathrm{O}$ emissions in the Southern Plains region were approximately $32.9 \mathrm{Tg} \mathrm{CO}_{2}$ eq. Of these emissions, $15.7 \mathrm{Tg} \mathrm{CO}_{2}$ eq. were emitted from croplands and $17.3 \mathrm{Tg} \mathrm{CO}_{2}$ eq. were emitted from grasslands. ${ }^{7}$ The greatest contributor of crop-related direct $\mathrm{N}_{2} \mathrm{O}$ emissions in the region (more than 58 percent) are from the production of corn, wheat, and cotton.

As indicated in Table 6, the largest contributors of $\mathrm{N}_{2} \mathrm{O}$ direct emissions are from corn, wheat, and cotton crops. The quantity and timing of nitrogen based fertilizer affects the rate of both direct and indirect $\mathrm{N}_{2} \mathrm{O}$ emissions. ${ }^{8}$ Table 7 indicates the percent of national acres that did not meet the rate or timing criteria as defined by Ribaudo et al. (2011). Timing criteria is defined in terms of best practices for quantity and timing of fertilizer application. Meeting the best practice rate criterion is defined as applying no more nitrogen (commercial and manure) than 40 percent more than that removed with the crop at harvest, based on the stated yield goal, including any carryover from the previous crop. Meeting the best practice timing criterion is defined as not applying nitrogen in the fall for a crop planted in the spring (Ribaudo et al., 2011). Acreages not meeting the criteria represent opportunities for GHG mitigation.

\footnotetext{
${ }^{7}$ Including both direct and indirect emissions; Table 6 includes only direct emissions from crops.

${ }^{8}$ Direct $\mathrm{N}_{2} \mathrm{O}$ emissions are emitted directly from agricultural fields and indirect $\mathrm{N}_{2} \mathrm{O}$ emissions are emissions associated with nitrogen losses from volatilization of nitrogen as ammonia $\left(\mathrm{NH}_{3}\right)$, nitrogen oxides (NOx), and leaching and runoff.
}

Greenhouse Gas (GHG) Emissions Profile from Agriculture and Forests within the Region and Mitigation Opportunities 


\begin{tabular}{|c|c|c|}
\hline Crop Type & $\begin{array}{c}\text { Direct } \mathrm{N}_{2} \mathrm{O} \\
\text { Emissions } \\
\left(\mathrm{Tg} \mathrm{CO} \mathrm{CO}_{2} \text { eq.) }\right.\end{array}$ & $\begin{array}{l}\% \text { of Region's } \\
\text { Cropland } \mathrm{N}_{2} \mathrm{O} \\
\text { Emissions }\end{array}$ \\
\hline Corn & 2.94 & $25.1 \%$ \\
\hline Wheat & 2.33 & $19.8 \%$ \\
\hline Cotton & 1.59 & $13.6 \%$ \\
\hline Sorghum & 1.44 & $12.3 \%$ \\
\hline Soybean & 1.05 & $8.9 \%$ \\
\hline Hay & 0.86 & $7.3 \%$ \\
\hline Non-major crops & 1.52 & $13.0 \%$ \\
\hline Total & 11.74 & $100.0 \%$ \\
\hline
\end{tabular}

Source: USDA (2011).
Table 7: National percent of acres not meeting rate and timing criteria

\begin{tabular}{|l|r|r|} 
Crop & \multicolumn{2}{|c}{$\begin{array}{c}\text { Not Meeting } \\
\text { Rate }\end{array}$} \\
\hline Corn & $35 \%$ & \multicolumn{1}{c}{$\begin{array}{c}\text { Not Meeting } \\
\text { Timing }\end{array}$} \\
\hline Sorghum & $24 \%$ & $34 \%$ \\
\hline Soybeans & $3 \%$ & $16 \%$ \\
\hline Wheat & $34 \%$ & $28 \%$ \\
\hline
\end{tabular}

Source: (Ribaudo et al., 2011).

\subsection{Livestock GHG Profile}

Livestock systems in the Southern Plains focus primarily on the production of beef and dairy cattle, poultry, swine, sheep, goats, and horses. In 2008, more than 191 million head of poultry, 27 million cattle (beef and dairy), and 5 million head of swine were raised in the region (U.S. Department of Agriculture, 2011). Nearly 97 percent of the cattle in the region are beef cattle. As with patterns in livestock production across the country, the primary source of GHGs from livestock is from enteric fermentation, digestive processes that result in the production of methane $\left(\mathrm{CH}_{4}\right)$ (referred to as enteric $\left.\mathrm{CH}_{4}\right)$. In 2008, Southern Plains livestock produced $32.3 \mathrm{Tg} \mathrm{CO}$ eq. of enteric $\mathrm{CH}_{4} .{ }^{9}$ Most of the remaining livestockrelated GHG emissions are from manure management practices-which produce both $\mathrm{CH}_{4}$ and $\mathrm{N}_{2} \mathrm{O} .{ }^{10}$ In 2008, manure management in the Southern Plains region resulted in $8.5 \mathrm{Tg} \mathrm{CO}_{2}$ eq., considering both $\mathrm{CH}_{4}$ and $\mathrm{N}_{2} \mathrm{O}$, with the majority attributed to $\mathrm{CH}_{4}$ (U.S. Department of Agriculture, 2011).

\section{Enteric Fermentation}

The primary emitters of enteric $\mathrm{CH}_{4}$ are ruminants (e.g., cattle and sheep).

Emissions are produced in smaller quantities by other livestock, such as swine, horses, and goats.

The per-head emissions of enteric $\mathrm{CH}_{4}$ for dairy cattle are 40 to 50 percent greater than for beef cattle (e.g., 2.2 metric tons $\mathrm{CO}_{2}$ eq./head/year for dairy vs. 1.6 metric tons for beef in 2008 due primarily to their greater body weight and increased energy requirements for extended periods of lactation (U.S. Environmental Protection
Table 8: Emissions from enteric fermentation in the Southern Plains, in $\mathrm{Tg}$ of $\mathrm{CO}_{2}$ eq. and as a percent of regional emissions

\begin{tabular}{|l|l|l|}
\multicolumn{2}{|l|}{$\begin{array}{l}\text { Animal Category } \\
\text { Beef cattle }\end{array}$} & Tg CO \\
\hline Dairy cattle $^{\mathrm{a}}$ & 29.86 & $\begin{array}{l}\text { eq of Region's } \mathrm{CH}_{4} \\
\text { Enteric Emissions }\end{array}$ \\
\hline Goats $^{\mathrm{b}}$ & 2.15 & $92.4 \%$ \\
\hline Horses $^{\mathrm{b}}$ & 0.04 & $6.7 \%$ \\
\hline Sheep $^{\mathrm{b}}$ & 0.05 & $0.1 \%$ \\
\hline Swine $^{\mathrm{b}}$ & 0.04 & $0.1 \%$ \\
\hline Total & 0.17 & $0.1 \%$ \\
\hline
\end{tabular}

${ }^{\mathrm{a}}$ Source: USDA (2011).

${ }^{\mathrm{b}}$ Source: Based on animal population from USDA (2011) and emission factors as provided in IPCC (2006). Agency, 2014). However, in the Southern Plains region, because 97 percent of all cattle are beef cattle, the overall contribution to enteric $\mathrm{CH}_{4}$ emissions from beef cattle of enteric fermentation is much higher than for dairy cattle (U.S. Department of Agriculture, 2011). Table 8 provides $\mathrm{CH}_{4}$ emissions by animal types in 2008. As indicated, the majority of emissions are from beef and dairy cattle.

\footnotetext{
${ }^{9}$ The enteric $\mathrm{CH}_{4}$ emissions total for the region includes cattle and non-cattle.

${ }^{10}$ Livestock respiration also produces carbon dioxide $\left(\mathrm{CO}_{2}\right)$, but the effects of ingesting carbon-based plants and expelling $\mathrm{CO}_{2}$ result in zero-net emissions.
}

Greenhouse Gas (GHG) Emissions Profile from Agriculture and Forests within the Region and Mitigation Opportunities 
Southern Plains Region

\section{Emissions from Manure Management Systems}

Manure management in the Southern Plains resulted in $5.0 \mathrm{Tg} \mathrm{CO}_{2}$ eq. of $\mathrm{CH}_{4}$ and $3.5 \mathrm{Tg} \mathrm{CO}_{2}$ eq. of $\mathrm{N}_{2} \mathrm{O}$ in 2008. Table 9 provides a summary of $\mathrm{CH}_{4}$ and $\mathrm{N}_{2} \mathrm{O}$ emissions by animal category. Swine and dairy and beef cattle waste account for the majority of manure related emissions, with dairy waste accounting for 38 percent of $\mathrm{CH}_{4}$ and 11 percent of $\mathrm{N}_{2} \mathrm{O}$, swine waste accounting for 37 percent and 4 percent, and beef cattle accounting for 17 and 81 percent, respectively.

The distribution of animal population among different farm sizes varies across animal categories. Forty-two percent of dairy cattle in the Southern Plains region are raised on farms with more than 2,500 head and 89 percent of swine exist on farms with more than 5,000 head; mitigation technologies such as anaerobic digesters ${ }^{11}$ are more economically feasible on large farm than small farm operations due to economies of scale. Figure 13 provides a summary of $\mathrm{CH}_{4}$ and $\mathrm{N}_{2} \mathrm{O}$ emissions by animal category and baseline manure management practices. ${ }^{12}$ The largest sources of $\mathrm{CH}_{4}$ are anaerobic lagoons, deep pits, and liquid/slurry systems, primarily with dairy, beef, and swine waste. The largest sources of $\mathrm{N}_{2} \mathrm{O}$ are beef dry lots. Figure 14 describes the proportion of beef cattle, dairy cattle, and swine that are managed using various manure management systems. The majority of beef waste is deposited on pasture, whereas dairy and swine waste is managed using a variety of systems, including anaerobic lagoons, deep pits, dry lots, and liquid/slurry systems.

\footnotetext{
${ }^{11}$ Anaerobic digesters are lagoons and tanks that maintain anaerobic conditions and can produce and capture methane-containing biogas. This biogas can be used for electricity and/or heat, or can be flared. In general, anaerobic digesters are categorized into three types: covered lagoon, complete mix, and plug flow digesters.

${ }^{12}$ Definitions for manure management practices can be found in Appendix 3-B of (ICF International, 2013).
}

Greenhouse Gas (GHG) Emissions Profile from Agriculture and Forests within the Region and Mitigation Opportunities 
Figure 13: $2008 \mathrm{CH}_{4}$ and $\mathrm{N}_{2} \mathrm{O}$ emissions from the Southern Plains by animal category and management system (Tg of $\mathrm{CO}_{2}$ eq.). Source: EPA (2010).

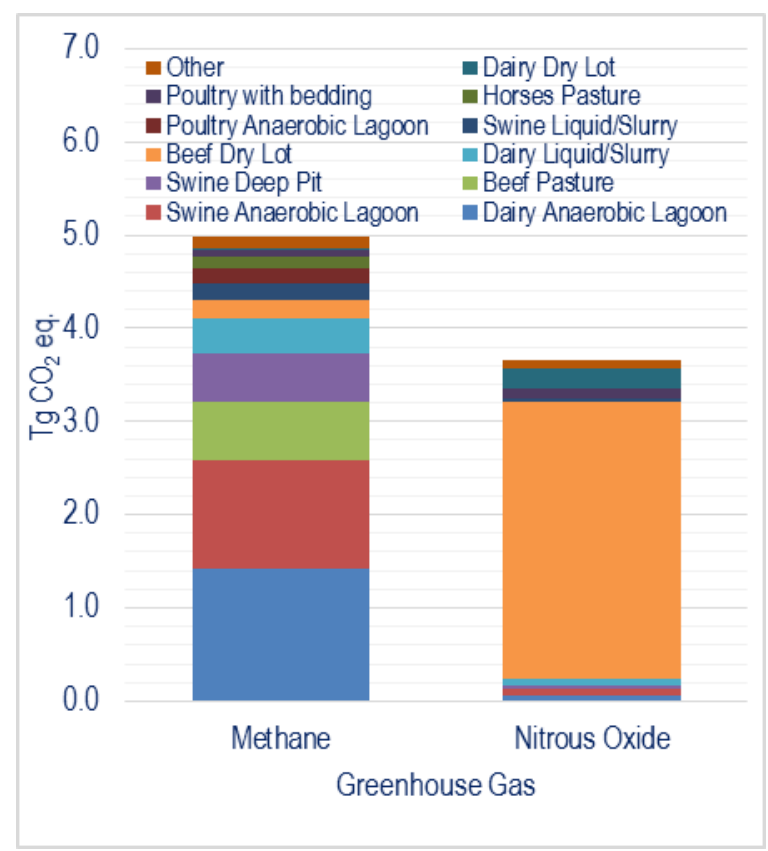

Figure 14: Proportion of beef cattle, dairy cattle, and swine managed by manure management system in the Southern Plains. Source: EPA (2010).

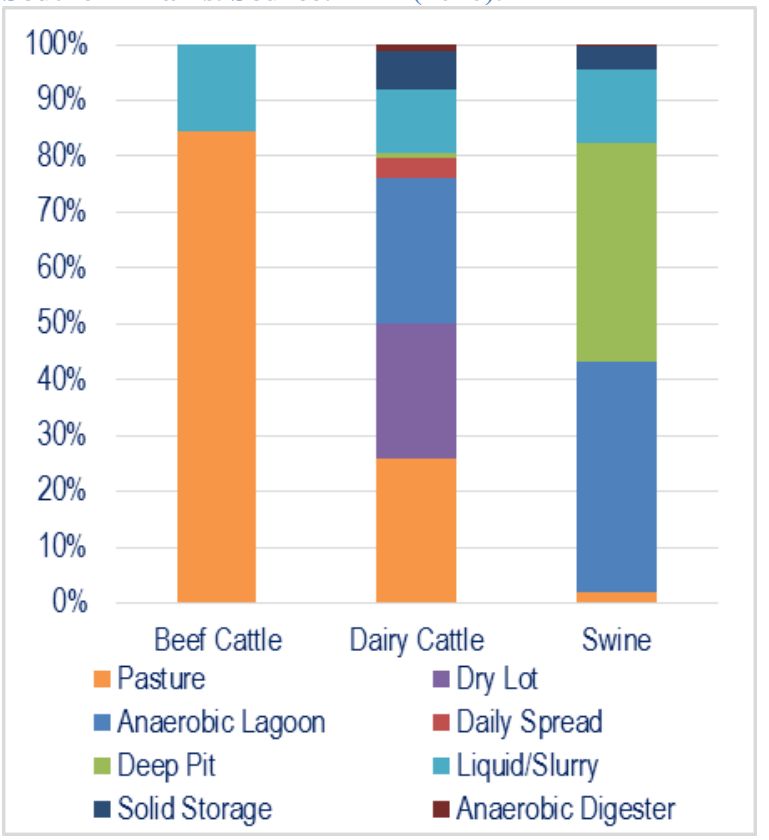

\subsection{Forest Carbon Stocks and Stock Changes}

In the annual GHG inventory reported by the USDA, forests and harvested wood products from forests sequester $26 \mathrm{Tg} \mathrm{CO}_{2}$ eq. per year in the Southern Plains (i.e., equivalent to negative emissions); in addition, the 70,096 thousand acres of forest land in the Southern Plains maintain 9,807 $\mathrm{Tg} \mathrm{CO}_{2}$ eq. in forest carbon stocks (Table 10). ${ }^{13}$

Managed forest systems in the Southern Plains focus primarily on the production of softwood timber, in addition to serving as riparian buffers and wind breaks. Forestry activities represent significant opportunities to manage GHGs. Forest managers in the Southern Plains use a wide variety of silvicultural techniques to achieve management objectives, most of which will have effects on the carbon
Table 10: Southern Plains forest carbon stock and stock changes

\begin{tabular}{|c|c|c|}
\hline Source & Units & $\begin{array}{l}\text { Southern } \\
\text { Plains }\end{array}$ \\
\hline Net area change & 1,000 ha/yr & 53 \\
\hline Non-soil stocks & $\mathrm{Tg} \mathrm{CO}_{2} \mathrm{eq}$. & 4,623 \\
\hline SOC & $\mathrm{Tg} \mathrm{CO}_{2}$ eq. & 5,184 \\
\hline Non-soil change & $\mathrm{Tg} \mathrm{CO}_{2}$ eq./yr & $-21^{\mathrm{a}}$ \\
\hline $\begin{array}{l}\text { Harvested wood products } \\
\text { change }\end{array}$ & $\mathrm{Tg} \mathrm{CO}_{2}$ eq./yr & $-5^{\mathrm{a}}$ \\
\hline \multicolumn{3}{|c|}{ Forest carbon stock summary ( $\mathrm{Tg} \mathrm{CO}_{2}$ eq.) } \\
\hline Non-soil stocks + SOC & & 9,807 \\
\hline \multicolumn{3}{|c|}{ Forest carbon stock change summary ( $\mathrm{Tg} \mathrm{CO}_{2}$ eq./yr) } \\
\hline Forest carbon stock change & & -26 \\
\hline
\end{tabular}

Source: USDA (2011).

${ }^{\text {a }}$ Negative values indicate a net removal of carbon from the atmosphere.

\footnotetext{
${ }^{13}$ Other GHGs such as $\mathrm{N}_{2} \mathrm{O}$ and $\mathrm{CH}_{4}$ are also exchanged by forest ecosystems. $\mathrm{N}_{2} \mathrm{O}$ may be emitted from soils under wet conditions or after nitrogen fertilization; it is also released when forest biomass is burned. $\mathrm{CH}_{4}$ is often absorbed by the microbial community in forest soils but may also be emitted by wetland forest soils. When biomass is burned in either a prescribed fire/control burn or in a wildfire, precursor pollutants that can contribute to ozone and other short-lived climate forcers as well as $\mathrm{CH}_{4}$ are emitted (U.S. Department of Agriculture, 2014).
}

Greenhouse Gas (GHG) Emissions Profile from Agriculture and Forests within the Region and Mitigation Opportunities 
dynamics. The primary effects of silvicultural practices on forest carbon include enhancement of forest growth (which increases the rate of carbon sequestration) and forest harvesting practices (which transfers carbon from standing trees into harvested wood products and residues, which eventually decay or are burned as firewood or pellets). Other forest management activities will result in accelerated loss of forest carbon, such as when soil disturbance increases the oxidation of soil organic matter, or when prescribed burning releases $\mathrm{CO}_{2}\left(\mathrm{~N}_{2} \mathrm{O}\right.$ and $\left.\mathrm{CH}_{4}\right)$.

Forest management activities and their effects on carbon storage vary widely across the Southern Plains with different forest types, ownership objectives, and forest stand conditions. However, there are commonly used silvicultural prescriptions for common forest types in the Southern Plains. For example, the USDA's Quantifying Greenhouse Gas Fluxes in Agriculture and Forestry: Methods for Entity-Scale Inventory Technical Bulletin (2014) provides this information for regions overlapping with the Southern Plains-i.e., the South Central and Great Plains regions (see Table 6-6 on page 6-59).

The USDA’s Forest Service 2010 Resources Planning Act Assessment General Technical Report (2012) describes future projections of forest carbon stocks in the United States resulting from various vulnerabilities (e.g., less-than-normal precipitation, above-normal temperature) and other stressors (e.g., urbanization, other land development, demand for forest fuel and fiber). The Resource Planning Act (RPA) Assessment projects that "declining forest area, coupled with climate change and harvesting, will alter forest-type composition in all regions.” For example, the report notes that, for a larger region (i.e., the Rocky Mountains) that includes Kansas and Oklahoma from the Southern Plains, the rate of urban growth is highest, and Douglas-fir and lodgepole pine areas are projected to decline, whereas fir-sprucehemlock and ponderosa pine areas are projected to increase.

\subsection{Mitigation Opportunities}

Figure 15 presents the mitigation potential by sector for the Southern Plains region. Each bar represents the GHG potential below a break-even price of $\$ 100$ /metric ton $\mathrm{CO}_{2}$ eq. ${ }^{14}$ A break-even price is the payment level (or carbon price) at which a farm will view the economic benefits and the economic costs associated with adoption as exactly equal. Conceptually, a positive break-even price represents the minimum incentive level needed to make adoption economically rational. A negative break-even price suggests the following: 1 ) no additional incentive may be required to make adoption cost-effective; or 2) there are nonpecuniary factors (such as risk or required learning curve) that discourage adoption. The break-even price is determined through a discounted cash-flow analysis such that the revenues or cost savings are equal to the costs. ${ }^{15}$ The left two bars represent reductions from changes in management practices that mitigate GHGs. The right three bars represent increased carbon storage from changes in management practices. A total of $2.6 \mathrm{Tg} \mathrm{\textrm {CO } _ { 2 }}$ eq. can be mitigated at a break-even price below $\$ 100 /$ metric tons $\mathrm{CO}_{2}$ eq. Changes in land management practices can increase carbon storage by $6.5 \mathrm{Tg}$ $\mathrm{CO}_{2}$ eq. at a break-even price below $\$ 100$ /metric tons $\mathrm{CO}_{2}$ eq. The color shading within a bar represents the mitigation potential or the potential increased carbon storage below different break-even prices indicated in the legend. For example, changes in land retirement practices have the potential to contribute to $2.2 \mathrm{Tg} \mathrm{CO}_{2}$ eq. of increased carbon storage for less than $\$ 20 /$ metric ton $\mathrm{CO}_{2}$ eq. (i.e., light blue and light green bar).

\footnotetext{
${ }^{14}$ Break-even prices are typically expressed in dollars per metric ton of $\mathrm{CO}_{2}$ eq. This value is equivalent to $\$ 100,000,000$ per $\mathrm{Tg}$ of $\mathrm{CO}_{2}$ eq. or $\$ 100,000,000$ per million metric tons of $\mathrm{CO}_{2}$ eq.

${ }^{15}$ See ICF International (2013) for additional details.

Greenhouse Gas (GHG) Emissions Profile from Agriculture and Forests within the Region and Mitigation Opportunities

Page $\mid 39$
} 
Figure 15: Mitigation potential in the Southern Plains, by sector

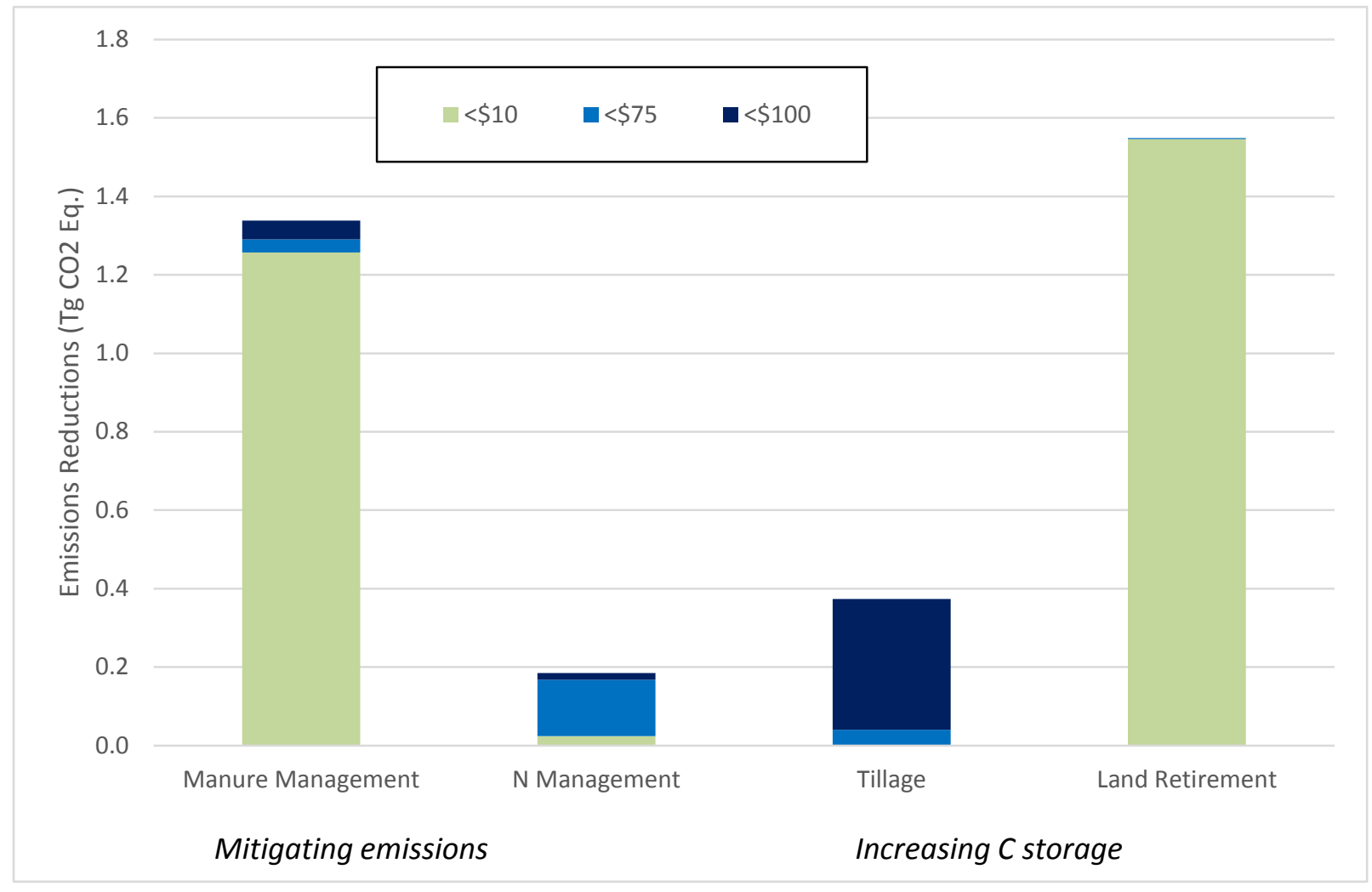

- Most of the opportunity for reducing net GHGs emissions is from land retirement practices such as retiring marginal soils and establishing conservation cover, and adoption of better manure management practices.

- The third largest opportunity is by increasing carbon stock in tillage management practices (i.e., adopting long term reduced tillage practices).

- The highest reductions in emissions from manure management are installing complete mix or covered lagoon digesters with electricity generation at swine and dairy farms, and installing improved separators at dairy farms with anaerobic lagoons. ${ }^{16}$

\section{Agricultural Soils}

For farms larger than 250 acres, variable rate technology is a relatively low cost option for reducing $\mathrm{N}_{2} \mathrm{O}$ emissions from fertilizer application. ${ }^{17}$ Reducing nitrogen application can be a relatively low-cost option for all farm sizes. Transitioning from conventional tillage to continuous no-tillage or reduced tillage to continuous no-tillage field management practices results in relatively large potential for carbon storage at low cost (i.e., the magnitude of the carbon storage potential is orders of magnitude higher than the potential to reduce $\mathrm{N}_{2} \mathrm{O}$ emissions). Carbon gains can only be realized if no-till is adopted permanently, otherwise gains will be reversed.

\footnotetext{
16 The emission reduction excludes indirect emission reductions from the reduced use of fossil fuels to supply the electricity for on farm use (i.e., the emission reductions only account for emissions within the farm boundaries).

${ }^{17}$ Variable rate technology (VRT), a subset of precision agriculture, allows farmers to more precisely control the rate of crop inputs to account for differing conditions within a given field. VRT uses adjustable rate controls on application equipment to apply different amounts of inputs on specific sites at specific times (Alabama Precision Ag Extension, 2011).
}

Greenhouse Gas (GHG) Emissions Profile from Agriculture and Forests within the Region and Mitigation Opportunities 


\section{Land Retirement}

This category includes retiring marginal croplands and establishing conservation cover, restoring wetlands, establishing windbreaks, and restoring riparian forest buffers. Establishing windbreaks around erosion-susceptible cultivated land and retiring marginal soils from cultivation in favor of establishing grassy conservation cover provide the most opportunities for increasing carbon storage.

\section{Manure Management}

The total $\mathrm{CH}_{4}$ mitigation potential for livestock waste in the Southern Plains is $2.3 \mathrm{Tg} \mathrm{CO}_{2}$ eq. Lower-cost GHG mitigation opportunities for manure management are primarily for large swine and dairy farms. The greatest $\mathrm{CH}_{4}$ reductions can be achieved on dairy operations by transitioning from anaerobic lagoons to improved solids separators, a covered anaerobic lagoon, a covered lagoon digester, or a complete mix digester. For large swine farms, the greatest and most cost-effective mitigation measures are to transition from anaerobic lagoons, deep pits, or liquid/slurry systems to complete mix digesters or covered lagoon digesters, or to cover an existing lagoon.

\section{Enteric Fermentation}

Emissions from enteric fermentation are highly variable and are dependent on livestock type, life stage, activity, and feeding situation (e.g., grazing, feedlot). Several practices have demonstrated the potential for efficacy in reducing emissions from enteric fermentation. Although diet modification (e.g., increasing fat content, providing higher quality forage, increasing protein content) and providing supplements (e.g., monensin, bovine somatotropin [bST]) have been evaluated for mitigation potential, the effectiveness of each option is not conclusive.

\section{USDA Programs}

The recently published USDA Climate Change Adaptation Plan ${ }^{18}$ presents strategies and actions to address the effects of climate change on key mission areas including agricultural production, food security, rural development, and forestry and natural resources conservation. USDA programs administered through Natural Resource Conservation Service (NRCS), U.S. Forest Service (USFS), Farm Service Agency (FSA), Rural Development (RD), Risk Management Agency (RMA), and Animal and Plant Health Inspection Service (APHIS) have been and will continue to play a vital role in sustaining working lands in a variable climate and are key partner agencies with the USDA Climate Hubs. The Southern Plains Hub partner agencies are also vulnerable to climate variability and have programs and activities in place to help stakeholders respond to climate-induced stresses.

\subsection{Natural Resources Conservation Service}

\section{Activities Most Vulnerable to Climate}

Agriculture in the Southern Plains of the United States will face continuing pressure due to the effects of climate change. Of immediate concern are the challenges the industry faces related to droughts of increased frequency, duration and severity as well as the negative effects related to increased flash flooding resulting from more intense rain events.

\footnotetext{
${ }^{18}$ The 2014 USDA Climate Change Adaptation Plan includes input from 11 USDA agencies and offices. It provides a detailed vulnerability assessment, reviews the elements of USDA's mission that are at risk from climate change, and provides specific actions and steps being taken to build resilience to climate change. Find more here: http://www.usda.gov/oce/climate_change/adaptation/adaptation_plan.htm.
} 
The ability of our production agriculture system to weather periods of reduced rainfall and increased heat, both to maintain crop production and to provide adequate forage and water for livestock is critical as we address the effects of a changing climate. Grazing pressure in response to a desire to maximize profits during droughts also exacerbates these issues. The Southern Plains has always been challenged by rates of precipitation and the timing of rainfall to maintain agriculture production. Whereas irrigated cropland is still abundant above the Ogallala aquifer, the aquifer is declining and producers have already been practicing deficit irrigation. Climate change increases the exposure of this area of the country to these challenges. Reduced crop production, inadequate water for livestock, both for consumption and forage production, and the potential for increased wind and water erosion of soil are all issues whose likelihood is increased by climate change. Intermittent stream flow in our rivers, creeks, and streams will also be affected by reduced rainfall and the lack of sub-soil moisture and its effects on the hydrological cycle, effecting both agriculture as well as municipal water supplies.

Violent rain events have always taken place on the Southern Plains. The changes in climate we have been experiencing have resulted in increased potential for even more extreme rain events than those normally experienced in the past. Increased gully, sheet, and rill erosion of soil due to heavy precipitation on exposed ground is of major concern. In addition, the risk of flash flooding and its effects on property, infrastructure, and human life are increased due to the changes climate change will cause to our rainfall patterns. Heavy rain events will also pose additional challenges related to increased run-off from agriculture land and the potential for increased levels of turbidity, nutrients, and bacteria in the form of non-point source pollution in surface water.

Additional pressure will be felt by production agriculture from issues such as late season freezes on winter wheat, increased exposure to invasive species and pests, later freeze kill on summer crops such as grain sorghum, and changes in rainfall events reducing the dependability of precipitation in the late fall and late spring months of the year.

While NRCS currently has a slate of programs in place through not only the Conservation Title of the Farm Bill but also through non-farm bill programs such as Conservation Technical Assistance (CTA) and the Small Watershed Program created through PL 566 to help producers manage these issues, the question remains as to whether current levels of staffing and the current funding levels for the agency are adequate to address the challenges posed to production agriculture by the effects of climate change. Over the last few years more and more dollars have been dedicated toward program delivery goals with less focus on conservation planning, non-program technical assistance and watershed planning through PL 566. In addition, the delivery goals of these programs are often directed at the symptoms of climate change with little focus given to the consideration of conservation practices as a way to address the whole ecosystem, capturing not only the benefits directly solved by a practice (reduced soil erosion by the conversion to notill as an example) but the other benefits generated by the practices as well (in the case of no-till conversion- improved water quality, reduced fuel use, improved soil health, and carbon sequestration in addition to reduced erosion). Additional resources are needed to address the growing concerns on the land while also providing an additional focus to addressing these issues in a manner that recognizes the total benefits generated by these practices and that looks to maximize the positive effect of conservation on an entire system. We also may look at partnering with sister agencies to maximize the positive results from all USDA programs as well as those operated by other environmental agencies (examples include Rural Utility Service programs directed at clean water funding and other voluntary clean water initiatives at other agencies).

\section{Programs to Address Risks and Vulnerabilities}

NRCS has many programs that can be of assistance in helping producers adjust to a changing climate. First and foremost is our ability, through Conservation Technical Assistance (CTA) to help producers identify challenges they are facing due to the pressures brought to their operations by climate change. NRCS's suite of conservation practices contain proven technologies and strategies for addressing 
conservation issues and kept up-to-date as new technologies and strategies are developed. NRCS provides a network of field offices and professionals available to help producers, through the planning process, to develop conservation plans consisting of conservation practices and systems which can result landscapes that are more resilient to weather extremes that climate change will exacerbate. This also will provide them a road map that will lead them to the right financial assistance program to help them implement this plan.

The Environmental Quality Incentives Program (EQIP), the Conservation Stewardship Program (CSP) and other Farm Bill Conservation Title programs are also valuable tools to help with the adaption to a changing climate by providing producers the financial assistance and support they need to implement the changes on their land that are necessary to adjust to weather extremes. Often times these changes are cost prohibitive in the short term for a producer to undertake without the assistance provided by these initiatives. In addition, the whole farm planning aspect of programs like CSP and the potential this program provides by rewarding a producer for good stewardship on their operation as a whole potentially has the ability to help agriculture not only adapt to the results of climate change, but to help mitigate some of the underlying causes of the phenomenon through carbon sequestration and greenhouse gas emissions avoidance through reduced fuel consumption and increased alternative energy usage.

Another program that provides a tool for dealing with the effects of climate change is the Small Watershed Program created under PL 566. When you look at the purposes originally outlined for this program in its organic act, purposes such as watershed protection, flood mitigation, water quality improvements, soil erosion reduction, municipal and industrial water supply, irrigation, water management, fish and wildlife enhancement, hydropower, and sediment control, you quickly see that this program can help the country better adapt to the challenges created by climate change. The flexibility and opportunity to build resilience to climate change on a watershed scale within the watershed program at USDA is almost unlimited. Planning and implementation guidelines for The Watershed Protection and Flood Prevention program set watershed boundaries as areas up to 250,000 acres. While smaller in scale than other well know watershed based boundaries such as the Chesapeake Bay or Mississippi River Basin initiatives, the benefits that that are provided in these smaller watersheds are significant and can be expanded upon. In addition, the Conservation Title of the Farm Bill provides the Federal Government with the authority to match local and state funding at the rate of $65 \%$ to $35 \%$ for the rehabilitation of aging flood structures constructed under this program and new guidance issued by NRCS headquarters in Washington D.C. has allowed for the full cost-share necessary to expand an existing structure into a reservoir. This change in the rules has made this program a much better tool to help with climate change adaptation by potentially supplying several of our communities with new water supplies while protecting lives and property from the effects of flash floods.

Additional opportunities exist in the Conservation Innovation Grant (CIG) program, the Regional Conservation Partnership Program (RCPP) and the National Water Quality Initiative for both the adaptation of agriculture to climate change and the ability of agriculture producers to help address challenges such as increased non-point source pollution, reduced stream flow, greenhouse gas levels in the atmosphere and diminished wildlife habitat.

The opportunity also exists to combine the abilities of the programs under the auspices of NRCS with those of sister agencies both in and outside of USDA. Many states have already explored options to partner with voluntary initiatives from sister agencies such as the Clean Water Act 319 program to maximize benefits to water quality. Communities undertaking improvements to address water quality issues could be encouraged to consider conservation practices in watersheds above their drinking water supplies as alternatives to brick and mortar water treatment plants, thus not only addressing non-point source pollution concerns, but also working with producers to undertake practices that help them adapt to climate change. NRCS could also explore working together with other agencies by combining targeted water quality improvements through Farm Bill Conservation Title programs with practices that help agriculture adapt to and mitigate climate change. 
NRCS may also continue working with the Farm Service Agency (FSA) to insure that any land taken out of the Conservation Reserve Program (CRP) is maintained in a manner designed to maximize conservation benefits on the land. Economic factors may dictate that some CRP acres will return to production. NRCS may focus efforts through CTA and other NRCS programs to minimize any negative effect this change could cause.

All of the concepts addressed above fit directly into the Soil Health Initiative NRCS is actively pursuing across the country. Improving the health of our soils in the United States is the key to helping agriculture both mitigate and adapt to climate change. From the first cut of the plow until today, farm ground in the United States has lost between 60 percent to 80 percent of the organic matter that was present at the time of settlement. This is important because its organic matter that feeds the microbial community under the soil and it is this community of bugs, bacteria and fungus that bind soil together, allows for the transfer of water through the soil structure, sequesters carbon dioxide into the ground and that makes nutrients more available to growing crops.

According to research from Kansas State University, every one percent increase in organic matter in the soil can triple that soils water holding capacity. That equals, on average, an additional 25,000 gallons of available water per acre for growing crops. Oklahoma State University has estimated that this increase in the water holding capacity of the soil in Oklahoma is the equivalent of a 3 inch rain. All this from increasing the ability of the soil to hold water when it does rain and by reducing the amount of water lost to evaporation during the summer months. Through the conversion of conventional tilled crop production to no-till cropping systems that also incorporate cover crops, we can greatly increase the infiltration rate of water in our farm ground while at the same time reducing the amount of moisture lost to evaporation when the land is tilled and exposed to the Sun. By holding on to more moisture when it does rain and by reducing the amount of water we lose to heat, we can help our cropping systems better weather the cycles of drought that are being exacerbated by climate change while providing more moisture for growing crops in summer months. This increase in soil moisture also helps to restore balance to the overall water cycle which in turn has been shown to increase average stream flow, thus making more water available for human use and wildlife habitat.

The same practices we would undertake on the land to accomplish this increase in soil moisture also have the added benefit of reducing the amount of soil erosion lost during heavy rain events-another challenge that is growing due to climate change. By reducing or eliminating tillage through minimum till and no-till crop production and by incorporating cover crops in rotation with traditional crops like winter wheat, we can greatly reduce the effect of sheet, gully and rill erosion to our farm ground while at the same time reducing the amount of run-off from agricultural land, thus not only protecting our soil, but also reducing non-point source pollution in our streams, rivers and lakes.

In addition, this same one percent increases in organic matter can, on average, make available up to $\$ 700$ worth of additional nutrients per acre for growing crops according to information from Ohio State University. It's been estimated that as much as $60 \%$ of the fertilizer applied to farm land today is wasted due to the lack of a healthy microbial soil community. By improving the health of the soil we can help plants more effectively absorb the nutrients available in the ground while reducing the need for chemical fertilizer, especially through the incorporation of legume cover crops that restore nitrogen to the soil naturally and through the inclusion of additional plant species in cover crop mixes that mine other available nutrients such as phosphorus from the soil and make them more available for the plants that follow the cover crops in rotation. This increase in turn can help us maintain existing yields and holds the potential to help us increase yields in the future to help feed an ever growing world population.

Converting from conventional till farming to no-till and the incorporation of cover crops in rotation with traditional crops such as winter wheat not only hold great promise in helping our agriculture system adapt to climate change, these same practices also have the potential to help reduce overall carbon dioxide levels in the atmosphere. According to research conducted by Kansas State University, no-till crop 
production on the southern plains can sequester, on average, roughly .5 metric tons of carbon per acre per year. While the size of this potential carbon sink is unclear, what is clear is that a change in farming practices to include greater use of no-till and cover crops can reduce carbon dioxide levels while improving the health of the soil while helping us adapt to wild weather extremes.

Organic carbon makes up roughly $60 \%$ of soil organic matter. As you increase organic matter in the soil, you restore soil health. As you restore soil health you help agriculture adapt to climate change. As you help agriculture adapt to climate change you help improve water quality, improve wildlife habitat and you help increase the fertility of the soil to potentially increase yields while at the same time helping to reduce the level of excess carbon dioxide in the atmosphere.

These results can all be realized utilizing the existing programs mentioned above if adequate funding is provided, the flexibility is available to undertake the work necessary to accomplish the goals and if NRCS personnel at all levels have a clear understanding of the way their programs interact with the issue of climate change and that they have the knowledge base necessary to identify opportunities to maximize the benefits of their work for both the agriculture community and the benefit of the health of the environment as a whole.

\subsection{United States Forest Service}

The Forest Service approach for adapting to climate change encompasses climate-specific strategies across the agency and direct program-by-program efforts to integrate climate-related policies and guidance. Climate change is one of many drivers of change to be considered in sustaining forest and grassland ecosystems. The Forest Service is involved in research, translation, and delivery of information and technical tools for use on public and private forest and rangelands. The Research and Development branch of the Forest Service is the principal in-house forestry and natural resource research arm of USDA. The State and Private Forestry (S\&PF) branch is the Federal leader in providing technical and financial assistance to landowners and resource managers to help conserve, protect, and enhance the Nation's non-Federal forests. The National Forest System comprises 193 million acres of national forests and grasslands, and is often the agency's "front line” for communicating with the public. The USDA Forest Service National Climate Assessment report indicates longer dry seasons and multiyear droughts will often become triggers for multiple stressors and disturbances (e.g., fire, insects, invasive species, and combinations thereof). These pulses of disturbance will change the structure and function of ecosystems across millions of acres over a short period of time.

\section{Characteristics}

The Forest Service is responsible for managing 1,265,804 acres of National Forests and National Grasslands in the Southern Plains Climate Hub Region (KS, OK and TX). Within these lands several issues are likely to arise due to climate change. Key natural resources within the Southern Plains Hub include five USDA Forest Service National Forests and six National Grasslands. The Ouachita National Forest in eastern Oklahoma and the Angelina, Davy Crockett, Sabine and Sam Houston National Forests in Texas comprise nearly one million acres. Texas alone has roughly 637,000 acres of National Forest and five state forests managed by the Texas Forest Service within Texas A\&M University that total 7,306 acres. The Ouachita National Forest has roughly 350,000 acres in Oklahoma. In the Southern Plains Hub, the Cimarron National Grasslands of Kansas, the Black Kettle, and Rita Blanca National Grasslands in Oklahoma and Texas along with the McClellan Creek, Caddo and Lyndon B. Johnson National Grasslands in Texas together amount to more than a quarter million acres. However, the National Grasslands are not solid and continuous expanses, but are instead interspersed in and among other federal, state, and privately owned lands.

One of the most harmful droughts affecting American rangelands and farmlands was the drought of the 1930s known as the Dust Bowl. Our National Grasslands were born when the federal government purchased and restored these damaged lands. The drought's direct effect is most often remembered as 
both agricultural and socioeconomic, with damage to crops, livestock, and ultimately humans. Reduced plant cover and increased bare ground led to dust storms during high winds, resulting in loss of topsoil. The resulting agricultural depression contributed to the Great Depression's bank closures, business losses, increased unemployment, and other physical and emotional hardships. Many lessons in resiliency and adaptation were learned in response to the calamitous effects of the Dust Bowl. These learned strategies helped to reduce the vulnerability of the region to future drought conditions, however there are still risks associated with our changing climate.

Risks

U.S. Forest Service activities and efforts most vulnerable to climate change in the Southern Plains include:

- National Forest and Grassland ecosystem management. Drivers of this problem that we are observing or anticipate include:

o Shifting animal and plant distributions and populations.

o Expansion of invasive species.

o Woody plant encroachment.

o Altered fire regimes.

o Altered fire suppression potential.

o Rise in housing losses, suppression costs, and human injuries and deaths resulting from wildfires in the Great Plains.

o Reduced forage for wildlife species.

o Reduced forage for livestock.

o Increased vegetation die-off due to drought conditions.

o Lowered water tables, reduced intermittent stream miles, reduction in surface water acres.

0 Changes in waterway connectivity, translating to habitat loss and also reduction in genetic exchange for native fish populations.

o Increased likelihood of bark beetle outbreaks and tree mortality.

- All activities that require water resources, including recreation, grazing, wildlife management, harvest of forest materials (including fuelwood), and provision of drinking water supplies to neighboring communities.

o Water resources at risk due to shifting hydrological regimes, increasing evaporative demand, and catastrophic wildfire (and subsequent soil erosion and sedimentation).

o Waterways also at risk of temperature increases.

- Maintenance of diverse ecological systems of high integrity.

- Protection of private property in the Wildland Urban Interface.

- Recreation activities are expected to be effected due to fire restrictions and closures, and increased duration of fire season.

- Clean air stewardship at risk due to predicted tree loss and increase in wildfire emissions.

- Quantifying the interaction of environmental (e.g., drought) influences and managerial strategies such as grazing and herbicide on fire frequency and seasonality is problematic given the lack of studies in this region. This presents unique challenges to managers seeking to understand, explain, and justify management strategies. This is especially true given the ever-increasing environment awareness exhibited by the public at large and increasing mounting consumption of goods and services from grasslands.

\section{Programs to Address Risks and Vulnerabilities}

Programs / measures in place to deal with risks and vulnerabilities from climate change include research, assessments, and tools to supply a scientific basis for management activities, and active land management by the National Forest System: 
Research

- The USDA Forest Service Rocky Mountain Research Station conducted a review and needs assessment that synthesizes knowledge about climate change effects on the native fauna and flora of many of these grasslands, shrublands, and deserts of the interior American West, including parts of the Southern Plains region (Finch, 2012). The assessment is complemented by a webbased tool for managers to assess vulnerability of species to climate change (Bagne et al., 2011).

- In the eastern portion of the Southern Plains and the pine-hardwood forests of Arkansas and Texas, multiple studies focus on the effects of climate change, forest management, and insect pests on wildlife and wildlife habitat to provide managers with better tools to restore and manage wildlife populations.

- Long-term experimental research is being conducted on the Kiowa, Pawnee, and Cimarron National Grasslands on the effects of cattle management, fire, drought, and climate change on grassland ecosystems.

- Research has developed and is testing an interactive decision support tool which models the effect of climate on fuelbed properties and associated ecological effects of climate on Great Plains grasslands.

\section{Management}

- Management practices within National Grasslands and Forests in the Southern Plains Region include thinning, prescribed fire, and restoration treatments, as well as use of natural wildfire to accomplish restoration goals.

- Small-scale fuel reduction projects are implemented on administrative units.

- On-going vegetation management activities, including managed fire, mechanized brush removal, and timber harvest, intended to improve (restore) vegetation structure, reduce vulnerability of vegetation to catastrophic wildfire, and to improve ecosystem resilience to perturbations (including those from climate change).

- Delayed turnout of livestock, and removal or reduction of allowable stocking levels, based on precipitation received.

- Fire restrictions and/or closures to reduce risk of catastrophic wildfire in drought conditions.

- Strategic placement of manmade water structures for use by wildlife.

- Grazing management to improve condition of riparian vegetation.

- Riparian improvements to reduce effects to stream temperatures and resilience of stream channels to extreme climatic events.

\section{Future Needs}

- An increase in the amount of grassland under conservation and grazing management to provide sufficiently large patches of diverse structural and compositional characteristics required by wildlife.

- Identification of several areas of contiguous grassland, with federal land included, to act as model landscapes for the creation and maintenance of structural and compositional heterogeneity at a scale relevant to wildlife, to "learn from doing," generate best-management guidelines and monitor the success of management and policy actions.

- The use of a variety of policy and management tools at a landscape scale to address the stressors facing grasslands both now and in light of climate change.

- Engaging agricultural policy at the national, state, and county levels to develop programs that promote both ecological and economic values.

\subsection{Farm Service Agency}

With more than 321 State and county offices throughout the three-state Southern Plains region, the Farm Service Agency is the face of USDA to producers who participate in the conservation and energy, 
commodity crop, disaster assistance, and farm loan programs it manages. In the Southern Plains region, food production and protection of our soil and water resources are extremely vulnerable to climate fluctuations.

\section{Activities Most Vulnerable to Climate Change}

Food production is the most vulnerable and the most important activity affected by climate change. Climate change and variability affects both food production and the economic security of food producers.

\section{Programs to Address risks and Vulnerabilities}

The three most important measures to continued food security are research, emergency assistance programs, and overall economic safety net programs that insure food continues to be produced at increased levels to feed an ever growing world population.

- Research investment is imperative in two areas. $1^{\text {st }}$ to identify and improve technologies that provide needed energy for human activity while minimizing the effect on climate change. $2^{\text {nd }}$ is a short and long term investment in research focused on improving the genetics of both plants and animals to acclimate to climate change. This may include genetically modified organisms that can thrive and produce food during times of drought, heat and other stress brought about by climate change.

- Emergency Assistance Programs delivered by USDA/FSA need to continue as they respond to and assist producers through dramatic swings in weather. The Emergency Conservation Program ECP for example assists producers in in acquiring access to water during drought or rebuilding fences after fire, floods and other natural disasters. Another example is the Livestock Forage Program that provides critical assistance to acquire feed under disaster conditions. The Livestock Indemnity Program LIP is another important disaster program that provides assistance for producers with animal death loss caused by dramatic weather conditions. The availability of FSA direct, guarantee and emergency loans are critical to provide producers financing following weather and economic disasters. Other important programs include the Noninsured Crop Disaster Program NAP and the Dairy Market Protection Program MPP.

- Overall safety net programs delivered through USDA/FSA provide economic stability through many natural and economic uncertainties. The Agricultural Risk Coverage Program and the Price Loss Coverage Program provide a vital income safety net that complement the previously mentioned programs to insure a secure food supply for the nation and the world.

\subsection{Rural Development}

Rural Development (RD) supports rural communities through loans, loan guarantees, and grants. For some RD programs, the agency holds liens or other security interests in facilities and related infrastructure in areas that could be affected by hydrological changes and sea-level rises resulting from effects such as inundation and erosion. Additionally, many climate change models predict greater frequency and severity of weather events such as tornados and hurricanes, which can damage utility facilities and infrastructure. Climate change therefore represents a risk to these agency assets and the communities they serve.

Within the Southern Plains region the occurrence of more extreme weather events such as drought, flooding, severe thunderstorms, tropical storms, hurricanes, and coastal storm surges. Damaging winds are also anticipated to cause: 1 ) disruption of electric and other energy supplies; 2) increased damage to structures/infrastructure from flooding, and 3) increase demand on water supply.

Rural Development has services in place to administer different program areas including the Rural Housing Service, Rural Business-Cooperative Service, and Rural Utilities Service. 


\section{Rural Housing Service}

The Rural Housing Service (RHS) administers programs which provide financial assistance (loans and grants) for quality housing and community facilities for rural residents within the all of the Climate Hub Regions.

RHS will implement the below prevention measures in an effort to reduce the effects of climate change and become more resilient to adverse effects predicted to be incurred by flooding, storm surges, hurricanes, tropical storms and other severe weather patterns which could adversely affect structures funded through RHS programs.

1) RHS will continue to provide training to staff on proper siting of facilities/infrastructure for the life-of-structure (30 to 50 years in some cases) in locations where the effects from climate change will not adversely affect the facility or the surrounding environment.

2) RHS will also continue to consider the effects of sea level rise, other potential flooding, and severe weather effects into long term planning.

3) RHS will continue to provide funding for the following programs which have been designed to lessen the need for fossil fuels, promote renewable energy, and increase energy efficiency in an effort to reduce the effects of climate change:

- Multi-family Housing Energy Efficiency Initiative

- Multi-family Housing Portfolio Manager, Capital Needs Assessment/Utility Usage

- Energy Independence and Security Act compliance - Affects Single Family Housing new construction

- Climate Action Plan installation of 100Mega Watt capacity onsite renewable energy MultiFamily Housing by 2020

\section{Rural Business-Cooperative Service}

The Rural Business-Cooperative Service (RBS) administers programs that lessen the need for fossil fuels, promote biomass utilization, renewable energy, and increase energy efficiency within all of the Climate Hub Regions. The Rural Energy for America Program lowers the demand on base plants by investing in energy efficiency and renewable energy. Lower base load demand conserves water and helps to reduce greenhouse gasses that contribute to climate change. Renewable energy investments can provide extra resiliency by distributing energy resources.

RBS is investing in alternative fuels, renewable chemicals, biogas, wastewater conservation, and harvesting combustible forest thinning's for advances biofuel.

\section{Rural Utilities Service}

The Rural Utilities Service (RUS) administers programs that provide clean and safe drinking water and sanitary water facilities, broadband, telecommunications, and electric power generation and transmission/distribution within all of the Climate Hub Regions.

The following programs or measures will help address resiliency and lessen the effect of droughts, floods and other natural disasters and increase energy efficiency:

- National Rural Water Association (NRWA) Grant - energy efficiency program designed to promote energy efficient practices in small water and wastewater systems. Performs energy assessments, recommends energy-efficient practices and technologies, and provides support in achieving recommendations.

- Memorandum of Agreement between the Unites States Environmental Protection Agency and the United States Department of Agriculture - Rural Development Rural Utilities Service Promoting Sustainable Rural Water and Wastewater Systems 
Goals are to increase the sustainability of drinking water and wastewater systems nationwide to ensure the protection of public health, water quality, and sustainable communities, to ensure that rural systems have a strong foundation to address $21^{\text {st }}$ century challenges, and assist rural systems in implementing innovative strategies and tools to allow them to achieve short- and long-term sustainability in management and operations.

- Emergency Community Water Assistance Grants (ECWAG)- Assist rural communities that have experienced a significant decline in quantity or quality of drinking water due to an emergency, or in which such decline is considered imminent, to obtain or maintain adequate quantities of water that meets the standards set by the Safe Drinking Water Act. Emergencies are considered to include incidents such as, but not limited to, drought, earthquake, flood, tornado, hurricane, disease outbreak, or chemical spill, leakage, or seepage.

- Electric Program - Energy Efficiency and Conservation Loan Program (EECLP) - The program is "for the purpose of assisting electric borrowers to implement demand side management, energy efficiency and conservation programs, and on-grid and off-grid renewable energy systems." Goals of the program include: (1) Increasing energy efficiency at the end user level; (2) modifying electric load such that there is a reduction in overall system demand; (3) affecting a more efficient use of existing electric distribution, transmission and generation facilities; (4) attracting new businesses and creating jobs in rural communities by investing in energy efficiency; and (5) encouraging the use of renewable energy fuels for either demand side management or the reduction of conventional fossil fuel use within the service territory.

- Principles, Requirements and Guidelines (PR\&G) - Application of the revised PR\&G in the near future to RUS water and wastewater program planning will include consideration of, among other factors, effects on and effects of climate change.

- Rural Development Climate Change Adaptation Planning Document - This document, from June 2012, would apply to all three RD agencies. The plan was prepared to in support of Departmental efforts to respond to EO 13514 (Federal Leadership in Environmental, Energy, and Economic Performance) as well as DR 1070-001. The Planning Document discusses increased efforts at risk assessment, and identifies 5 specific actions related to climate change planning and adaptation.

- Engineering Design Standards and Approved Materials - The RUS electric program envisions increased incorporation of climate change-related effects as it revised its standards and materials for RUS-financed infrastructure. Already, some borrowers for example in coastal areas and the Great Plains have received agency approval for 'hardened' electric poles and lines.

\subsection{Risk Management Agency}

The Risk Management Agency (RMA) provides a variety of actuarially sound crop and livestock related insurance products to help farmers and ranchers manage the risks related to agricultural production. Coverage is provided against agricultural production losses due to unavoidable natural perils such as drought, excessive moisture, hail, wind, hurricane, tornado, lightning, and insects, etc. In 2014, the Federal crop insurance program provided U.S. agricultural producers with over \$109.8 billion in protection for agricultural commodities. These policies provide financial stability for agricultural producers and rural communities, and are frequently required by lenders.

As climate change is an ongoing process, the risk environment for agricultural production will also be undergoing constant change, e.g., some perils may occur with greater (or lesser) frequency and/or severity. Climate change will also promote adaptive responses by producers, such as adopting new production practices, planting new varieties, or shifting the locations of farming operations.

RMA continually strives to improve the effectiveness of programs by refining insurance offers to recognize changes in production practices; and where appropriate, adjusting program parameters (e.g., 
premium rates, planting dates, etc.) within each county to recognize structural changes to the risks of growing the crop in those areas. In that regard, RMA monitors climate change research and, to the extent that climate changes emerge over time, update these program parameters to reflect such adaptation or other changes. As well, RMA updates loss adjustment standards, underwriting standards, and other insurance program materials to ensure that they are appropriate for prevailing production technologies.

In the Southern Plains Climate Hub Region, RMA's Topeka, Kansas Regional Office manages crop insurance programs in Kansas. The Oklahoma City, Oklahoma Regional Office manages crop insurance programs in Oklahoma and Texas.

In 2010, RMA’s crop insurance National liability (book of business) was $\$ 78$ billion. In 2014, RMA’s National liability increased to $\$ 109.8$ billion. Kansas, Oklahoma, and Texas accounted for over $\$ 7.4$ billion in Liability in 2010, and in 2014 the Liability increased to over $\$ 10.5$ billion. The Federal crop insurance book of business in the Southern Plains region consists of both field crops such as cotton, corn, peanuts, soybeans, grain sorghum, wheat; pasture, rangeland and forage; nursery, sunflowers, sugarcane, and specialty crops such as pecans, peaches, citrus and citrus trees, and other crops important to farmers and ranchers in this region of the U.S.

Over the last five years (2010-2014) participation in the Federal crop insurance program in the Southern Plains has increased:

- Kansas has the largest liability in the Southern Plains: Total Liability went from \$3.5 billion in 2010 to over $\$ 4.8$ billion in 2014. In 2014, the crops with the most liability exposure in Kansas were Wheat with a liability of $\$ 1.68$ billion; followed by Corn with a liability of $\$ 1.63$ billion; and Soybeans with a liability of $\$ 935$ million.

- Texas’s Total Liability went from \$3.2 billion in 2010 to over $\$ 4.7$ billion in 2014. In 2014, the crops with the most liability exposure in Texas were Cotton with a liability of $\$ 2.0$ billion; followed by Corn with a liability of $\$ 793$ million; Wheat with a liability of $\$ 527$ million; and Pasture, Rangeland and Forage with a liability of \$436 million.

- Oklahoma’s Total Liability went from \$669 million in 2010 to over \$993 million in 2014. In 2014, the crops with the most liability exposure in Oklahoma were Wheat with a liability of \$583 million; followed by Corn with a liability of $\$ 121$ million; and Cotton with a liability of $\$ 82$ million.

The five crop programs with the highest liability exposure in 2014 for the Federal crop insurance program in the Southern Plains Climate Hub Region are Cotton, Wheat, Corn, Soybeans and Pasture, Rangeland and Forage.

\section{Vulnerabilities in Southern Plains}

\section{Kansas}

- Variability in climate has caused serious flooding along the Missouri River and tributaries in the past few years, especially the flood of 2011.

- Significant drought in the past few years, again starting in 2011. That has affected both the nonirrigated as well as the irrigated production in western Kansas, western Nebraska, and eastern Colorado.

To address these risks in Kansas, RMA:

- Maintains accurate high risk maps for the flood prone areas in eastern Kansas in an effort to accurately assess and rate flood risk in comparison to the upland areas.

- Maintains good working relationships with levee districts, and local government agencies to remain apprised of any developments along the extensive levee system protecting the low-lying areas along the Missouri River and tributaries. In the western part of the Topeka RO Region, 
RMA has worked extensively with irrigation districts, state government agencies, and other groups to gain a better understanding of the issues facing irrigated production.

- Topeka RO worked with the Kansas Water Office and other interested stakeholders to develop a Limited Irrigation Practice, offered in a select area in northwest Kansas. See attached Informational Memorandum, April 15, 2015: http://www.rma.usda.gov/fields/ks rso/irrigation/2015aprillimitedirrigation.pdf

\section{Texas and Oklahoma}

- Areas in Texas and Oklahoma have been in a severe to extreme drought situation since the 2011 crop year with many areas transiting from drought to excess moisture conditions for the 2015 crop year.

- Many surface Water Districts have limited or nonexistent water supplies. Many producers have had to rely on prevented planting indemnity payments through the Federal Crop Insurance Program.

- Ground water levels in these state's aquifers continues to decline each year, with the decline rates increasing during recent drought conditions. Some water districts are setting up conservation plans and reducing water allotments to producers through district irrigation plans.

To address these risks in Texas and Oklahoma, RMA:

Provides farmers and ranchers with information on Irrigation links on RMA's website to help them manage risks:

- IRRSCH, New Mexico State University. A Computer model allows user to evaluate current irrigation practices, and schedule future irrigations based on recent events relative to the field under consideration. Expected yield, water consumption, and plant development can be estimated. http://aces.nmsu.edu/aes/irrigation/irrigation-scheduling-in.html

- TexasET, Texas A\&M Extension: Irrigation Technology Program which contains weather information, evapotranspiration, and crop watering recommendations of the Agriculture Program of the Texas A\&M University system.

- http://texaset.tamu.edu/

RMA's Topeka and Oklahoma City Regional Offices located in the Southern Plains Climate Hub Region, will continue to monitor adverse weather events, such as drought, flooding, excessive moisture, or failure of irrigation water supply. RMA Regional Offices will respond to Approved Insurance Providers and producer inquiries during these events, as well as continuing to provide estimates of liabilities, losses and the potential effect that natural disasters have on the Federal crop insurance program to RMA headquarters in Washington, D.C., as needed.

\subsection{Animal and Plant Health Inspection Service}

The Animal and Plant Health Inspection Service (APHIS) is responsible for protecting and promoting U.S. agricultural and forest health, regulating certain genetically engineered organisms, enforcing the Animal Welfare Act, and carrying out wildlife damage management activities. APHIS works to defend U.S. plant and animal resources from agricultural and forest pests and diseases. Once a pest or disease is detected, APHIS works in partnership with affected regions to manage and eradicate the outbreak. In its Strategic $\operatorname{Plan}^{19}$ for 2015, APHIS lists seven goals:

1. Prevent the entry and spread of agricultural pests and diseases.

2. Ensure the humane treatment and care of covered vulnerable animals.

${ }^{19}$ http://www.aphis.usda.gov/about_aphis/downloads/APHIS_Strategic_Plan_2015.pdf 
3. Protect forests, urban landscapes, rangelands and other natural resources, as well as private working lands from harmful pests and diseases.

4. Ensure the safety, purity, and effectiveness of veterinary biologics and protect plant health by optimizing our oversight of genetically engineered organisms.

5. Ensure the safe trade of agricultural products, creating export opportunities for U.S. producers.

6. Protect the health of U.S. agricultural resources, including addressing zoonotic disease issues and incidences, by implementing surveillance, preparedness and response, and control programs.

7. Create an APHIS for the 21st century that is high-performing, efficient, adaptable, and embraces civil rights.

APHIS works to achieve these goals through the actions of several mission area programs and support units. The text below describes the APHIS programs and their respective responsibilities, as well as their expected vulnerabilities related to a changing climate, and the measures in place to minimize risks from these vulnerabilities. As an agency with nationwide regulatory concerns, APHIS programs are typically national in scope and application.

\section{Animal Care (AC)}

The mission of the AC program is to protect animal welfare by administering the Animal Welfare Act and the Horse Protection Act. AC also protects the safety and well-being of pet owners and their pets during disasters by supporting the Federal Emergency Management Agency (FEMA).

AC's supporting role in these efforts may be vulnerable to climate change. An increase in the frequency and severity of storms as the climate warms may increase the need for evacuations and other response activities. In anticipation of the increase in emergency response activities, AC proactively organizes and participates in emergency planning together with FEMA, Emergency Support Function (ESF) \#11 ${ }^{20}$, and other response partners to strengthen the Nation's capacity to respond to natural disasters.

\section{Biotechnology Regullatory Services (BRS)}

BRS implements the APHIS regulations for genetically engineered (GE) organisms that may pose a risk to plant health. APHIS coordinates these responsibilities along with the Environmental Protection Agency and the Food and Drug Administration as part of the Federal Coordinated Framework for the Regulation of Biotechnology.

While no BRS actions are directly "vulnerable” to climate change, they may shift geographically if climate change affects the distribution of agricultural crops and other plants that BRS regulates. For example, if growing areas for regulated GE plants shift, BRS would need to conduct field inspections in those new locations.

BRS has in place a flexible staffing plan and practice—not all of its staff members are centrally located; they are set up to provide mobile inspection service to wherever GE crops are growing in field trials. Additionally, BRS receives reports each year from those holding permits for conducting field trials. BRS uses this information to plan inspections throughout the life cycle of the field trials. The flexibility and regular use of new information inherent in BRS planning and practice will help minimize risks from climate change.

\section{Plant Protection and Quarantine (PPQ)}

PPQ is responsible for safeguarding and promoting U.S. agricultural health. PPQ is constantly working to defend U.S. agricultural and forest resources from plant pests and diseases. Once a quarantine plant pest or disease (one not previously found in the U.S. or, if found, is under official control) is detected, PPQ

\footnotetext{
${ }^{20} \underline{\text { http://www.fema.gov/pdf/emergency/nrf/nrf-esf-11.pdf }}$
} 
works in partnership with affected regions to manage and eradicate the outbreak. PPQ has three strategic goals:

1. Strengthen PPQ's pest exclusion system.

2. Optimize PPQ's domestic pest management and eradication programs.

3. Increase the safety of agricultural trade to expand economic opportunities in the global marketplace.

In the face of an increasingly variable climate and more erratic weather conditions, PPQ will continue to play a central role in responding to risk and managing vulnerabilities. In this capacity, PPQ operates on the international and national levels, with regional emphasis as needed, to address and divert plant pest incursions.

PPQ is tasked with assessing risk and predicting where an invasive plant pest may be introduced, establish, and spread; these assessments are often based on climatic conditions and host availability. As climate changes, host distribution and landscape conditions deviate from what is considered "normal." PPQ assessments are based on available data that often reflect past conditions. As climate changes, the actual relevance of these data may lessen our ability to accurately predict and understand risk.

Some of the challenges in predicting future risk under climate change require a shift from analyzing mean responses (e.g., an increase of 2 to 3 degrees temperature on average) and instead to focus on trying to understand how pest invasiveness and the potential for establishment change with greater weather variability and more extreme events. For example, several years of warmer than normal weather can allow the establishment of invading pest populations and result in their spread to new areas. Once arriving in new areas, if such pest populations can secure warmer microclimates to survive the winter, they can become more prevalent earlier the following season. Anticipating global trade shifts in response to climate change is another challenge, as is the subsequent risk of new crop pests and diseases associated with them.

PPQ partners with other agencies, universities, and the Climate Hubs to increase our capacity to obtain and analyze data and implement models that inform climate change-specific policies and pest programs. PPQ is increasing its capacity to perform pest risk modeling at regional, national, and global levels with new platforms. These platforms are designed to project climate change scenarios onto the landscape to model geographic shifts in climatic suitability and host availability. PPQ is also developing phenological models that can be used to analyze how climate change and increased weather variability might affect temporal sequencing of pest development and subsequent population response. Being able to produce robust projections of such shifts will improve: 1) the efficacy of PPQ's early detection surveillance programs conducted in cooperation with States and Territories and 2) the scientific rigor and utility of risk analyses that are used to inform regulatory policy regarding plant pests.

\section{Veterinary Services (VS)}

VS works in a variety of ways to protect and improve the health, quality, and marketability of our nation's animals (including various wildlife), animal products, and veterinary biologics. VS is responsible for regulating the importation and interstate movement of animals and their products to prevent the introduction and spread of foreign animal diseases of livestock. If a foreign animal disease is detected in the United States, VS is responsible for responding to the outbreak in coordination with States, Territories, Tribes, and producers. VS also regulates the licensing of veterinary biologics such as vaccines.

Most of the risks described for the Southern Plains Region livestock industries in Section 2.2 (above) are relevant to VS programs; the risks can affect animal health through decreasing the resilience and overall health of animals as well as increasing potential exposure to endemic and emerging infectious diseases.

\section{Vulnerabilities}

Changes in Animal Health and Production 
- The risks identified for the Southern Plains Region such as drought, extreme weather events, decrease in water supplies, and changes to crop production and grazing lands can all affect the health and resiliency of animals, making them more vulnerable to disease and cause a decrease in productivity. For example, the recent drought in Texas decreased the amount of feed, water and forage for cattle, which decreased the health of the animals, as well as the number of beef cattle produced.

- The Southern Plains Region hosts areas of both coastal and inland aquaculture. Marine and freshwater food fish populations have already seen significant declines due to warming waters and the attendant effects that include acidification, oxygen depletion, algal blooms, and increased pathogen loads. These effects exacerbate effects of overharvesting, which has depleted many wild fish populations, placing pressure on the aquaculture industry for higher production and mitigation of health effects. Drought, weather extremes and increased agricultural runoff all affect aquaculture production, and the health of these species.

Changes to Endemic Disease Patterns and Exposure to Emerging Infectious Diseases

- Along the Southern Gulf Coast, the potential for more extreme hurricane seasons and precipitation events could have direct effects on vegetation and could create favorable ecological niches for emerging infectious diseases of animals (e.g. de la Rocque et. al. 2008).

- Changes to the environment can enhance the dispersal and redistribution of arthropod vectors along with the ability of these vectors to transmit economically important pathogens, potentially allowing their spread from areas where they are already established to new locations. The Southern Plains Region is home to competent vectors (species that could serve as vectors) for many sporadic or currently absent vector-borne diseases, and is vulnerable to the establishment of new vectors, particularly in the face of climate change risks.

- Many aquaculture species host diseases that thrive at certain temperature ranges. Changes in average temperatures could increase disease burden, and weather extremes can increase the potential for disease emergence.

\section{Changes to the wildlife-livestock interface}

Increased pest infestation, fires, and expansion of the wilderness-urban interface could alter wild animal distribution, movements, and feeding patterns, thereby increasing contact and the potential for disease exchange with agricultural animal populations. Habitat suitability may improve for species such as whitetailed deer and feral swine which could increase contact and subsequent disease transmission between these wild species and livestock. Habitat changes may also increase competition for scarce resources.

Current VS measures in the Southern Plains Region addressing vulnerabilities:

- National Animal Health Monitoring System (NAHMS) Studies: NAHMS conducts periodic studies on livestock industries in the U.S.; these studies provide stakeholders in the private and public sectors with valuable information on disease occurrence and exposure to disease agents, management practices, productivity, knowledge gaps, and other important topics. These data support many information needs, can help describe the changing industry, and can help users identify mitigation actions to pursue.

- Active surveillance: VS conducts surveillance on regulated diseases such as tuberculosis and brucellosis; observation of changes in the distribution or behavior of these diseases can help with identification of for mitigations, as well as alert decision-makers to new factors related to disease emergence.

- Passive surveillance: VS conducts passive surveillance, including several projects in the Southern Plains Region that monitor passive animal health data, looking for changes to animal health. The information can be used to identify health trends (including trends secondary to climate change) that may lead to useful mitigations. 
- VS has a project in collaboration with Texas Animal Health Commission and Texas A\&M University conducting tick surveillance at livestock markets; the data is used to enhance data available for development of tick species distribution maps, particularly cattle fever ticks (Rhipicephalus annulatus and $R$. microplus) which carry cattle fever and which have been predicted to spread north from Mexico and Texas.

- VS is a collaborator in the APHIS Wildlife Services-led program to investigate and mitigate agricultural and natural resource damage and disease risks from feral swine, including studies in the Southern Plains and adjacent regions. The Southern Plains Region is home to a large population of feral swine. Information gained from this program will help identify and quantify disease risks to domestic livestock from feral swine, as well as the risks associated with feral swine distribution changes (including climate).

- VS is involved in research and response to wildlife-livestock interactions and health risks from diseases, such as tuberculosis and brucellosis in the United States, which can be spread through livestock contact with free ranging cervids, including elk, white-tailed deer, and other wildlife species.

\section{Policy and Program Development (PPD)}

PPD performs economic, environmental, and other analyses to support the actions of the APHIS programs. PPD analyses would be more robust over time if they were better able to incorporate economic and environmental effects of climate change to relevant agricultural systems and ecosystems. Robust projections of climate change and its effect on the distribution of production areas for various commodities, as well as anticipated needs for commodity movements at an international and domestic scale, can inform economic analyses. These projections, along with information on pollinators, water, and other resources, as well as effects on low-income, minority, and tribal communities, will better inform our environmental analyses.

PPD is incorporating climate change into many of its environmental compliance (e.g., National Environmental Policy Act; NEPA) documents and is leading an agency-wide effort to develop guidance for addressing climate change in our NEPA documents.

\section{Wildllife Services (WS)}

The mission of WS is to provide Federal leadership and expertise to resolve wildlife conflicts to allow people and wildlife to coexist. WS conducts program delivery, research, and other activities through its Regional and State Offices, the National Wildlife Research Center (NWRC) and its Field Stations, as well as through its National Programs. Since the work of WS is greatly influenced by distributions of wildlife, which are expected to shift as the climate changes, much of this work will be changing, as well. The following examples reflect some of those changes that are likely to affect the Southern Plains:

\section{Managing diseases spread by wildlife}

Climate change will likely have dramatic effects on the distribution of both agricultural diseases of concern as well as on zoonotic diseases, both of which can be spread by wildlife. It is expected that some areas will see a decrease in endemic disease risks, while others may see new diseases emerge in areas where they were not previously documented. Given the sensitivity of insect vectors to changes in weather-related variables, it is likely that initial changes in disease distribution resulting from climate change will take place for those diseases that are vector-borne. WS NWRC is conducting surveillance and research on diseases and vectors to gather baseline data on their distribution for use in climate change models and future studies. WS NWRC also maintains tissue archives of wildlife samples that are made available for retrospective research on diseases to identify changes in pathogen distribution and prevalence. 


\section{Wildlife management for aviation safety}

As climate changes, so may the breeding and wintering ranges of wildlife, especially birds, that affect aviation safety. Airports and military installations should be prepared to deal with new challenges associated with changes in bird ranges. Also, species' migration patterns may change. As an example, WS has developed migration models for osprey in relation to military aircraft movements. These models will likely become outdated quickly with climate change since it is expected that species' migration patterns will be greatly influenced by climate change. Proper habitat management is crucial to successful management of wildlife hazards to aviation. Distribution of plant species that grow on airports and military installations may change in the future. Thus, habitat management strategies may also need to adapt to a changing climate. WS NWRC is gathering data on species and habitat distribution, so it should be able to detect changes in species ranges and migration and movement patterns, and therefore adjust its habitat management strategies accordingly. NWRC is also researching alternative land covers that could be used at airports and military installations across the United States as conditions change.

\section{Wildlife management to protect agriculture}

WS conducts research and management on wildlife and invasive species, such as feral swine, that can have a significant effect on agricultural commodities. As climate changes, the distribution of these species as well as the agricultural crops they affect will also change. Information on population densities and distribution of target species is important for understanding how climate change will affect production of these agricultural commodities.

\section{Predator management}

As climate changes, so may landscapes and habitats shift along with changes in prey distribution and abundance. Changes in native vegetation, and therefore forage, will alter feeding patterns of native wildlife, which will alter the distribution of predators, such as mountain lions, black bears, and coyotes. These shifts will influence the distribution and abundance of such predators and will alter the predictive ability of models related to spatial patterns, behavior, abundance, and habitat use by predators. Results of climate-informed models may be needed to inform predator management strategies in order to adapt to climate change. WS NWRC researchers are gathering data on changes in species distribution and abundance, behavior, and habitat use for predators from around the country that are already affected by climate change (e.g., polar bears) and will use these studies as a foundation for incorporating climate change into studies of species found locally. WS NWRC is also incorporating climate change models into projections about future habitat availability for predators. 
Southern Plains Region

\section{References}

Alabama Precision Ag Extension. (2011). Variable-Rate Technology. Retrieved February 24, 2015, from http://www.aces.edu/anr/precisionag/VRT.php

Atchison, R, Daniels, R, \& Martinson, E. (2010). 2.2 Agroforestry Kansas Forest Action Plan (pp. 1516).

Ayres, MP, \& Lombardero, MJ. (2000). Assessing the Consequences of Global Change for Forest Disturbance from Herbivores and Pathogens. Science of the Total Environment, 262(3), 263-286.

Bagne, KE, Friggens, MM, \& Finch, DM. (2011). A System for Assessing Vulnerability of Species (Savs) to Climate Change. Fort Collins, CO: USDA Forest Service, Rocky Mountain Research Station.

Clifford, MJ, Royer, PD, Cobb, NS, Breshears, DD, \& Ford, PL. (2013). Precipitation Thresholds and Drought-Induced Tree Die-Off: Insights from Patterns of Pinus Edulis Mortality Along an Environmental Stress Gradient. New Phytologist. doi: 10.1111/nph.12362

Crouch, J. (2015). State of the Climate: National Overview for May 2015 from https://www.climate.gov/news-features/featured-images/may-2015-was-wettest-month-everrecorded-us

Dickey, GL. (1988). Crop Use and Water Conservation Benefits from Windbreaks. Agriculture, Ecosystems and Environment, 22(23), 243-260.

Dosskey, M. (2015). Agbufferbuilder: A Geographic Information System (Gis) Tool for Precision Design and Performance Assessment of Filter Strips. Journal Soil \& water Conservation, 70, 209-217.

Economic Research Service. (2011a). Arms Farm Financial and Crop Production Practices. Washington, DC: U.S. Department of Agriculture, Economic Research Service.

Economic Research Service. (2011b). Persistent Poverty Counties and Poverty Rates of at Least 20 Percent in Ach U.S. Census 1980, 1990, and 2000, and American Community Survey 5-Year Estimates, 2007-2011.: U.S. Department of Agriculture.

Finch, DM. (2012). Climate Change in Grasslands, Shrublands, and Deserts of the Interior American West: A Review and Needs Assessment (pp. 139). Rocky Mountain Research Station: U.S. Department of Agriculture, Forest Service

Food and Agriculture Organization of the United Nations. (2002). Defining the Peri-Urban: Rural-Urban Linkages and Institutional Connections. Retrieved September 3, 2015, from http://www.fao.org/docrep/003/x8050t/x8050t02.htm

Ford, PL. (2011). Site Characteristics of Intact Shortgrass Steppe in the Southern Great Plains USA. In S. R. O. Feldman, G.E.; Sacido, M.B. (Ed.), Ix Intern. Rangeland Congr.: Diverse Rangelands for a Sustainable Society April 3-10, 2011 (pp. 174). Rosario, Argentina: IRC2001 Congress.

Ford, PL, \& Johnson, GV. (2006). Effects of Dormant- Vs. Growing-Season Fire in Shortgrass Steppe: Biological Soil Crust and Perennial Grass Responses. Journal Arid Environment, 67, 1-14. 
Geyer, WA, Nepple, T, Brooks, K, \& Carlisle, J. (2000). Woody Vegetation Protects Streambank Stability During the 1993 Flood in Central Kansas. Journal of Soil \& Water Conservation, 55, 483-486.

Hatfield, JL, \& Prueger, JH. (2015). Temperature Extremes: Effect on Plant Growth and Development. . Weather and Climate Extremes. doi: 10.1016/j.wace.2015.08.001.

ICF International. (2013). Greenhouse Gas Mitigation Options and Costs for Agricultural Land and Animal Production within the United States. In S. D. Biggar, D. Man, K. Moffroid, D. Pape, M. Riley-Gilbert, R. Steele, \& V. Thompson (Eds.), (Vol. Prepared under USDA Contract No. AG3142-P-10-0214). Washington DC: U.S. Department of Agriculture, Office of the Chief Economist.

Intergovernmental Panel on Climate Change. (2006). 2006 Ipcc Guidelines for National Greenhouse Gas Inventories, Volume 4: Agriculture, Forestry and Other Land Use.

Johnson, E, Geissler, G, \& Murray, D. (2010). The Oklahoma Forest Resource Assessment, 2010. Oklahoma City, OK: Oklahoma Department of Agriculture, Food, and Forestry Retrieved from http://www.forestry.ok.gov/Websites/forestry/Images/Oklahoma\%20Forest\%20Resource\%20Ass essment,\%20FINAL\%20FOR\%20WEB.pdf.

Kunkel, KE, Stevens, LE, Stevens, SE, Sun, L, Janssen, E, Wuebbles, D, Kruk, MC, Thomas, DP, Shulski, M, Umphlett, N, Hubbard, K, Robbins, K, Romolo, L, Akyuz, A, Pathak, T, Bergantino, T, \& Dobson, JG. (2013). Regional Climate Trends and Scenarios for the U.S. National Climate Assessment Part 4. Climate of the U.S. Great Plains (pp. 142-144, 182 pp.): NOAA Technical Report NESDIS.

McGuire, VL. (2014). Water-Level Changes and Change in Water in Storage in the High Plains Aquifer, Predevelopment to 2013 and 2011-13: U.S. Geological Survey Scientific Investigations Report 2014-5218 (pp. 14). USGS: Department of the Interior.

McNulty, S, Lorio, P, Jr., Ayres, M, \& Reeve, J. (1998). Predictions of Southern Pine Beetle Populations Using a Forest Ecosystem Model. In R. Mickler \& S. Fox (Eds.), The Productivity and Sustainability of Southern Forest Ecosystems in a Changing Environment (Vol. 128, pp. 617634): Springer New York.

Melillo, JM, Richmond, TC, \& Yohe, GW (Eds.). (2014). Climate Change Impacts in the United States: The Third National Climate Assessment: U.S. Global Change Research Program.

National Agricultural Statistics Service. (2014). 2012 Census of Agriculture. Washington DC. : Retrieved from http://www.agcensus.usda.gov/Publications/2012/.

National Oceanic and Atmospheric Administration. (2015a). Drought-August 2011. from http://www.ncdc.noaa.gov/sotc/national/201108

National Oceanic and Atmospheric Administration. (2015b). Global Surface Temperature Anomalies. Retrieved March 13, 2015, 2015, from http://www.ncdc.noaa.gov/monitoringreferences/faq/anomalies.php

Nickerson, C, Ebel, R, Borchers, A, \& Carriazo, F. (2011). Major Uses of Land in the United States, 2007 (pp. 67). Economic Research Service: U.S. Department of Agriculture. 
Ojima, DS, Steiner, J, McNeeley, S, Cozzetto, K, \& Childress, AN. (2015). Great Plains Regional Technical Input Report. Washington, DC.: Island Press.

Oklahoma Climatological Survey. (2015a). Severe Weather Threat Climatology. from http://climate.ok.gov/index.php/climate/category/tornadoes_severe_storms

Oklahoma Climatological Survey. (2015b). Temperature History-Annual, Statewide. from http://climate.ok.gov/index.php/climate/climate_trends/temperature_history_annual_statewide/C D00/tavg/Annual/oklahoma climate

Oklahoma Mesonet. (2015). Historic May Rains Eliminate Drought. from http://www.mesonet.org/index.php/news/article/historic_may_rains_eliminate_drought

Patel-Weynand, T (Ed.). (In Review). Agroforestry and Climate Change: Reducing Threats \& Enhancing Resiliency in Agricultural Systems: US Forest Service.

Ribaudo, M, Delgado, J, Hansen, L, Livingston, M, Mosheim, R, \& Williamson, J. (2011). Nitrogen in Agricultural Systems: Implications for Conservation Policy (Vol. ERS Report Number 127): U.S. Department of Agriculture, Economic Research Service.

Saenz-Romero, C, Rehfeldt, GE, Crookston, NL, Duval, P, St-Amant, R, Beaulieu, J, \& Richardson, BA. (2010). Spline Models of Contemporary, 2030, 2060, and 2090 Climates for Mexico and Their Use in Understanding Climate-Change Impacts on the Vegetation. Climatic Change, 102, 595623.

Schoeneberger, M, Bentrup, G, deGooijer, H, Soolanayakanahally, R, Sauer, T, Brandle, J, Zhou, X, \& Current, D. (2012). Branching Out: Agroforestry as a Climate Change Mitigation and Adaptation Tool for Agriculture. Journal of Soil and Water Conservation, 67(5), 128A-136A.

Simpson, H, Taylor, E, Li, Y, \& Barber, B. (2013). Texas Statewide Assessment of Forest Ecosystem Services A comprehensive analysis of regulating and cultural services provided by Texas' forests. College Station, TX Texas A\&M Forest Service.

Sun, G, Noormets, A, Chen, J, \& McNulty, SG. (2008). Evapotranspiration Estimates from Eddy Covariance Towers and Hydrologic Modeling in Managed Forests in Northern Wisconsin, USA. Agricultural and Forest Meteorology, 148, 257-267.

Texas A\&M Forest Service. (2012). Texas a\&M Forest Service Survey Shows 301 Million Trees Killed by Drought. Retrieved October, 2015, from http://texasforestservice.tamu.edu/main/popup.aspx?id=16509

U.S. Department of Agriculture. (2011). U.S. Agriculture and Forestry Greenhouse Gas Inventory: 19902008 (C. C. P. Office, Trans.) (Vol. Technical Bulletin No., 1930, pp. 159): U.S. Department of Agriculture, Office of the Chief Economist.

U.S. Department of Agriculture. (2014). Quantifying Greenhouse Gas Fluxes in Agriculture and Forestry: Methods for Entity-Scale Inventory. In M. Eve, D. Pape, M. Flugge, R. Steele, D. Man, M. RileyGilbert, \& S. Biggar (Eds.), (Vol. Technical Bulletin Number 1939, pp. 606). Washington, DC: U.S. Department of Agriculture, Office of the Chief Economist. 
U.S. Environmental Protection Agency. (2010). Inventory of U.S. Greenhouse Gas Emissions and Sinks: 1990-2008 (Vol. EPA 430-R-14-003). Washington, DC: U.S. Environmental Protection Agency.

U.S. Environmental Protection Agency. (2014). Inventory of U.S. Greenhouse Gas Emissions and Sinks: 1990-2012 (pp. 529). Washington D.C.: U.S. Environmental Protection Agency

U.S. Forest Service. (2012). Future of America's Forest and Rangelands: Forest Service 2010 Resources Planning Act Assessment (Vol. General Technical Report WO-87, pp. 198). Washington, DC: U.S. Department of Agriculture.

U.S. Geological Survey. (2011). National Land Cover Database. Retrieved from: http://www.mrlc.gov/ 